\title{
Glutathione S-transferases and head and neck cancer
}

Citation for published version (APA):

Ophuis, M. B. O. (2003). Glutathione S-transferases and head and neck cancer. [Doctoral Thesis, Maastricht University]. Universiteit Maastricht. https://doi.org/10.26481/dis.20030926mo

Document status and date:

Published: 01/01/2003

DOI:

10.26481/dis.20030926mo

Document Version:

Publisher's PDF, also known as Version of record

\section{Please check the document version of this publication:}

- A submitted manuscript is the version of the article upon submission and before peer-review. There can be important differences between the submitted version and the official published version of record.

People interested in the research are advised to contact the author for the final version of the publication, or visit the DOI to the publisher's website.

- The final author version and the galley proof are versions of the publication after peer review.

- The final published version features the final layout of the paper including the volume, issue and page numbers.

Link to publication

\footnotetext{
General rights rights.

- You may freely distribute the URL identifying the publication in the public portal. please follow below link for the End User Agreement:

www.umlib.nl/taverne-license

Take down policy

If you believe that this document breaches copyright please contact us at:

repository@maastrichtuniversity.nl

providing details and we will investigate your claim.
}

Copyright and moral rights for the publications made accessible in the public portal are retained by the authors and/or other copyright owners and it is a condition of accessing publications that users recognise and abide by the legal requirements associated with these

- Users may download and print one copy of any publication from the public portal for the purpose of private study or research.

- You may not further distribute the material or use it for any profit-making activity or commercial gain

If the publication is distributed under the terms of Article $25 \mathrm{fa}$ of the Dutch Copyright Act, indicated by the "Taverne" license above, 
Glutathione S-transferases and head and neck cancer 
Financial support Abbott, Alk Abelló, Almirall Prodesfarma, Alphatron Medical \& Microwave Systems, ARTU Biologicals Europe, Entermed, Glaxo Smith Kline, Hoorcomfort Nederland, Mediprof, Ooms Allergie, Pfizer, Schering Plough, Schoonenberg Hoorcomfort, Streukens Hoorapparaten, Veenhuis Medical, VieCuri Medisch Centrum voor Noord-Limburg

ISBN 90-9017247-5

- Michael B Oude Ophuis, Venlo 2003

Vormgeving en druk door Datawyse / Universitaire Pers Maastricht Omslagillustratie door Maria Oude Ophuis 


\title{
Glutathione S-transferases and head and neck cancer
}

\author{
Proefschrift
}

ter verkrijging van de graad van doctor

aan de Universiteit Maastricht

op gezag van de Rector Magnificus

Prof. dr. A.C. Nieuwenhuijzen Kruseman

volgens het besluit van het College van Decanen

in het openbaar te verdedigen

op vrijdag 26 september 2003 om 12:00 uur

door

Michael Bernardus Oude Ophuis

geboren te Rotterdam in 1967 


\section{Promotor}

Prof. dr. J.J. Manni

\section{Co-promotor}

Dr. W.H.M. Peters (Universitair Medisch Centrum Nijmegen)

\section{Beoordelingscommissie}

Prof. dr. ir. P.A. van den Brandt (voorzitter)

Dr. B.J.M. Braakhuis (Vrije Universiteit Amsterdam)

Prof. dr. G.J. Hordijk (Universiteit Utrecht)

Prof. dr. P. Lambin

Prof. dr. F.C.S. Ramaekers 
Voor Marianne, Martijn en Janneke Aan mijn ouders 


\section{TABLE OF CONTENTS}

List of Abbreviations $\quad 8$

Introduction to the Chapters

Chapter 1

General introduction: Genetic Polymorphisms in glutathione S-transferases and head and neck cancer susceptibility; a review. Submitted for publication

Chapter 2

Glutathione S-transferase M1 and T1 and cytochrome P4501A1 polymorphisms in relation to the risk for benign and malignant head and neck lesions.

Cancer 1998; 82: 936-943

Chapter 3

Demographic variation in the distribution of the glutathione S-transferase T1 null polymorphism in Dutch healthy controls; implications for genotype research in head and neck cancer. Submitted for publication

Chapter 4

Plasma glutathione S-transferase P1-1 levels in patients with head and neck squamous cell carcinoma.

Cancer 1998; 82: 2434-2438 
Polymorphisms of the glutathione S-transferase P1 gene and head and neck cancer susceptibility.

Head and Neck 2003; 25: $37-43$

Chapter 6

The association between glutathione S-transferase P1 genotype and plasma level in patients with head and neck cancer.

Laryngoscope 2001; 112: 462-465

\section{Chapter 7}

Multiple genetic polymorphisms in detoxification enzymes and head and neck cancer susceptibility.

\section{Chapter 8}

Meta- and pooled analyses of GSTM1, GSTT1, GSTP1, CYP1A1

polymorphisms and risk of head and neck cancers.

Submitted for publication

Summary, Conclusions, Discussion and Future Perspectives 


\section{LIST OF ABBREVIATIONS}

$\begin{array}{ll}\text { BHNL } & \text { benign head and neck lesions } \\ { }^{\circ} \mathrm{C} & \text { degrees Celcius } \\ \mathrm{CI} & \text { Confidence Interval } \\ \text { CYP } & \text { cytochrome P 450 } \\ \text { DNA } & \text { deoxyribonucleic acid } \\ \text { EDTA } & \text { ethylene diamine tetra-acetic acid } \\ \text { ELISA } & \text { enzyme linked inmmuno sorbent assay } \\ \text { EPHX } & \text { epoxide hydrolase } \\ \text { GSH } & \text { glutathion } \\ \text { GST } & \text { glutathione S-transferase (enzyme) } \\ \text { GST } & \text { glutathione S-transferase (gene) } \\ \text { H } & \text { hours } \\ \text { HN } & \text { all sites of head and neck malignancies } \\ \text { HNSCC } & \text { head and neck squamous cell carcinoma } \\ \text { Ile } & \text { isoleucine } \\ \text { LR } & \text { likelyhood ratio } \\ \text { Min } & \text { minutes } \\ \text { N } & \text { number of patients or controls } \\ \text { n.S. } & \text { not specified } \\ \text { OR } & \text { Odds Ratio } \\ \text { PAH } & \text { polycyclic aromatic hydrocarbon } \\ \text { PCR } & \text { polymerase chain reaction } \\ \text { RFLP } & \text { restriction fragment length polymorphism } \\ \text { SCC } & \text { squamous cell carcinoma } \\ \text { SSCP } & \text { single strand conformational polymorphism } \\ \text { V } & \text { volts } \\ \text { Val } & \text { valine } \\ 2 & \text { chi square } \\ & \end{array}$




\section{INTRODUCTION TO THE CHAPTERS}

Head and neck cancer is the sixth most common cancer in the world. The definition of head and neck cancer in this thesis includes squamous cell carcinomas of the oral cavity, pharynx, and larynx. Other head and neck tumor localisations and other histopathological types have been excluded from this study. The risk of head and neck squamous cell carcinoma (HNSCC) is strongly associated with smoking of tobacco and consumption of alcohol, both of which may be responsible for a considerable load of (pre)carcinogens. Metabolism and detoxification of such exogenous harmful compounds often occurs by phase I and phase II enzymes such as cytochrome P450 (CYP), microsomal epoxide hydrolase (EPHX) and glutathione S-transferase (GST).

Because genetic polymorphisms exist in the cytochrome P4501A1, glutathione S-transferase M1, T1, P1 and EPHX genes, that may lead to complete absence (GSTM1 and GSTT1) or altered (CYP1A1, GSTP1 and EPHX) enzyme activity, individuals bearing such genetic polymorphisms and therefore lacking a (partially) normally functional enzyme, may be at higher risk of developing HNSCC. Therefore, next to smoking and drinking habits, it is believed that also genetic factors may contribute to the risk for HNSCC. The aim of this study is to determine whether genetic polymorphisms of the CYP, EPHX or GST detoxification enzyme systems influence the individual susceptibility for HNSCC.

Chapter 1 gives an overview of studies on genetic polymorphisms in biotransformation enzymes in relation to head and neck cancer. In chapter 2, genetic polymorphisms in CYP1A1, GSTM1 and GSTT1 are evaluated in relation to HNSCC susceptibility. Several years later, we discovered that demographic variation may influence this outcome. In chapter 3 we again evaluated the GSTM1, GSTT1 and GSTP1 genotypes, but now in control populations recruited from both the Nijmegen and Maastricht regions. Chapter 4 describes the quantification of blood plasma GSTP1-1 enzyme levels in patients with HNSCC to find out whether these values are suitable as tumor markers to monitor progression of HNSCC. Polymorphisms of the GSTP1 gene in relation to HNSCC are investigated in chapter 5. A study on the association between plasma GSTP1-1 enzyme levels and the GSTP1 genotype is presented in chapter 6 . A study on the number of polymorphisms in the genes studied in this thesis in relation to HNSCC susceptibility, is presented in chapter 7 . Chapter 8 is an international collaborative meta analysis on polymorphisms of the GSTM1, GSTT1, GSTP1 and CYP1A1 genes in relation to HNSCC susceptibility. The summary recapitulates the contents of the individual chapters.

In this thesis the genotypes and the enzymes of glutathione S-transferases are discussed. For a better distinction between these two, the genotypes or gene polymorphisms are printed in italic (e.g. GSTP1), whereas the enzymes are in normal print (e.g. GSTP1-1). 


\section{CHAPTER}

GENERAL INTRODUCTION:

GENETIC POLYMORPHISMS IN GLUTATHIONE

S-TRANSFERASES AND HEAD AND NECK CANCER SUSCEPTIBILITY; A REVIEW

Michael B Oude Ophuis ${ }^{1}$, Wilbert HM Peters ${ }^{2}$, Johannes J Manni ${ }^{1}$

${ }^{1}$ Dept. of Otorhinolaryngology, Head and Neck Surgery, University Hospital Maastricht, The Netherlands

${ }^{2}$ Dept. of Gastroenterology, University Medical Center Nijmegen, The Netherlands

Submitted for publication 


\section{Summary}

Background The etiology of head and neck squamous cell carcinoma (HNSCC) may be closely related to toxification-detoxification processes of products that appear during smoking and/or alcohol consumption. The individual susceptibility to HNSCC may be determined by alterations of the detoxification process due to genetic polymorphisms of glutathione S-transferases (GSTs).

Methods Through an extensive search in PubMed and reference backtracking a selection was made of all English publications that evaluated one or more GST polymorphisms in relation to HNSCC.

Results A review is given on all literature to this date where one or more GST polymorphisms are evaluated in a HNSCC population. The site, size, race, and Odds Ratio are evaluated in the case and control populations.

Conclusions The studies on GST polymorphisms and HNSCC susceptibility published so far have reported contradicting results. Possible explanations in the variations of study results are given. Carefully designed, population-based studies will be necessary. 


\section{Introduction}

The global incidence of head and neck squamous cell carcinoma (HNSCC) is approximately $5 \%$. In several regions, the incidence of HNSCC is higher, which may be related to the consumption of specific substances, toxic or carcinogenic for head and neck tissues. Several individuals at risk for HNSCC can be readily identified by their excessive consumption of alcohol or tobacco, where it is also known that synchronous consumption of both substances increases the toxicity of the other (1). The incidence of HNSCC in the high-risk alcohol and tobacco consumer-group is significantly higher compared to non-consumers. Within this high-risk group however, the majority of the individuals ultimately do not develop HNSCC and therefore seem to be not susceptible to these hazardous substances. The question then arises: what is the explanation for this phenomenon; why does a person with a moderate or high intake of alcohol and tobacco contract HNSCC, whereas another person with comparable intake of both substances does not? It is hypothesized that this may be due to inter-individual differences in genetic susceptibility towards alcohol or tobacco.

One of the first steps in the initiation of head and neck cancer may be the binding of reactive metabolites of alcohol or tobacco smoke constituents to the DNA of mucosal cells. This process is strongly influenced by phase I and phase II enzymes which are involved in the toxification or detoxification of ingested compounds. For instance many polycyclic aromatic hydrocarbons (PAHs), chemicals that are present in large amounts in tobacco smoke (2), after ingestion may be first activated by phase I enzymes such as cytochromes P450 (CYP) or epoxide hydrolases (EPHX) to become potential carcinogens, which subsequently need to be detoxified by phase II enzymes such as the glutathione S-transferases (GSTs). An imbalance between the phase I and phase II drug metabolizing or detoxification enzymes may contribute to the individual susceptibility to HNSCC (see diagram 1).

a.

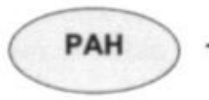

b.

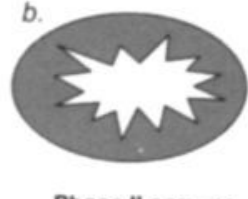

Phase II enzyme
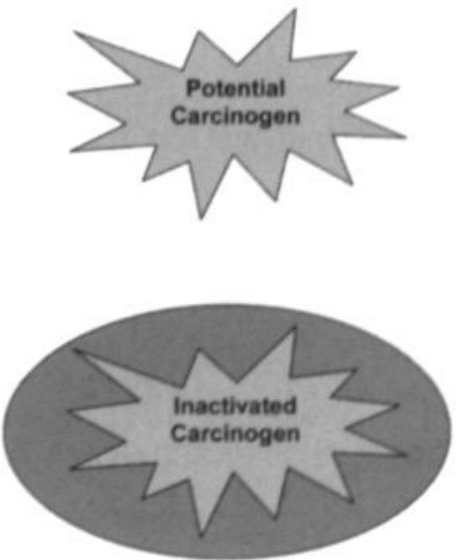

Diagram 1 Schematic presentation of the detoxification of carcinogens by phase I and phase II enzymes (a. and b. respectively). (PAH: polycyclic aromatic hydrocarbons) 
As a result of conjugation with glutathione, catalyzed by the glutathione S-transferases, the potential carcinogens are eliminated and DNA or other important biomolecules are protected against damage or adduct formation (3-6). In humans, the GST enzymes can be divided into four main classes: Alpha (GSTA), Mu (GSTM), Pi (GSTP) and Theta (GSTT). Each class consists of one or more isoenzymes with different but sometimes overlapping substrate specificities $(5,6)$. At present genetic polymorphisms have been demonstrated in GSTM1, GSTT1, GSTA1 and GSTP1 (6-11).

Many polymorphisms in genes coding for risk modulating proteins or enzymes have been identified recently which appear to be related to the risk for a number of diseases. Therefore, it seems important to investigate whether the differences in susceptibility towards alcohol and tobacco as described above, can be attributed to genetic variations in systems that are involved in the detoxification of alcohol or tobacco-related carcinogens. Head and neck tissues, which are often exposed to alcohol or tobacco smoke, are protected by enzyme systems such as the glutathione S-transferases.

\section{Glutathione and glutathione S-transferase system}

Glutathione (GSH) is an intracellular thiol that neutralizes precarcinogenic and highly reactive electrophillic compounds, a process most commonly taking place by enzymatic conjugation catalyzed by glutathione S-transferases (GSTs). GSH is produced mainly in the liver (hepatocytes), and to a lesser extent in other cell types such as head and neck mucosal cells, by coupling of the amino acids glycine, cysteine and glutamic acid (12). When the GSH production is reduced or GSH is depleted, more electrophillic compounds may freely circulate and may cause damage to DNA or other important biomolecules. Since detoxification by GSH is strongly coupled to the GST enzymes, also a reduction or deficiency of GST isoforms in a similar way may result in higher levels of (DNA) damage.

Any factor that may disturb the metabolic balance of detoxification, can result in increased levels of carcinogenic compounds and in an increased risk for developing cancer. In this way GSH and GSTs may regulate the ability of each individual to metabolize environmental carcinogens.

Genetic polymorphisms, mostly resulting in significant reduction of corresponding enzyme activities, have been described in GSTM1, GSTT1, GSTP1, and GSTA1 (8-11). For GSTM1 and GSTT1, null polymorphisms may be present, resulting in complete absence of enzyme activity. The fact that GSTM1 and GSTT1 null genotypes in Caucasians are common (20-50\%), implicates that their co-occurrence is also relatively common (approximately 10\%), which suggests that their possible contribution to the susceptibility to HNSCC could be of considerable importance.

The polymorphism in GSTP1 may result in considerable loss of the corresponding GSTP1-1 enzyme activity $(13,14)$. The polymorphism in GSTA1 probably is also widespread and may have significant consequences for the corresponding enzyme activities but it has hardly been studied yet since it was described only recently (11). 
The studies performed so far have provided the following information: GSTM1 and GSTT1 null genotype frequencies are highly variable in the HNSCC case populations which have been studied (range 43 - $78 \%$ for GSTM1 null, and 9 - $59 \%$ for GSTT1 null; see Table 1 and 2 respectively). However, similar variable frequencies are also seen in the control populations studied by the same researchers. When patients are selected according to HNSCC tumor site, also similar varying GST null frequencies are reported.

HNSCC susceptibility of individuals with the GST null genotype however, appears to be similar in most studies with non-null genotype individuals. However, it may be hypothesized that susceptibility is higher when interaction of GSTs with other factors such as tobacco smoking and/or alcohol consumption is considered. It appears however, that the contribution of the GST null genotypes in the susceptibility of HNSCC is small or even absent, especially when compared to the main risk factors described before (tobacco, alcohol).

A more detailed review on the literature with respect to studies on genetic polymorphisms in GSTs in relation to HNSCC is provided below.

\section{GST genotypes and head and neck cancer}

\section{GSTM1 genotype}

The GSTM enzyme family exists in different isoforms, where 5 have been isolated in humans. Specifically the GSTM1 enzyme may be of interest for HNSCC, since it detoxifies metabolites of benzo [a] pyrene and other epoxides, which are tobacco related carcinogens (6).The corresponding gene GSTM1 displays three different genotypes, two functional (GSTM1 A and GSTM1 B) and one nonfunctional genotype (GSTM1 null) have been identified. In Caucasian populations approximately $50 \%$ lacks the functional genotypes GSTM1 A or GSTM1 B (see Table 1). The GSTM1 null genotype frequencies however, do vary in and between countries and races, which makes it difficult for instance to compare the results of studies on Caucasians with those of other racial populations. Many studies reported a high frequency of GSTM1 null for other sites of cancer than head and neck. Considering the studies on HNSCC, as shown in Table 1, this seems not the case.

Kihara et al. (15) in Japanese smokers found that the GSTM1 null genotype was not associated with laryngeal cancer eventhough there was a link to the smoking history. In smokers with non-laryngeal HNSCC, however, GSTM1 null genotype was observed more frequently $(62.7 \%)$ as compared to controls $(48.7 \%)(O R 1.8 ; \mathrm{Cl} 1.0-3.0)(15)$. The same authors suggest that GSTM1 null genotype also may be a potential risk factor for HNSCC depending on smoking history.

Several research groups found no significant association between GSTM1 null genotype and any head and neck tumor localisation (16-22). Other researchers described an increased risk for HNSCC related to the GSTM1 null genotype (23-25). Nair et al. (26) in an Indian beetle quid or tobacco consuming population, found a significant higher frequency of GSTM1 null genotype in patients with oral leukoplakia, a possible precursor of oral squamous cell carcinoma. Cabelguenne et al. (27) reported no 
GSTM 1 null genotype frequencies in control and HNSCC patient populations
GSTM1 null

No association GSTM1 null

\section{enotype vs HNSCC}

Cabelguenne et al. (27)

Gronau et al. (55)

Deakin et al. (16)

Deakralez et al. (51)

Hung et al. (18)

Jannke et al. (30)

lannke et al. (29)

lourenkova et al. (36)

Katoh et al. (39)

Kinara et al. (15)

Kinara et al. (15) (31)

McWilliams et al. (52)

Morita et al. (34)

Oishan et al. (32)

Oishan ephuis et al. (20)

\section{Park et al. (17)}

Park et al. (17)

Sreelekha at al. (57)

Worral et al. (19)

\section{Association GSTM1 null}

genotype vs HNSCC

Buch et al. (53)

cheng et al. (54)

Cheng et al. (54)

Coutelle et al. (24)

Hanna et al. (59)

Hong et al. (49)

Kinara et al. (15)

Sato et al. (56)

Satoet al (56)

$\begin{array}{llll}46.5(264) & 49.6(162) & \text { n.s. } & \begin{array}{l}\text { France } \\ \text { Germany }\end{array} \\ 48.0(37) & 62.0(21) & \text { n.s. } & \text { UK } \\ 48.0(60) & 64.0(83) & \text { Caucasian } & \text { Spain } \\ 54.7(128) & 55.0(34) & \text { Caucasian } & \text { Taiwan } \\ 54.0(200) & 58.0(75) & \text { Chinese mased } & \text { Germany } \\ 57.7(123) & 58.5(41) & \text { Caucasian } & \text { Germany } \\ 52.0(216) & 56.2(269) & \text { Caucasian } & \text { France } \\ 57.7(145) & 50.8(169) & \text { Caucasian } & \text { France } \\ 52.3(172) & 47.9(129) & \text { Caucasian } & \text { France } \\ 52.3(172) & 44.8(67) & \text { Caucasian } & \text { Japan } \\ 52.3(172) & 52.0(50) & \text { Japanese } & \text { Japan } \\ 46.3(147) & 58.7(92) & \text { Japanese } & \text { Germany } \\ 48.7(174) & 48.1(158) & \text { Caucasian } & \text { Germany } \\ 53.4(219) & 58.2(126) & \text { Caucasian } & \text { Germany } \\ 53.4(219) & 57.0(272) & \text { Caucasian } & \text { USA } \\ 53.4(219) & 57.4(398) & \text { Caucasian } & \text { Japan } \\ 46.5(129) & 46.2(147) & \text { Japanese } & \text { USA } \\ 50.6(164) & 49.0(145) & \text { Caucasian } & \text { The Netherlands } \\ 45.0(168) & 50.0(109) & \text { Caucasian } & \text { The Netherlands } \\ 51.7(207) & 50.8(185) & \text { Caucasian } & \text { The Netherlands } \\ 51.7(207) & 50.0(76) & \text { Caucasian } & \text { USA } \\ 51.7(207) & 53.4(73) & \text { Caucasian } & \text { India } \\ 51.0(135) & 51.0(135) & \text { Indian } & \text { Japan } \\ 33.3(60) & 49.0(98) & \text { Japanese } & \text { UK } \\ 42.0(100) & 43.0(100) & \text { Caucasian } & \end{array}$

$10(0.6-1.5)$

$1.8(0.5-6.2)$

n.s.

$1.0(0.5-2.0)$

n.s.

n.s.

$0.9(0.5-1.5)$

$0.8(0.4-1.5)$

$1.3(0.6-2.6)$

$1.8(1.0-3.3)$

$1.0(0.5-1.8)$

$1.2(0.8-2.0)$

$1.0(0.7-1.5)$

$0.2(0.1-0.5)$

$1.0(0.6-1.6)$

$1.1(0.6-2.0)$

$1.2(0.8 \cdot 2.0)$

$1.0(0.7-1.5)$

$1.1(0.6-1.8)$

$0.9(0.5-16)$

$1.0(0.6-1.7)$

$1.3(0.4-4.8)$

$0.4(0.2-1.0)$

n.s.
$3.2(2.4-4.3)$

$1.5(1.0-2.2)$

$4.7(1.0-21.8)$

n.s.

$3.5(1.3 .9 .8)$

$1.6(1.0-2.8)$

$1.8(1.0-3.0)$

$2.2(1.4-3.6)$

$2.4(1.2-4.7)$
Larynx

Larynx

Larynx

Non larynx

Oral
$24.0(450)$
$42.9(315)$

$48.0(37)$

$52.4(63)$

$52.3(172)$

$48.7(474)$
53.1(162) Caucasian

$80.0(20)$ M.s.

$68.3(82) \quad$ Caucasian

$60.5(129) \quad$ Japanese

Japanese

64.8(100) Mixed
France

USA

France

Japan

USA

(8)


difference in frequency of GSTM1 in a HNSSC total group or several subgroups, except for a subgroup of laryngeal cancer patients where an Odds Ratio of 2.6 (range 1.6-6.1) was found for patients with the GSTM1 null genotype.

\section{GSTT1 genotype}

Similar to research on the GSTM1 genotype, the GSTI1 gene is of interest because of the capacity of the corresponding GSTT1-1 enzyme to detoxify alkyl halogenides, ethylene oxide, and other low molecular weight metabolic products. GSTT1 also displays a genetic polymorphism resulting in a GSTT1-1 null phenotype being fully inactive. Since the detoxification of many toxic low molecular weight compounds may be deficient in individuals with the GSTT1 null genotype, such an individual may be potentially at risk. The GSTT1 null genotype occurs in approximately $20 \%$ of a normal Caucasian population. In other racial populations, this frequency may vary considerably as reported by Nelson et al. (28). For instance Hung et al. (18) in a Taiwanese study described GSTT1 null genotype frequencies of $52.9 \%$ and $58.5 \%$ in controls and cases respectively (see Table 2).

In contrast, there appears no racial difference in the data of Hung et al. (18) on GSTM1 null genotype rates compared to those of other investigators (see Table 1). However, in accordance with most results by other groups (see Table 2), Hung et al. did not find association of GSTT1 null genotype and HNSCC susceptibility. Furthermore, it is surprising that Jahnke et al. and Matthias et al. (29-31), who used overlapping patient and control samples, did reach different conclusions on the GSTT1 null genotype as a factor of HNSCC susceptibility.

There appears to be an interaction with the degree of tobacco smoke exposure in several studies. Olshan et al. (32) analysed tobacco users and non-users and revealed no indication of increased risk among moderate users with the GSTT1 null genotype. However GSTT1 null genotype individuals having smoked more than 40 pack years showed a higher OR compared to individuals with a functional gene. Also Hamel et al. (33) found a significant increase in OR for HNSCC in GSTT1 null light smoking individuals (OR 6.53; Cl 2.25-19.0).

\section{GSTP1 genotype}

The enzyme GSTP1-1, encoded by the GSTP1 gene, is also involved in the detoxification of tobacco related carcinogens (6). GSTP1 displays two variant genotypes GSTP1 $A B$ and GSTP1 BB next to the most common GSTP1 AA genotype. In a normal control population, the frequency of the GSTP1 AA genotype ranges from approximately 40-70\%. The variant GSTP1 genotypes show a decreased specific activity and affinity for substrates of the corresponding GSTP1-1 enzyme, since the polymorphism results in an amino acid substitution near the substrate binding site area of the enzyme (8). Since the GSTP1 BB genotype occurs only in approximately $10 \%$ of the population, the two variant genotypes GSTP1 AB and GSTP1 BB have been combined in Table 3. As seen for GSTT1, for GSTP1 also a strong correlation with race was found. Morita et al. (34) in a Japanese population found significant lower frequencies of the variant GSTP1 $A B$ and GSTP1 BB genotypes for controls and cases as compared to Caucasian study groups. The genotype frequencies in another japanese population with HNSCC described by Katoh et al. (35) are comparable to the frequencies found by other 
Table 2. GSTT 1 null genotype frequencies in control and HNSCC patient populations

Author Site GSTT1 null

GSTT1 null Race

Country

Ddds Ratio

Controls

$\%$ of totali in)

\section{No association GSTT1 null}

\section{genotype vs HNSCC}

Buch et al. (53)

Deakin et al. (16)

Deakin et al. (16)
Hanna et al. (50)

Hong et al. (49)

Hung et al. (18)

Jourenkova et al. (23)

Jourenkova et al. (36)

Katoh et al. (39)

Matthias et al. (31)

McWilliams et al. (52)

Olshan et al. (32)

Oude Ophuis et al. (20)

Sreelekha et al. (57)

Irizna et al. (25)

Worral et al. (19)

$\begin{array}{ll}\text { Oral } & 12.3(450) \\ \text { HN } & 19.4(264) \\ \text { Oral } & 18.5(129) \\ \text { Larynx } & 20.0(20) \\ \text { Larynx } & 36.5(63) \\ \text { Oral } & 52.9(123) \\ \text { Larynx } & 15.7(172) \\ \text { Pharynx } & 15.7(172) \\ \text { Oral } & 51.0(147) \\ \text { Larynx } & 22.2(203) \\ \text { Oropharynx } & 22.2(203) \\ \text { HN } & 22.2(203) \\ \text { HN } & 18.3(109) \\ \text { HN } & 13.0(168) \\ \text { HN } & 20.3(207) \\ \text { Oral/oropharynx } & 20.3(207) \\ \text { Larynx } & 20.3(207) \\ \text { Oral } & 8.3(60) \\ \text { HN } & 36.0(42) \\ \text { Oral } & n . s .\end{array}$

\begin{tabular}{|c|c|}
\hline $18.3(29.7)$ & Indian \\
\hline $18.1(16.2)$ & n.s. \\
\hline $11.8(34)$ & Caucasian \\
\hline $15.0(20)$ & n.s. \\
\hline $57.3(82)$ & Korean \\
\hline 58.5 (41) & Chinese mixed \\
\hline $19.4(129)$ & Caucasian \\
\hline $18.0(50))$ & Caucasian \\
\hline $47.7(92)$ & Japanese \\
\hline $19.4(26,3)$ & Caucasian \\
\hline $27.7(11: 9)$ & Caucasian \\
\hline $22.0(38,2)$ & Caucasian \\
\hline $16.9(14: 2)$ & Caucasian \\
\hline $17.0(109)$ & Caucasian \\
\hline $19.5(18.5)$ & Caucasian \\
\hline 19.7 (76) & Caucasian \\
\hline $20.5(73)$ & Caucasian \\
\hline $18.4(98)$ & Indian \\
\hline $45.0(186)$ & Mixed \\
\hline n.s. & Caucasian \\
\hline
\end{tabular}

India

France

UK

USA

Korea

Taiwan

France

France

Japan

German

German

German

USA

USA

The Netherlands

The Netheriands

The Netheriands

India

USA

Oral

n.s.

Caucasiar

\section{Association GSTT1 null}

\section{genotype vs HNSCC}

Cheng et al. (54)

Hamel et al. (33)

Jahnke et al. $(29,30)$

$\mathrm{HN}$

$\mathrm{HN}$

Larynx

Jourenkova et al. (36)

$\begin{array}{lcl}17.5(315) & 32.7(162) & \text { Mixed } \\ 20.0(101) & 9.0(70) & \text { Mixed } \\ 12.4(145) & 21.3(169) & \text { Caucasian } \\ 15.7(172) & 22.4(67) & \text { Caucasian } \\ 15.7(172) & 21.5(1.21) & \text { Caucasian }\end{array}$

USA

Canada

Germany

France

France
$1.6(1.0-2.6)$

$1.0(0.6-1.7)$

nes.

$1.8(0.7 .4 .8)$

$1.2(0.6-2.5)$

$1.4(0.7-2.9)$

$1.4(0.6-3.7)$

$0.7(0.4-1.2)$

$0.9(0.5-1.4)$

$1.5(0.9-2.5)$

n.s.

$0.9(0.5-1.5)$

$1.4(0.7 .2 .7)$

$1.1(0.6-1.7)$

$1.0(0.5 \cdot 2.0)$

$10(0.5-1.9)$

$2.5(0.3-21.7)$

$1.5(0.7-3.0)$

n.s.

2.3(1.4-3.6)

$2.5(1.1 .5 .9)$

n.s.

$2.4(1.0-5.5)$

$2.0(1.0-4.0)$

n.s. not specified, $n=$ total number of patients or controls in group, $\mathrm{HN}=$ all sites of head and neck malignancies, $\mathrm{Cl}=$ confidence interval 
researchers in caucasian populations. This is however not so for their controls. All other studies were performed on Caucasian populations and show comparable frequency percentages.

Katoh et al. (35) observed the frequency of GSTP1 AB/BB genotypes to be significantly higher in never smoking oral cancer patients than control individuals (OR 2.78; $\mathrm{CI}$ 1.1-7.5). This suggests that non-smoking individuals with GSTP1 $A B$ or $B B$ genotype have a higher susceptibility for oral cancer.

Jourenkova et al. (36) reported no interaction of the GSTP1 gene and oral or pharyngeal cancers separately, however, when these two patient groups were combined, only a borderline significant increase in risk of developing cancer of the oral cavity and pharynx was found (OR 1.6; $\mathrm{Cl} 1.0-2.8$ ). Matthias et al. (37) suggest that different sites of HNSCC may be associated with different GST polymorphisms, since the GSTP1 $A B / B B$ genotypes show lower frequencies in patients with laryngeal, but not with oropharyngeal malignancies.

\section{Discussion}

The reason for the variable results with respect to the genetic polymorphisms in GSTs and their association with HNSCC, as found in the many studies summarized in the Tables 1-3, is not clear. Possibly the effect of one variant genotype on HNSCC susceptibility is too weak. Perhaps the occurrence of more than one genetic polymorphism in phase I and/or phase II enzymes, acting as a cascade, will have more effect and may significantly influence individual susceptibility. Many conflicting reports on the cancer susceptibility of GST genotypes have been published in the past decades. Most of these studies have been conducted for other localisations than head and neck cancer. Possible explanations in such variations in study results will be given.

Several reports describe patients with null genotypes of GSTM1 and/or GSTT1 who had an increased oral cancer risk compared with individuals who had non-null genotypes of both GSTM1 and GSTT1, suggesting that there are gene-gene and gene-environment interactions in the development of oral cancer (18). The combined GSTM3 ( $A B$ or $B B$ ) and GSTM1 null genotype conferred a 4-fold risk of laryngeal cancer as compared with the combined GSTM3 AA and GSTM1 positive genotypes (38). However, the effect of GSTM3 ( $A B$ or $B B$ ) genotype was similar among individuals with GSTM1 positive or GSTM1 null genotypes (38).

Combined null genotypes of GSTM1 and GSTT1 prevailed in $60.2 \%$ of Indian cases with oral leukoplakia whereas no individuals with this combination were detected in a control group (26). This is a striking difference, which however may be due to racial differences or due to the use of different methods for the isolation of DNA, since control and patient material in this study was processed completely different (26).

Coutelle et al. (24) found that alcoholics (defined as individuals consuming more than $100 \mathrm{~g}$ ethanol per day during at least 10 years) with the GSTM1 null genotype who were also homozygous for a polymorphism in alcohol dehydrogenase (ADH), denoted as 
Table 3. GSTP1 genotype (GSTP1 AB and GSTP1 B8) frequencies in control and HNSCC patient populations

Site

Author

No association of GSTP1 AB/BB

No association of GSTP1

Cabelguenne et al. (27)

Jahnke et al. (58)

Jourenkova et al. (38

Jourenkova et al. (36)

Kelders et al. (48)

Matthias et al. (37)

Matthias et al. (37)

McWilliams et al. (52)

Morita et al. (34)

Oishan et al. (32)

Oude Ophuis et al. (47)

\section{Association of GSTP1 AB/BB}

genotype and HNSCC

Jahnke et al. (58)

Jourenkova et al. (36)

Katoh et al. (35)

$\mathrm{HN}$

HN

$\mathrm{HN}$

$\mathrm{HN}$

GSTP1 AB/BE

GSTP1 AB/BB Cases Population

Country

Odds Ratio

Controls

\% of total (n)

HN
Larynx
Larynx
Oral
Pharynx
HN

$53.0(264)$

$46.9(216)$

$50.0(172)$

$50.0(172)$

$50.0(172)$

$49.0(25)$

Larynx

$47.2(180)$

Oropharynx $\quad 47.2(180)$

$53.2(124)$

Larynx

$31.1(164)$

Pharynx $\quad 31.1(164)$

$31.1(164)$
$31.1(164)$

$60.0(168)$

Oral/ oropharynx $\quad 56.1(285)$

Larynx $\quad 56.1(285)$

$56.1(285)$
$56.1(285)$

$45.0(162)$
51.5 (n.s.)
$51.9(129)$
$58.2(67)$
$58.0(50)$
$58.6(51)$
$51.5(260)$
$62.5(120)$
$58.9(146)$
$18.9(69)$
$26.6(45)$
$24.9(145)$
$63.0(109)$
$53.5(114)$
$49.0(100)$
$50.6(235)$

n.s.

Caucasian

France

Germany

Caucasian

Caucasian

Caucasian

Caucasian

Caucasian

Caucasian

Caucasian

Japanese

Japanese

Japanese

Caucasian

Caucasian

Caucasian

Caucasian

France

France

France

The Netherlands

Germany

Germany

USA

Japan

Japan

Japan

USA

The Netherlands

The Netheriands

The Netherlands

$\begin{array}{ll}\text { Oropharynx } & 46.9(216) \\ \mathrm{HN} & 50.0(172) \\ \text { Oral } & 23.8(22)\end{array}$

62.5 (n.s.)
58.7 (1.21)
37.3 (83)

Caucasian

Germany

France

Japan

Japanese

$1.6(1.0-2.8)$

$\mathrm{n}=$ total number of patients or controls in group, $\mathrm{n.s} .=$ not specified, $\mathrm{HN}=$ all sites of head and neck malignancies, $\mathrm{Cl}=$ confidence interval 
$\mathrm{ADH}_{3}{ }^{1} / \mathrm{ADH}_{3}{ }^{1}$ which is associated with a rapid generation of acetaldehyde, had at least an $80 \%$ greater risk of developing laryngeal cancer than alcoholics who were GSTM1 positive and who were not bearing the $\mathrm{ADH}_{3}{ }^{1} / \mathrm{ADH}_{3}{ }^{1}$ genotype.

Individuals with concurrent lack of both functional GSTM1 and GSTT1 genes had a tendency for a higher risk of laryngeal cancer as compared with those individuals having at least one of the above mentioned functional genes (OR 2.0; $\mathrm{Cl}$ 0.8-5.2), and had an almost a 3-fold higher risk (OR 2.7; $\mathrm{Cl} 1.0-7.4$ ) when compared with individuals having both functional genes (23). These data suggest that a combination of genetic polymorphisms in detoxification enzymes, either phase I or phase II, could modulate the risk for malignant degeneration.

There are also studies that have shown an association between smoking and null genotype. Kihara et al. (15) found more individuals bearing the GSTM1 null genotype in the smoking patient group than in the healthy control group ( $56.7 \%$ vs $48.5 \%$ ), whereas there was an equal distribution in gender. The same authors also described a smoking $(n=128)$ and non-smoking $(n=30)$ HNSCC group, and found a higher frequency of GSTM1 null genotype in the former group. HNSCC patients usually are smokers, and the higher frequency of GSTM1 null genotype in this group may suggest a role for GSTM1 in the detoxification of tobacco smoke constituents.

However, associations found are not straightforward, since Park et al. (17) observed no association between the prevalence of GSTM1 null genotype and the levels of smoking or alcohol consumption in the HNSCC cases, whereas Jourenkova et al. (23) found that the GSTM1 null genotype was associated with an increased risk of larynx cancer among individuals who smoked 20 cigarettes/day or less but not among more heavier smokers. No interaction was found between GSTM1 null genotype and duration of tobacco consumption. For the GSTT1 null genotype, Jourenkova et al. (23) found the opposite result; no interaction between levels of tobacco consumption, but limited effect by long term smokers. Katoh et al. (39) found no effect of GSTM1 and GSTT1 null genotypes on oral cancer in combination with smoking or drinking. The GST genotype of an individual may determine his smoking behavior in a similar way as the $A D H$ genotype may influence alcohol consumption.

Differences in the way the GST system is assessed may explain part of the conflicting reports on the susceptibility of GSTs. There are studies that evaluated phenotypic expression of GSTs in relation to HNSCC (40-46), whereas others evaluated the genetic polymorphism $(15,20,23,31,36-38,47)$ or a combination of both $(48)$.

The collection of cell material for genotyping is different in the various studies. DNA isolation from peripheral lymphocytes/leukocytes $(18,20,23,25,36,38,47-49)$ is the method of choice for genotyping. DNA isolation from tumor tissue, and especially paraffin embedded tissue (26), may not be as reliable due to possible mutations that may have occurred during carcinogenesis. Also, the use of DNA extracted from tissues processed in a different way, such as exfoliated (buccal mucosa) cells in the control group and paraffin embedded tissue in the patient group, as performed by Nair et al. (26) may introduce artefacts. 
The moment of patient sampling (before, during, or after treatment) may influence the phenotypic, and to a much lesser extent the genotypic expression of the GST system, either locally or systemically, since it is well known that such therapies may generate new mutations. Results obtained from previously untreated patients therefore may be different compared to those having received earlier radio- or chemo-therapy. No mention of this has been made in any study published so far.

Note the extreme small groups of cases as well as controls by Hanna et al. (50), which makes it difficult to correctly interpret the results.

Combination studies with other than GST genes make interpretation of results more difficult and not transparant, for instance evaluation of GSTs with other genes such as p53 and p16 (22). However, it should be realized that GST enzymes most likely do not act as a stand alone system for carcinogenesis but probably act together with other enzymes or proteins.

In conclusion, we found that most studies conducted on the association between genetic polymorphisms in GSTs and the risk for HNSCC are difficult to interpret. Several factors, such as small sizes of control and patient populations studied, variations in the methods used, interracial-, demographic- or other differences in the patient and control populations studied may contribute to the variable results obtained so far. The finding that high consumption of alcohol and tobacco is a predominant factor for HNSCC has invariably been shown in most studies, whereas interaction with genotype could be demonstrated only now and then. New studies with mucn iarger patient ana control populations, or a meta analysis where all these contributing factors are critically evaluated and discussed would be highly desirable.

\section{References}

1. Blot WJ, McLaughlin JK, Winn DM, et al. Smoking and drinking in relation to oral and pharyngeal cancer. Cancer Res 1988;48:3282-3287.

2. Pelkonen O, Nebert DW. Metabolism of polycyclic aromatic hydrocarbons: etiologic role in carcinogenesis. Pharmacol Rev 1982;34:189-222.

3. Mannervik B, Danielson UH. Glutathione transferases structure and catalytic activity. CRC Crit Rev Biochem 1988;23:283-337.

4. Board P, Coggan M, Johnston P, Ross V, Suzuki T, Webb G. Genetic heterogeneity of the human glutathione transferases: a complex of gene families. Pharmacol Ther 1990;48:357-369.

5. Beckett GJ, Hayes JD. Glutathione S-transferases: biomedical applications. Adv Clin Chem 1993;30:281-380.

6. Hayes JD, Pulford DJ. The glutathione S-transferase supergene family: regulation of GST and the contribution of the isoenzymes to cancer chemoprotection and drug resistance. Crit Rev Biochem Mol Biol 1995;30:445-600.

7. Ahmad H, Wilson DE, Fritz RR, et al. Primary and secondary structural analyses of glutathione S-transferase Pi from human placenta. Arch Biochem Biophys 1990;278:398-408. 
8. Ali-Osman F, Akande O, Antoun G, Mao JX, Buolamwini J. Molecular cloning, characterization, and expression in Escherichia coli of full-length cDNAs of three human glutathione S-transferase $\mathrm{Pi}$ gene variants. Evidence for differential catalytic activity of the encoded proteins. J Biol Chem 1997;272:10004-10012.

9. Pemble S, Schroeder KR, Spencer SR, et al. Human glutathione S-transferase theta (GSTT1): cDNA cloning and the characterization of a genetic polymorphism. Biochem J 1994;300:271-276.

10. Harries LW, Stubbins MJ, Forman D, Howard GC, Wolf CR. Identification of genetic polymorphisms at the glutathione S-transferase $\mathrm{Pi}$ locus and association with susceptibility to bladder, testicular and prostate cancer. Carcinogenesis 1997;18:641-644.

11. Coles BF, Morel F, Rauch C, et al. Effect of polymorphism in the human glutathione S-transferase A1 promoter on hepatic GSTA1 and GSTA2 expression. Pharmacogenetics 2001;11:663-669.

12. Meister A. Glutathione metabolism and its selective modification. J Biol Chem 1988;263:17205-17208.

13. van Lieshout EMM, Roelofs HMJ, Dekker S, et al. Polymorphic expression of the glutathione S-transferase P1 gene and its susceptibility to Barrett's esophagus and esophageal carcinoma. Cancer Res 1999:59:586-589.

14. Watson MA, Stewart RK, Smith GB, Massey TE, Bell DA. Human glutathione S-transferase P1 polymorphisms: relationship to lung tissue enzyme activity and population frequency distribution. Carcinogenesis 1998;19:275-280.

15. Kihara M, Kihara M, Kubota A, Furukawa M, Kimura H. GSTM1 gene polymorphism as a possible marker for susceptibility to head and neck cancers among Japanese smokers. Cancer Lett 1997;112:257-262.

16. Deakin M, Elder J, Hendrickse C, et al. Glutathione S-transferase GSTT1 genotypes and susceptibility to cancer: studies of interactions with GSTM1 in lung. oral, gastric and colorectal cancers. Carcinogenesis 1996:17:881-884.

17. Park JY, Muscat JE, Ren Q, et al. CYP1A1 and GSTM1 polymorphisms and oral cancer risk. Cancer Epidemiol Biomarkers Prev 1997;6:791-797.

18. Hung HC, Chuang J, Chien YC, et al. Genetic polymorphisms of CYP2E1, GSTM1, and GSTT1; environmental factors and risk of oral cancer. Cancer Epidemiol Biomarkers Prev 1997;6:901-905.

19. Worrall SF, Corrigan M, High A, et al. Susceptibility and outcome in oral cancer: preliminary data showing an association with polymorphism in cytochrome P450 CYP2D6. Pharmacogenetics 1998;8:433-439.

20. Oude Ophuis MB, van Lieshout EMM, Roelofs HMJ, Peters WHM, Manni JJ. Glutathione S-transferase M1 and T1 and cytochrome P4501A1 polymorphisms in relation to the risk for benign and malignant head and neck lesions. Cancer 1998;82:936-943.

21. Tanimoto K, Hayashi S, Yoshiga K, Ichikawa T. Polymorphisms of the CYP1A1 and GSTM1 gene involved in oral squamous cell carcinoma in association with cigarette dose. Oral Oncology 1999;35:191-196.

22. Lazarus $\mathrm{P}$, Sheikh SN, Ren Q, et al. p53, but not p16 mutations in oral squamous cell carcinomas are associated with specific CYP1A1 and GSTM1 polymorphic genotypes and patient tobacco use. Carcinogenesis 1998;19:509-514. 
23. Jourenkova N, Reinikainen M, Bouchardy C, Dayer P, Benhamou S, Hirvonen A. Larynx cancer risk in relation to glutathione S-transferase M1 and T1 genotypes and tobacco smoking. Cancer Epidemiol Biomarkers Prev 1998;7:19-23.

24. Coutelle C, Ward PJ, Fleury B, et al. Laryngeal and oropharyngeal cancer, and alcohol dehydrogenase 3 and glutathione S-transferase M1 polymorphisms. Hum Genet 1997:99:319-325.

25. Trizna Z, Clayman GL, Spitz MR, Briggs KL, Goepfert H. Glutathione S-transferase genotypes as risk factors for head and neck cancer. Am J Surg 1995;170: 499-501.

26. Nair UJ, Nair J, Mathew B, Bartsch H. Glutathione S-transferase M1 and T1 null genotypes as risk factors for oral leukoplakia in ethnic Indian betel quid/tobacco chewers. Carcinogenesis 1999;20:743-748.

27. Cabelguenne A, Loriot MA, Stucker I, et al. Glutathione-associated enzymes in head and neck squamous cell carcinoma and response to cisplatin-based neoadjuvant chemotherapy. Int J Cancer 2001;93:725-730.

28. Nelson HH, Wiencke JK, Christiani DC, et al. Ethnic differences in the prevalence of the homozygous deleted genotype of glutathione S-transferase theta. Carcinogenesis 1995;16:1243-1245.

29. Jahnke V, Strange R, Matthias C, Fryer A. Erste Ergebnisse über Glutathion-STransferase GSTM1 und GSTT1 Genotypen und die genetische Prãdisposition beim Larynxkarzinom. Laryngorhinootologie 1995;74:691-694.

30. Jahnke V, Matthias C, Fryer A, Strange R. Glutathione S-transferase and cytochrome-P-450 polymorphism as risk factors for squamous cell carcinoma of the larynx. Am J Surg 1996;172:671-673.

31. Matthias C, Bockmuhl U, Jahnke V, et al. Polymorphism in cytochrome P450 CYP2D6, CYP1A1, CYP2E1 and glutathione S-transferase, GSTM1, GSTM3, GSTT1 and susceptibility to tobacco-related cancers: studies in upper aerodigestive tract cancers. Pharmacogenetics 1998;8:91-100.

32. Olshan AF, Weissler MC, Watson MA, Bell DA. GSTM1, GSTT1, GSTP1, CYP1A1, and NAT1 polymorphisms, tobacco use, and the risk of head and neck cancer. Cancer Epidemiol Biomarkers Prev 2000;9:185-191.

33. Hamel N, Karimi S, Hebert-Blouin MN, et al. Increased risk of head and neck cancer in association with GSTT1 nullizygosity for individuals with low exposure to tobacco. Int J Cancer 2000;87:452-454.

34. Morita S, Yano M, Tsujinaka T, et al. Genetic polymorphisms of drug-metabolizing enzymes and susceptibility to head-and-neck squamous-cell carcinoma. Int J Cancer 1999;80:685-688.

35. Katoh T, Kaneko S, Takasawa S, et al. Human glutathione S-transferase P1 polymorphism and susceptibility to smoking related epithelial cancer; oral, lung, gastric, colorectal and urothelial cancer. Pharmacogenetics 1999;9:165-169.

36. Jourenkova-Mironova N, Voho A, Bouchardy C, et al. Glutathione S-transferase GSTM1, GSTM3, GSTP1 and GSTT1 genotypes and the risk of smoking-related oral and pharyngeal cancers. Int J Cancer 1999;81:44-48.

37. Matthias C, Bockmuhl U, Jahnke V, et al. The glutathione S-transferase GSTP1 polymorphism: effects on susceptibility to oral/pharyngeal and laryngeal carcinomas. Pharmacogenetics 1998;8:1-6. 
38. Jourenkova-Mironova N, Voho A, Bouchardy C, et al. Glutathione S-transferase GSTM3 and GSTP1 genotypes and larynx cancer risk. Cancer Epidemiol Biomarkers Prev 1999;8:185-188.

39. Katoh T, Kaneko S, Kohshi K, et al. Genetic polymorphisms of tobacco- and alcohol-related metabolizing enzymes and oral cavity cancer. Int J Cancer 1999;83: 606-609.

40. Bongers V, Snow GB, de Vries N, et al. Second primary head and neck squamous cell carcinoma predicted by the glutathione S-transferase expression in healthy tissue in the direct vicinity of the first tumor. Lab Invest 1995;73:503-510.

41. Hirata S, Odajima T, Kohama G, Ishigaki S, Niitsu Y. Significance of glutathione S-transferase-pi as a tumor marker in patients with oral cancer. Cancer 1992;70:2381-2387.

42. Oude Ophuis MB, Mulder TPJ, Peters WHM, Manni JJ. Plasma glutathione S-transferase P1-1 levels in patients with head and neck squamous cell carcinoma. Cancer 1998;82:2434-2438.

43. Janot F, Massaad L, Ribrag V, et al. Principal xenobiotic-metabolizing enzyme systems in human head and neck squamous cell carcinoma. Carcinogenesis 1993;14:1279-1283.

44. Mulder TPJ, Manni JJ, Roelofs HMJ, Peters WHM, Wiersma A. Glutathione S-transferases and glutathione in human head and neck cancer. Carcinogenesis 1995:16:619-624.

45. Lafuente A, Pujol F, Carretero P, Villa JP, Cuchi A. Human glutathione S-transferase mu (GST mu) deficiency as a marker for the susceptibility to bladder and larynx cancer among smokers. Cancer Lett 1993;68:49-54.

46. Lafuente A, Maristany M, Arias C, et al. Glutathione and glutathione S-transferases in human squamous cell carcinomas of the larynx and GSTM1 dependent risk. Anticancer Res 1998;18:107-111.

47. Oude Ophuis MB, Roelofs HMJ, van den Brandt PA, Peters WHM, Manni JJ. Polymorphisms of the glutathione S-transferase P1 gene and Head and Neck cancer suscepitbility. Head and Neck 2003; 25:37-43.

48. Kelders WPA, Oude Ophuis MB, Roelofs HMJ, Peters WHM, Manni JJ. The association between glutathione S-transferase P1 genotype and plasma level in head and neck cancer. Laryngoscope 2002;112:462-466.

49. Hong YJ, Lee JK, Lee GH, Hong SI. Influence of glutathione S-transferase M1 and T1 genotypes on larynx cancer risk among Korean smokers. Clin Chem Lab Med 2000;38:917-919.

50. Hanna E, MacLeod S, Vural E, Lang N. Genetic deletions of glutathione Stransferase as a risk factor in squamous cell carcinoma of the larynx: a preliminary report. Am J Otolaryngol 2001;22:121-123.

51. Gonzalez MV, Alvarez V, Pello MF, Menendez MJ, Suarez C, Coto E. Genetic polymorphism of $\mathrm{N}$-acetyltransferase-2, glutathione S- transferase-M1, and cytochromes P450IIE1 and P450IID6 in the susceptibility to head and neck cancer. J Clin Pathol 1998:51:294-298.

52. McWilliams JE, Evans AJ, Beer TM, et al. Genetic polymorphisms in head and neck cancer risk. Head and Neck 2000;22:609-617.

53. Buch SC, Notani PN, Bhisey RA. Polymorphism at GSTM1, GSTM3 and GSTT1 gene loci and susceptibility to oral cancer in an Indian population. Carcinogenesis 2002;23:803-807. 
54. Cheng L, Sturgis EM, Eicher SA, Char D, Spitz MR, Wei Q. Glutathione S-transferase polymorphisms and risk of squamous-cell carcinoma of the head and neck. Int J Cancer 1999;84:220-224.

55. Gronau S, Konig-Greger D, Rettinger G, Riechelmann H. GSTM1 Genpolymorphismus bei Patienten mit Kopf-Hals-Tumoren. Laryngorhinootologie 2000;79: 341-344.

56. Sato M, Sato T, Izumo T, Amagasa T. Genetic polymorphism of drug-metabolizing enzymes and susceptibility to oral cancer. Carcinogenesis 1999;20:1927-1931.

57. Sreelekha T, Ramadas K, Pandey M, Thomas G, Nalinakumari KR, Pillai MR. Genetic polymorphism of CYP1A1, GSTM1 and GSTT1 genes in Indian oral cancer. Oral Oncol 2001:37:593-598.

58. Jahnke V, Matthias C, Bockmuhl U, Strange RC. Genetische Prädisposition für die Entstehung von Kopf- und Hals- Karzinomen. Laryngorhinootologie 1999;78: 24-27. 


\section{CHAPTER}

GLUTATHIONE S-TRANSFERASE M1 AND T1 AND

CYTOCHROME P4501A1 POLYMORPHISMS IN RELATION TO THE RISK FOR BENIGN AND MALIGNANT HEAD AND NECK LESIONS

Michael B Oude Ophuis ${ }^{1}$, Esther MM van Lieshout ${ }^{2}$, Hennie MJ Roelofs ${ }^{2}$, Wilbert HM Peters $^{2}$, Johannes J Manni ${ }^{1}$

${ }^{1}$ Dept. of Otorhinolaryngology, Head and Neck Surgery, University Hospital Maastricht, The Netherlands

${ }^{2}$ Dept. of Gastroenterology, University Medical Center Nijmegen, The Netherlands

Published in Cancer 1998; 82: 936-943 


\section{Abstract}

Background Susceptibility to head and neck cancer in a particular individual may depend in part on the metabolic balance between phase I enzymes such as cytochromes P450 (CYPs) and phase II enzymes such as glutathione S-transferases (GSTs). Genetic variability in CYP and GST isoenzymes may contribute to individual differences in susceptibility to chemical carcinogenesis. GSTM1 and GSTT1 null genotypes as well as polymorphic variants in the CYP1A1 gene were described which may determine in part the risk for head and neck cancer.

Methods Polymorphisms of GSTM1, GSTT1, and CYP1A1 in whole blood were detected by polymerase chain reaction method (PCR) in: 185 patients with head and neck squamous cell carcinoma (HNSCC), 78 patients with benign head and neck lesions (BHNL) and 207 blood donors.

Results GSTM1 null genotype was demonstrated to be equally frequent in patients with HNSCC (50.8\%), patients with BHNL $(47.4 \%)$ and blood donors (51.7\%). GSTT1 null genotype occurred significantly more often in patients with BHNL (33.3\%) as compared to blood donors (20.3\%), demonstrating that lack of GSTT1 may be a risk factor for BHNL. Presence of the rare valine in the CYP1A1/Ncol site was found in $33(17.8 \%)$ patients with HNSCC, in 20 (25.6\%) patients with BHNL and in $34(16.4 \%)$ blood donors. For the presence of the rare cytosine nucleotide in the CYP1A1/Msp/ sito those frequencies were $17.8,15.4$ and $15.9 \%$, respectively.

Conclusions The occurrence of polymorphic variants in the GSTM1, GSTT1, and CYP1A1 genes did not differ between the groups investigated, therefore indicating no significant contribution to the development of head and neck cancer. 


\section{Introduction}

Head and neck squamous cell carcinoma (HNSCC) appears to be related to smoking and alcohol consumption (1-5). Polycyclic aromatic hydrocarbons (PAHs), present in tobacco smoke or metabolites of alcohol, are precursors of chemicals that increase the risk of cancer (6). One of the first steps in head and neck cancer may be the binding of exogenic electrophillic compounds to the DNA of mucosal cells (7-9). Most PAHs first require activation by phase I enzymes, such as cytochrome P4501A1 (CYP1A1), to become an ultimate carcinogen. These activated forms may be subjected to detoxification by phase II enzymes, especially glutathione S-transferases (GSTs). Thus, genetically determined susceptibility to head and neck cancer may depend on the metabolic balance between these enzymes.

Glutathione S-transferases are a family of dimeric enzymes, involved in the biotransformation of a large variety of compounds. GSTs catalyse the nucleophillic conjugation of glutathione to many different biologically active and potential carcinogenic compounds (10-13), which may be further metabolized to mercapturic acids. As a result the possible toxins or carcinogens are eliminated. In humans, the GST family can be divided into class Alpha (A), Mu (M), Pi (P) and Theta (T) enzymes, each class consisting of several isoenzymes with a (partly) overlapping substrate specificity $(12,13)$. Genetic polymorphisms have been demonstrated for the genes coding for the GSTM1 and CSTT1 ondymoe.

The GSTM1 enzyme is involved in the detoxification of tobacco related carcinogens, like epoxides and hydroxylated metabolites of benzo[a]pyrene (13). Two functional alleles $\left(G S T M 1{ }^{\star} A\right.$ and $G S T M 1{ }^{\star} B$ ) and a non-functional null-allele (GSTM1 ${ }^{\star} 0$ ) have been identified in the GSTM1 gene. Approximately $45 \%$ of the human Caucasian population lacks a functional allele (14-17). In oiher ethnic groups this proportion may be much higher (14). Carcinogenesis could be related to the absence of the functional GSTM1 alleles resulting in an incapacity of detoxifying tobacco related carcinogens. Several studies have shown that the GSTM1 polymorphism is associated with an increased risk of lung, bladder, gastric, colorectal, skin and larynx cancer (14,18-25). Other studies, however, revealed that the impact of the GSTM1 trait may be low or even undetectable in different cancer populations (26-32).

The GSTT1 gene also has a functional and a non-functional allele. Approximately $20 \%$ of the human Caucasian population lacks the functional allele (33), whereas in other ethnic groups this percentage may be different $(23,34)$. Since the GSTT1 enzyme is involved in the biotransformation of several low molecular weight toxins such as methyl-halogenids or ethylene oxide (13), part of the population lacking this enzyme might be more susceptible to smoking or alcohol related cancers. Lack of the GSTT1 enzyme has been associated with bladder cancer (24), whereas other studies did not find an association with lung and skin cancer $(32,35)$.

Many chemical compounds are metabolically activated to forms that have deleterious effects on organisms (36), and this metabolic activation is an obligatory initiation step in human carcinogenesis. Cytochrome P450 plays a major role in the formation of chemical carcinogens $(37,38)$. Many isoenzymes of CYP have been found in humans. 
Genetic variability in these isoenzymes may be responsible for the individual differences in susceptibility towards cancer $(37,39)$. The CYP1A1 enzyme is involved in the activation of benzo[a]pyrene and other aromatic hydrocarbons in tobacco smoke (36-42). Two genetic polymorphisms have been demonstrated in the CYP1A1 gene, which both may result in an increased enzyme activity (43-45): (i) an isoleucine/valine substitution in exon 7, the heme binding region (CYP1A1/Ncol) $(46,47)$, and (ii) a thymine/cytosine point mutation in the $3^{\prime}$ flanking non-coding region (CYP1A1/Mspl). Both genetic polymorphisms seem to be involved in an increased susceptibility to carcinogenesis of the lung $(44,46-48)$. It has been suggested that homozygotes of the variant allele of each mutation are correlated with an enhanced susceptibility to smoking-related lung cancer in a Japanese population $(31,44,46,47)$. No such relationship has been observed in black and non-black populations of Rio de Janeiro (49) or in Caucasian populations (50-52), where the occurrence of the susceptible alleles is very rare.

In the present study we investigated genetic polymorphisms in GSTM1, GSTT1 and CYP1A1 in patients with malignant and benign head and neck lesions (HNSCC and BHNL respectively), in comparison with a group of healthy blood donors.

\section{Materials and Methods}

\section{Patients and controls}

A total of 185 patients with head and neck squamous cell carcinoma (HNSCC) were recruited preoperatively or postoperatively during their scheduled outpatient visit at the University Hospital Maastricht (The Netherlands) between 1994 and 1996 (mean age $59.6 \pm 11.8$ years; range $23-86$ ). This group consists of 73 patients with larynx carcinoma (mean age $61.6 \pm 10.6$ years; range $36-86$ ), 76 patients with oral and

Table 1. Classification of patients with HNSCC

\begin{tabular}{llr} 
Site - subsite of tumor & Number of patients \\
\hline Oral cavity & floor of mouth & 17 \\
& tongue & 11 \\
& retromolar trigonum & 7 \\
& alveolar process & 4 \\
Oropharynx & mucosa cheek & 2 \\
& tonsil & 12 \\
& soft palate & 6 \\
& overlapping areas & 5 \\
& base of tongue & 5 \\
& lateral wall & 3 \\
& vallecular region & 2 \\
Larynx & posterior wall & 2 \\
Other & glottis & 49 \\
& supraglottis & 24 \\
& hypopharynx & 16 \\
& neck metastases of unknown primary & 11 \\
& nasopharynx & 3 \\
Total & sinus & 2 \\
& parotid gland & 2 \\
& skin & 2
\end{tabular}


oropharynx carcinoma (mean age $57.8 \pm 12.0$ years; range $23-82$ ) and a remaining group of 36 patients (mean age $60.4 \pm 12.6$ years; range $28-86$ ), consisting of carcinomas of the hypopharynx $(n=16)$, nasopharynx $(n=3)$, sinus $(n=2)$, parotid gland $(n=2)$, skin $(n=2)$ and neck metastases of unknown primary origin $(n=11)$. Table 1 shows the classification of the patients according to tumor risk. Table 3 shows a further specification.

Our second population consists of 78 patients with benign head and neck lesions (BHNL) such as polyps, cysts, and vocal cord nodules (mean age $49.2 \pm 15.9$ years; range 16-86). A further specification of these patients is presented in Table 2 and 3.

A group of 207 healthy blood donors (76 men; 131 women) recruited at the University Medical Center Nijmegen, (The Netherlands) served as a control group (mean age $34.3 \pm 11.5$ years; range $19-64)$.

At the time when informed consent was obtained, medical and other anamnestic data were obtained by interview. The investigations were approved by the Medical Ethical Review Committee.

Table 2. Classification of patients with BHNL

\begin{tabular}{ll} 
Site - type of lesion & Number of patients \\
\hline Vocal cord - nodules / cysts & 22 \\
Parotid gland - pleiomorphic adenoma & 16 \\
Nose - polyps & 13 \\
Neck - cysts (medial / lateral) & $9(7 / 2)$ \\
Submandibular gland - sialolithiasis & 8 \\
Oral cavity - leucoplakia & 4 \\
Oral cavity - fibromas & 3 \\
Nose - cyst & 2 \\
Tonsil - retention cyst & 1 \\
& \\
Total & 78
\end{tabular}

Table 3. Age and gender of the patients with HNSCC (total group as well as subclasses), BHNL. and controls

\begin{tabular}{llllll} 
& \multicolumn{2}{c}{ HNSCC } & BHNL & Controls \\
\cline { 2 - 5 } & Total group & Larynx carcinoma & Oropharynx carcinoma & & \\
\hline $\mathrm{N}$ & 185 & 73 & 76 & 78 & 207 \\
$\begin{array}{l}\text { Age (yrs) } \\
\text { Mean } \pm \text { S.D. }\end{array}$ & $59.6 \pm 11.8$ & $61.6 \pm 10.6$ & $57.8 \pm 12.0$ & $49.2 \pm 15.9$ & $34.3 \pm 11.5$ \\
$\begin{array}{l}\text { Range } \\
\text { Gender (\%) }\end{array}$ & $23-86$ & $36-86$ & $23-82$ & $16-86$ & $19-64$ \\
$\quad \begin{array}{l}\text { Male } \\
\text { Female }\end{array}$ & 79.5 & 88.2 & 70.7 & 46.8 & 36.7 \\
& 20.5 & 11.8 & 29.3 & 53.2 & 63.3
\end{tabular}

\section{Blood sampling and extraction of DNA}

Blood was collected by venapuncture in sterile siliconized EDTA K3 (15\%) $4 \mathrm{ml}$ Vacutainer tubes (Becton Dickinson). Immediately after collection whole blood was stored at $-20^{\circ} \mathrm{C}$ until use. Genomic DNA was isolated from whole blood using the Wiz$\operatorname{ard}^{\mathrm{TM}}$ genomic DNA purification kit, according to the instructions of the manufacturer (Promega, Madison Wisconsin, USA). 


\section{Genotyping}

Genetic polymorphisms were detected by PCR and all primers were selected based on studies by others. The primers were synthesized by Pharmacia Biotech (Roosendaal, the Netherlands). All chemicals needed for PCR were purchased from Promega (USA). For GSTM1 (primer set G2 and G3, ref. 27) and GSTT1 (primer set T1 and T2, ref. 53) one primer was situated in the deleted area. Genetic polymorphism in exon 7 of the CYP1A1 gene was determined by PCR (primer set CYP1A1/1 and CYP1A1/2, ref. 48) and restriction enzyme digestion according to Shields et al. (48). Here a primer was designed so that the presence of the rare G allele (valine) results in the loss of a Ncol restriction enzyme site. Genetic polymorphism in the $3^{\prime}$ flanking region in the CYP1A1 gene was detected by PCR and restriction enzyme digestion, using the primers C44 and $\mathrm{C} 47$ (44). Here, one of the primers was designed so that the presence of the rare $C$ nucleotide results in the appearance of a Mspl restriction enzyme site.

Fifty to hundred $\mathrm{ng}$ of DNA were amplified in a total volume of $25 \mu \mathrm{l}$ containing $10 \mathrm{mM}$ Tris/ $\mathrm{HCl}$ pH 9.0, $50 \mathrm{mM} \mathrm{KCl}, 0.1 \%$ Triton X-100, 2 mM MgCl 2 (1.5 mM for CYP1A1/1 and CYP1A1/2), $200 \mu \mathrm{M}$ of deoxynucleotide triphosphate, $1 \mu \mathrm{M}$ of each primer, and 0.2 units of Taq polymerase, overlaid with one drop of mineral oil. PCR was carried out in a programmable Thermojet thermocycler (Eurogentec, Seraing, Belgium). After 5 min of pretreatment at $95^{\circ} \mathrm{C}, 35$ cycles of $30 \mathrm{sec}$ denaturation at $95^{\circ} \mathrm{C}, 30 \mathrm{sec}$ annealing at $59^{\circ} \mathrm{C}$ (GSTM1 and GSTT1) or $55^{\circ} \mathrm{C}$ (CYP1A1) and 90 sec extension at $72^{\circ} \mathrm{C}$.

For evaluating GSTM1 and GSTT1 polymorphisms, reaction mixture products were analysed by gel electrophoresis ( $2 \%$ agarose; $60 \mathrm{~V} ; 1 \mathrm{~h}$ ) for the presence of a 650 -base pair product, which was indicative of the GSTM1 gene or a 480-base pair product, indicative of the GSTT1 gene. The lack of an amplification product is consistent with the null genotype. Detection of CYP1A1 PCR products served as a positive control.

Amplification products of the CYP1A1 gene were subjected to restriction fragment length digestion using Mspl or $\mathrm{Ncol}$ (Promega; 10 units; $37^{\circ} \mathrm{C}, 1.5 \mathrm{~h}$ ). Analysis of the Ncol site by gel electrophoresis ( $2 \%$ agarose; $60 \mathrm{~V} ; 2.5 \mathrm{~h}$ ) revealed a 163 - and 32-base pair fragments for wild type alleles (isoleucine) or a single 195 base pair fragment when the mutation (valine) was present. Analysis of the Mspl site by gel electrophoresis ( $2 \%$ agarose; $60 \mathrm{~V} ; 1.5 \mathrm{~h}$ ) revealed a 340-base pair fragment for mutant alleles (cytosine) or 200- and 140-base pair fragments for wild type alleles (thymine).

\section{Statistical analyses}

Statistical significance of differences for individual and combined polymorphisms between different groups was tested with a $\chi^{2}$ analysis with Yates correction in $2 \times 2$ or $2 \times 4$ contingency tables, respectively.

\section{Results}

The distribution of the GSTM1 and GSTT1 genes in patients with HNSCC or BHNL and blood donors is summarized in Table 4. Presence of the GSTM1 gene in patients with HNSCC $(49.2 \%)$ did not differ significantly from the distribution in a population with 
either benign head and neck lesions $(52.6 \%, p=0.71)$ or healthy blood donors $(48.3 \%$, $\mathrm{p}=0.95$ ). In subgroups based on tumor localisation (larynx and oral-oropharynx) these expression frequencies were maintained (46.6\% and $50.0 \%$, respectively) and no significant differences were obtained. The GSTM1 polymorphism also did not show any significant difference between benign head and neck lesions and blood donors $(p=0.61)$.

The BHNL group showed a significantly lower expression of the GSTT1 gene (66.7\%) as compared to the blood donor group $\left(79.7 \% ; \chi^{2}=4.6, p=0.03\right)$ and the HNSCC group $\left(80.5 \% ; \chi^{2}=5.1, p=0.02\right)$. Compared to the blood donor population, the HNSCC group showed no significant difference in GSTT1 expression ( $79.7 \%$ and $80.5 \%$, respectively: $\mathrm{p}=0.94)$. In the HNSCC subgroups no differences in GST1 gene distribution were noted.

Presence of both GSTM1 and GSTT1 genes occurred less frequently in patients with BHNL as compared to patients with $\operatorname{HNSCC}\left(\chi^{2}=10.2, p=0.01\right)$, whereas no significant difference was found between healthy volunteers and patients with BHNL or HNSCC.

Table 4. GSTM1 and GSTT1 expression in patients with HNSCC, BHNL and in controls

\begin{tabular}{|c|c|c|c|}
\hline & $\operatorname{HNSCC}(\%)$ & BHNL (\%) & Controls (\%) \\
\hline GSTM1* & $91(49.2)$ & $41(52.6)$ & $100(48.3)$ \\
\hline GSTM1 & $94(50.8)$ & $37(47.4)$ & $107(51.7)$ \\
\hline GSTI $1^{*}$ & $149(80.5)$ & $52(66.7)$ & 165 (79.7) \\
\hline GSTI1 & $36(19.5)$ & 26 (33.3) & $42(20.3)$ \\
\hline GSTM1 $1^{+}$GSTT1 $1^{+}$ & $79(42.7)$ & $26(33.3)$ & $81(39.1)$ \\
\hline GSTM $1^{*}$ GSTT1 & $12(6.5)$ & $15(19.2)$ & $19(9.2)$ \\
\hline GSTM1 GSTI1 ${ }^{+}$ & $70(37.8)$ & $26(33.3)$ & $84(40.6)$ \\
\hline GSTM1 GSTI1 & $24(13.0)$ & $11(14.1)$ & $23(11.1)$ \\
\hline
\end{tabular}

$\because$ gene present: , gene absent

Table 5 shows the expression rates of the polymorphic variants of the CYP1A1/Ncol and CYP1A1/Msp/ sites in patients with HNSCC, BHNL patients and healthy blood donors. The expression rates of the different polymorphic variants were not statistically significant between the different groups. Presence of the rare $\mathrm{G}$ (valine) allele in the Ncol site ranges from $16.4 \%$ in the blood donor group to $25.6 \%$ in BHNL patients. In the $\mathrm{Mspl}$ site the rare $\mathrm{C}$ nucleotide occurred approximately equally frequent as the rare allele in the $\mathrm{Ncol}$ site and ranges from $15.4 \%$ in BHNL patients to $17.8 \%$ in $\mathrm{HNSCC}$ patients. Chi square analyses gave p-values of 0.7114 and 0.9561 when comparing HNSCC or BHNL with blood donors, and here again no statistically significant differences could be found.

In the BHNL group, rare alleles in both the CYP1A1/Ncol and CYP1A1/Mspl sites (Table 5 ) were found in $7(9.0 \%)$ cases, whereas a rare allele in only one of the sites was found in 18 patients $(23.1 \%)$ and no rare alleles in 53 patients $(67.9 \%)$. In the HNSCC group these percentages were $8.1,20.0$ and $71.9 \%$, respectively. Finally, in the blood donor group these rates were $7.2,17.9$ and $74.9 \%$, respectively. The balance between the different polymorphic variants in the CYP1A1/Mspl and CYP1A1/Ncol sites was significantly correlated in each population studied. 
Table 5. Distribution of polymorphic variants in CYP1A1/Ncol and CYP1A1/Mspl sites in patients with HNSCC, BHNL and in controls

\begin{tabular}{|c|c|c|c|}
\hline & HNSCC (\%) & BHNL (\%) & Controls (\%) \\
\hline Ncorm & $151(81.6)$ & $58(74.4)$ & $173(83.6)$ \\
\hline Ncol pare & $34(18.4)$ & $20(25.6)$ & $34(16.4)$ \\
\hline$M s p /{ }^{m t}$ & $152(82.2)$ & $66(84.6)$ & $174(84.1)$ \\
\hline Mspfare & $33(17.8)$ & $12(15.4)$ & $33(15.9)$ \\
\hline Nco/m, Msp/m & $133(71.9)$ & $53(67.9)$ & 155 (74.9) \\
\hline $\mathrm{Nco}^{m}$, Msp $\mathrm{f}^{\mathrm{are}}$ & $18(9.7)$ & $5(6.4)$ & $19(9.2)$ \\
\hline Ncol ${ }^{a r e}, M s p / m$ & $19(10.3)$ & $13(16.7)$ & $18(18.7)$ \\
\hline Noof ${ }^{a r e}$, Msp fare & $15(8.1)$ & $7(9.0)$ & $15(7.2)$ \\
\hline GSTM1',Msp/ ${ }^{m}$ & $78(42.2)$ & $40(51.3)$ & $84(40.6)$ \\
\hline GSTM $1^{\circ}$, Msprare & $13(7.0)$ & $1(1.3)$ & $16(7.7)$ \\
\hline GSTM1:Msp/m & $74(40.0)$ & $26(33.3)$ & $90(43.5)$ \\
\hline GSTM1,Msp/are & $20(10.8)$ & $11(14.1)$ & $17(8.2)$ \\
\hline
\end{tabular}

Combining polymorphic expressions of GSTM1 and CYP1A1/Mspl, GSTT1 and CYP1A1/Mspl or GSTT1 and CYP1A1/Ncol only showed one statistically significant difference: The GSTM1 null genotype and a rare allele in the CYP1A1/Mspl site occurs more frequently in patients with BHNL than in blood donors $\left(\chi^{2}=8.8, p=0.03\right)$.

\section{Discussion}

Extensive consumption of tobacco and/or alcohol are regarded as risk factors for head and neck cancer (1-5). Tobacco smoke contains several (pre)carcinogenic compounds. Enzymes such as GSTM1, GSTT1 and CYP1A1 are involved in the metabolism of several of these chemical (pre)carcinogens. In the assessment of individual cancer risk the identification of heritable variations in the expression of these enzymes, which could predispose subjects to such environmentally induced cancer, deserve considerable interest. GSTM1 shows a polymorphic expression and about half the population in various racial groups is deficient of the GSTM1 gene (14). Because the GSTM1 enzyme can detoxify potential carcinogens like epoxides and aromatic hydrocarbons from tobacco smoke (13), smokers lacking GSTM1 activity were suggested to be at high risk of developing lung cancer (17). The GSTM1 null genotype was associated with high risk for lung, bladder, gastric, colorectal, skin, head and neck, and larynx cancer in several recent articles (18-26,54,55). However, other data were presented in which no contribution of the GSTM1 null genotype for cancer risk was found (29,35,56-60).

Our data on the GSTM1 null genotype in patients with HNSCC were in agreement with the latter reports. We found no difference in GSTM1 gene expression between patients with HNSCC or BHNL and healthy blood donors. In the HNSCC subgroups of patients with larynx or oral-oropharynx tumors, no differences could be observed either. Therefore, GSTM1 polymorphism does not seem to influence the susceptibility for BHNL or HNSCC in the total group or in subgroups of larynx and oral-oropharynx carcinoma. This suggests that presumed carcinogenic or toxic compounds causing either of these lesions are detoxified by enzymes other than GSTM1. 
In addition, the recently discovered polymorphism of GSTT1, which is a result from a gene deletion (33) was investigated by PCR. The GSTT1 null genotype was found to be related to increased colorectal and larynx cancer susceptibility $(56,57)$, whereas other reports found no relationship between GSTT1 null genotype and lung, oral and gastric cancer, and cutaneous basal cell carcinoma $(35,56,58)$. However, no higher incidence of GSTT1 null genotype in benign lesions was reported before. We demonstrated an increase in GSTT1 null genotypes in patients with BHNL as compared to blood donors and patients with HNSCC. In the HNSCC subgroups as well as the total group of patients with HNSCC the null genotype frequency equalled that of the blood donor group. This suggests that GSTT1 deficiency indicates an increased risk for BHNL, but not for HNSCC. This could implicate that BHNL and HNSCC may be caused by different mechanisms, and possibly one of the factors involved in BHNL may be a substrate for the GSTT1 enzyme.

Because Chevenix-Trench et al. (54) recently suggested a trend of lower percentage of GSTT1 null genotypes in geriatric controls versus unselected (and most probably younger) controls, we looked for the same tendency in our control population. Thus, the control group was split up into two age groups (below 40 years and 40 years and above). We could not find a difference in the distribution of GSTT1 null genotypes between these two groups and a percentage of $24 \%$ null genotypes was found in the age group of 40 years and above. In addition, because in our study the number of GSTT1 null individuals in healthy volunteers matched very well with both data in the literature $(12,54)$ and the frequencies found in patients with HNSCC, we believe the age difference between controls and patients may not be of any consequence for the genetic analyses as performed here.

Combined analysis of GSTM1 and GSTT1 polymorphisms demonstrated a statistically significant impact on head and neck carcinogenesis. It has previously been shown that combined GSTM1 and GSTT1 null genotype was related to lung cancer risk (35). No relation, however, between GSTM1 and GSTT1 null genotype and multiple cutaneous basal cell carcinoma (32) was found.

In addition to polymorphisms in phase II enzymes, genetic polymorphisms in the phase I enzyme CYP1A1 gene were correlated to an increased susceptibility to chemical carcinogenesis $(37,39,44,46-48)$. The CYP1A1 enzyme is involved in the activation of benzo[a]pyrene and other aromatic hydrocarbons in tobacco smoke (36-42). Genetic variants in the CYP1A1 gene investigated here can result in an enhancement of the CYP1A1 enzyme activities $(43,45)$. We demonstrated no difference in the distribution of genetic variants of the CYP1A1/Ncol nor of the CYP1A1/Mspl site between patients with HNSCC, BHNL and blood donors, suggesting that these variations do not have a significant impact on the risk for these head and neck lesions and that compounds causing these lesions may not be activated by this enzyme. The Mspl polymorphism of the CYP1A1 gene was associated with a reduced survival in patients with non-small cell lung cancer (59). It was also an independent factor indicative for bad prognosis at the nonresectable advanced stage of this disease (59). In bladder cancer and squamous cell cancer of the lung, however, no impact of CYP1A1/Msp/ variants on cancer susceptibility was found. Genetic variation in the CYP1A1/Ncol site was weakly 
but nonsignificantly associated with enhanced postmenopausal breast cancer risk (29), whereas another study reported a stronger association (30).

Individually, presence of the rare allele in the CYP1A1/Msp/ site or a GSTM1 null genotype had no effect on the development of squamous or small cell carcinoma of the lung (31). Combined, however, they were significant risk factors $(p<0.01)(31)$. We now found that having both GSTM1 null genotype and a rare allele in the CYP1A1/Msp/ site had a significant impact on the risk of BHNL as compared to blood donors. This strongly suggests that generation of reactive metabolites by the CYP1A1 enzyme and subsequent lack of detoxification by the GSTM1 enzyme may be of importance in the etiology of BHNL. Several other studies showed comparable results with respect to combined polymorphisms and increased risk for development of malignancies. Combination of GSTM1 null genotype and the rare CYP1A1/Mspl allele showed an increased risk of squamous cell carcinoma of the lung when diagnosed before 66 years of age (61), and patients with non-small lung cell cancer carrying this combination of polymorphisms had remarkable shortened survival (59). The interactive effect of GSTM1 and CYP1A1 genotypes (45) suggests that the influence of detoxifying enzymes in mediating cancer risk may be modified by polymorphisms at other relevant loci as well. This is an important point which needs further attention in the future.

In summary, our study shows that (a) GSTT1 null genotype is a risk factor for BHNL, but not for HNSCC, and (b) combined GSTM1 null genotype and a rare C nucleotide in the CYP1A1/Mspl site was more often detected in patients with BHNL as compared to blood donors, but not in patients with HNSCC.

\section{References}

1. IARC. Cancer Incidence in five continents. IARC monographs on the evaluation of carcinogenesis risks of chemicals to humans. Lyon, France. IARC 1987; 88.

2. Tomatis L. Cancer, causes, occurrence and control. Lyon, France. IARC 1990; 100.

3. Merletti F, Boffetta P, Ciccone G, Mashber A, and Terracini B. Role of tobacco and alcohol beverages in the etiology of cancer of the oral cavity/oropharynx in Torino, Italy. Cancer Res 1989; 49: 4919-4924.

4. Blot WJ, McLaughlin JK, Winn DM, Austin DF, Greenberg RS, Preston-Martin S, et al. Smoking and drinking in relation to oral and pharyngeal cancer. Cancer Res 1988; 48: 3282-3287.

5. Chow CH, McLaughlin JK, Hrubec Z, Nam JM, and Blot WJ. Tobacco use and nasopharyngeal carcinoma in a cohort of US veterans. Int J Cancer 1993; 55 : 538-540.

6. Pelkonen 0, Nebert DW. Metabolism of polycyclic aromatic hydrocarbons: etiologic role in carcinogenesis. Pharmacol Rev 1982; 34: 189-222.

7. Harris CC. Chemical and physical carcinogenesis: advances and perspectives for the 1990s. Cancer Res 1991; 51: 5023-5044.

8. Sryfter K, Hemminki D, Sryfter W, Szmeja Z, Banaszewski J, Yang K. Aromatic DNA adducts in larynx biopsies and leucocytes. Carcinogenesis 1994; 15: 2195-2199. 
9. Degawa M, Stern SJ, Martin MV, Guengerich FP, Fu PP, llett KF, et al. Metabolic activation and carcinogen-DNA adduct detection in human larynx. Cancer Res 1994: 54: 4915-4919.

10. Mannervik B, Danielsen UH. Glutathione transferases - structure and catalytical activity. CRC Crit Rev Biochem 1988; 23: 283-337.

11. Board P, Coggan M, Johnson P, Ross V, Suzuki T, Webb G. Genetic heterogeneity of the human glutathione transferases: a complex of gene families. Pharmac Ther 1990; 48: 357-369.

12. Beckett GJ, Hayes JD. Glutathione S-transferases: biomedical applications. Adv Clin Chem 1993; 30: 281-380.

13. Hayes JD, Pulford DJ. The glutathione S-transferases supergene family: regulation of GST and contribution of the isoenzymes to cancer chemoprevention and drug resistance. Crit Rev Biochem Mol Biol 1995; 31: 445-600.

14. Lin HJ, Han C-Y, Bernstein DA, Hsiao W, Lin BK, Hardy S. Ethnic distribution of the glutathione transferase Mu1-1 (GSTM1) null genotype in 1473 individuals and application to bladder cancer susceptibility. Carcinogenesis 1994; 15: 1077-1081.

15. Board PG. Biochemical genetics of glutathione S-transferase in man. Am J Hum Genet 1981; 33: 36-43.

16. Board PG. Gene deletion and partial deficiency of the glutathione S-transferase (ligandin) system in man. FEBS Lett 1981; 135: 12-14.

17. Seidegard J, Vorachek WR, Pero RW, Pearson WR. Hereditary differences in the expression of the human glutathione transferase active of trans-stilbene oxide are due to a gene deletion. Proc Natl Acad Sci USA 1988; 85: 7293-7297.

18. Hirvonen A, Husgafvel-Pursiainen K, Anttila S, Vianio H. The GST M1 null genotype as a potential risk modifier for squamous cell carcinoma of the lung. Carcinogenesis 1993; 14: 1479-1481.

19. Seidegard J, Pero RW, Markowitz MM, Roush G, Miller DG, Beattie EJ. Isoenzyme(s) of glutathione transferases (class $\mathrm{Mu}$ ) as a marker for susceptibility to lung cancer: a follow up study. Carcinogenesis 1990; 11: 33-36.

20. Kihara M, Kihara M, Noda K, Okamoto N. Increased risk of lung cancer in Japanese smokers with class Mu glutathione S-transferase gene deficiency. Cancer Lett 1993; 71: 151-155.

21. Nazar-Stewart V, Motulsky AG, Eaton DL, White E, Hornung SK, Leng ZT, et al. The glutathione S-transferase mu polymorphism as a marker for susceptibility to lung carcinoma. Cancer Res 1993; 53: 2313-2318.

22. Lafuente A, Pujol F, Carretero P, Villa J, Cuchia A. Human glutathione S-transferase mu deficiency as a marker for the susceptibility to bladder and larynx cancer among smokers. Cancer Lett 1993; 68: 49-54.

23. Katoh T, Nagata N, Kuroda Y, Itoh H, Kawahara A, Kuroki N, et al. Glutathione S-transferase M1 (GSTM1) and T1(GSTT1) genetic polymorphism and susceptibility to gastric and colorectal adenocarcinoma. Carcinogenesis 1996; 17 : 1855-1859.

24. Brockmöller J, Cascorbi I, Kerb R, Roots I. Combined analysis of inherited polymorphisms in arylamine $\mathrm{N}$-acetyltransferase 2, glutathione S-transferase M1 and T1, microsomal epoxide hydrolase, and cytochrome P450 enzymes as modulators of bladder cancer risk. Cancer Res 1996; 56: 3915-3925. 
25. Seidegard J, Pero RW, Miller DG, Beatty EJ. A glutathione transferase in human leukocytes as a marker for the susceptibility to lung cancer. Carcinogenesis 1986; 7: 751-753.

26. Shanley SM, Chevenix-Trench G, Palmer J, Hayward N. Glutathione S-transferase GSTM1 null genotype is not overrepresented in Australian patients with nevoid basal cell carcinoma syndrome or sporadic melanoma. Carcinogenesis 1995; 16: 2003-2004.

27. Brockmöller J, Kerb R, Drakoulis N, Nitz M, Roots I. Genotype and phenotype of glutathione S-transferase class mu isoenzymes mu and psi in lung cancer patients and controls. Cancer Res 1993; 53: 1004-1011.

28. Lin HJ, Probst NM, Ingles SA, Han C.Y, Lin BK, Lee DB, et al. Glutathione transferase (GSTM1) null genotype, smoking, and prevalence of colorectal adenomas. Cancer Res 1995; 55: 1224-1226.

29. Ambrosone CB, Freudenheim JL, Graham S, Marshall JR, Vena JE, Brasure JR, et al. Cytochrome P450 CYP1A1 and glutathione S-transferase (M1) genetic polymorphisms and postmenopausal breast cancer. Cancer Res 1995; 55: 3483-3485.

30. Rebbeck T, Rosvold EA, Duggan DJ, Zhang J, Buetow KH. Genetics of CYP1A1: coamplification of specific alleles by polymerase chain reaction and association with breast cancer. Cancer Epidemiol Biomarkers Prev 1994; 3: 511-514.

31. Kihara M, Kihara M, Noda K. Risk of smoking for squamous and small cell carcinomas of the lung modulated by combinations of CYP1A1 and GSTM1 gene polymorphisms in a Japanese population. Carcinogenesis 1995; 16: 2331-2336.

32. Heagerty A, Smith A, English J, Lear J, Perkins W, Bower B, et al. Susceptibility to multiple cutaneous basal cell carcinomas: significant interactions between glutathione S-transferase GSTM1 genotype, skin type and male gender. Br J Cancer 1996; 73: 44-48.

33. Pemble S, Schroeder KR, Spencer SR, Meyer DJ, Hallier E, Bolt HM. Human glutathione S-transferase Theta (GSTT1): cDNA cloning and the characterization of a genetic polymorphism. Biochem J 1994; 300: 271-276.

34. Abdelrahman SZ, Elzein RA, Anwar WA, Au WW. A multiplex PCR procedure for polymorphic analysis of GSTM1 and GSTT1 genes in population studies. Cancer Lett 1996; 107: 229-233.

35. Kerb R, Brockmöller J, Cascorbi I, Roots I. Glutathione S-transferase of class Mu and Theta as modulators of lung cancer susceptibility. ISSX proceedings 1995; 7: 76 .

36. Heidelberger C. Chemical carcinogenesis. Annu Rev Biochem 1975; 44: 79-121.

37. Guengerich FP. Roles of cytochrome P450 enzymes in chemical carcinogenesis and cancer chemotherapy. Cancer Res 1988; 48: 2946-2954.

38. Conney AH. Induction of microsomal enzymes by foreign chemicals and carcinogenesis by polycyclic aromatic hydrocarbons. Cancer Res 1982; 42: 4875-4917.

39. Gonzalez FJ. The molecular biology of cytochrome P450s. Pharmacol Rev 1988; 40: 243-288.

40. Cuzick J, Routledge MN, Jenkins D, Garner RC. DNA adducts in different tissues of smokers and non-smokers. Int J Cancer 1990; 45: 673-678. 
41. Gonzalez FJ, Gelboin HV. Role of human cytochromes P450 in the metabolite activation of chemical carcinogens and toxins. Drug Metab Rev 1994; 26: 165-183.

42. McManus ME, Burgess WM, Veronese ME, Huggett A, Quattrochi LC, Tuckey RH. Metabolism of 2-acetylaminofluorene and benzo[a]pyrene and activation of food-derived heterocyclic amine mutagens by human cytochromes P450. Cancer Res 1990; 50: 3367-3376.

43. Crofts F, Taioli E, Trachman J, Cosma GN, Currie D, Tonioli P, et al. Functional significance of different human CYP1A1 genotypes Carcinogenesis 1994; 15: 2961-2963.

44. Hayashi S, Watanabe J, Nakachi K, Kawajiri K. Genetic linkage of lung cancer-associated Mspl polymorphisms with amino acid replacement in the heme binding region of the human cytochrome P450 1A1 gene. J Biochem 1991; 110: 407-411.

45. Nakachi K, Imai K, Hayashi S, Kawajiri K. Polymorphisms of the CYP1A1 and glutathione S-transferase genes associate with susceptibility to lung cancer in relation to cigarette dose in a Japanese population. Cancer Res 1993; 53: 2994-2998.

46. Kawajiri K, Nakachi K, Imai K, Yoshi A, Shinoda N, Watanabe J. Identification of genetically high risk individuals to lung cancer by DNA polymorphism of the cytochrome P4501A1 gene. FEBS Lett 1990; 263: 131-133.

47. Nakachi K, Imai K, Hayashi S, Watanabe J, Kawajiri K. Genetic susceptibility to squamous cell carcinoma of the lung in relation to cigarette smoking dose. Cancer Res 1991; 51: 5177-5180.

48. Shields PG, Bowman ED, Harrington AM, Doan VT, Weston A. Polycyclic aromatic hydrocarbon-DNA adducts in human lung and cancer susceptibility genes. Cancer Res 1993; 53: 3486-3492.

49. Sugimuru H, Suzuki I, Hamada GS, Isvase T, Takahashi T, Nagura K, et al. Cytochrome P4501A1 genotype in lung cancer patients and controls in Rio de Janeiro, Brazil. Cancer Epidemiol Biomarkers Prev 1994: 3: 145-148.

50. Tefre T, Ryberg D, Haugen A, Nebert DW, Skaug V, Brogger A, et al. Human CYP1A1 (cytochrome P450) gene: lack of association between the Mspl restriction fragment length polymorphism and incidence of lung cancer in a Norwegian population. Pharmacogenetics 1991; 1: 20-25.

51. Hirvonen A, Husgafvvel-Pursiainen K, Karjarlainen A, Anttila S, Vainio H. Pointmutational Mspl gene and lle-Val polymorphisms closely linked in the CYP1A1 gene: lack of association with susceptibility to lung cancer in a Finnish population. Cancer Epidemiol Biomarkers Prev 1992; 1: 485-489.

52. Drakoulis N, Cascorbi I, Brockmöller J, Gross CR, Roots I. Polymorphisms in the human CYP1A1 gene as susceptibility factors for lung cancer: exon-7 mutation (4889 A to G), and a T to C mutation in the $3^{\prime}$ flanking region. Clin Invest 1994; 72: $240-248$.

53. Pemble S, Schroeder KR, Spencer SR, Meyer DJ, Hallier E, Bolt HM, et al. Human glutathione S-transferase theta (GSTT1) cDNA cloning and the characterization of a genetic polymorphism. Biochem J 1994: 300: 271-276.

54. Chevenix-Trench E, Young J, Coggan M, Board P. Glutathione S-transferase M1 and T1 polymorphisms: susceptibility to colon cancer and age of onset. Carcinogenesis 1995: 16: 1655-1657. 
55. Trizna Z, Clayman GL, Spitz MR, Briggs KL, Goepfert H. Glutathione S-transferase genotypes as risk factor for head and neck cancer. Am J Surg 1995; 170: 499-501.

56. Deakin M, Elder J, Hendrickse C, Peckham D, Baldwin C, Pantin C, et al. Glutathione S-transferase GSTT1 genotypes and susceptibility to cancer: studies of interactions with GSTM1 in lung, oral, gastric, and colorectal cancers. Carcinogenesis 1996; 17: 881-884.

57. Jahnke V, Strange R, Matthias C, Fryer AA. Erste Ergebnisse über Glutathion S-Transferase GSTM1 und GSTT1 Genotypen und die genetische Prädisposition beim Larynxkarzinom. Laryngol Rhinol Otol 1995; 74: 691-694.

58. Yengi L, Inskip A, Gilford J, Alldersea J, Bailey L, Smith A, et al. Polymorphism at the glutathione S-transferase locus GSTM3: interactions with cytochrome P450 and glutathione S-transferase genotypes as risk factors for multiple cutaneous basal cell carcinoma. Cancer Res. 1996; 56: 1974-1977.

59. Goto I, Yoneda S, Yamamoto M, Kawajiri K. Prognostic significance of germ line polymorphisms of the CYP1A1 and glutathione S-transferase genes in patients with non-small cell lung cancer. Cancer Res 1996; 56: 3725-3730.

60. Yu MW, Gladek-Yarborough A, Chiamprasert S, Sanbella RM, Liaw YF, Chen CJ Cytochrome P450 2E1 and glutathione S-transferase M1 polymorphisms and susceptibility to hepatocellular carcinoma. Gastroenterology 1995; 109: 1266 1273.

61. Alexandrie A-K, Sundberg MI, Seidegard J, Tornling G, Rannung A. Genetic susceptibility to lung cancer with special emphasis on CYP1A1 and GSTM1: a study on host factors in relation to age of onset, gender and histological cancer types. Carcinogenesis 1994; 15: 1785-1790. 


\section{CHAPTER}

DEMOGRAPHIC VARIATION IN THE DISTRIBUTION OF THE GLUTATHIONE S-TRANSFERASE T1 NULL POLYMORPHISM IN DUTCH HEALTHY CONTROLS; IMPLICATIONS FOR GENOTYPE RESEARCH IN HEAD AND NECK CANCER

Michael B Oude Ophuis ${ }^{1}$, Johannes J Manni ${ }^{1}$, Wilbert HM Peters ${ }^{2}$

${ }^{1}$ Dept. of Otorhinolaryngology, Head and Neck Surgery, University Hospital Maastricht, The Netherlands

${ }^{2}$ Dept. of Gastroenterology, University Medical Center Nijmegen, The Netherlands

Submitted for publication 


\section{Abstract}

Background We compared the GSTM1, GSTT1 and GSTP1 genotype frequencies in two groups of healthy blood donors, recruited from different, but neighboring regions in the Netherlands. The effect of cross linked comparisons for head and neck squamous cell carcinoma (HNSCC) on the outcome of a study previously published in Cancer is analysed.

Methods The GSTM1, GSTT1 and GSTP1 genotype frequencies in two Dutch Caucasian control populations ( $n=207$ and $n=285$ ) from different but neighboring geographical regions (Maastricht/Nijmegen; distance, $125 \mathrm{~km}$ ) were determined by polymerase chain reaction (PCR) related methods.

Results For the occurrence of the GSTT1 null genotype we found a significant difference ( $p=0.003$ ) between the two control groups $(20.3 \%$ vs. $33.0 \%$ null genotype in the Nijmegen and Maastricht control groups, respectively). Since the HNSCC patients are recruited from the Maastricht area, comparison with the Maastricht controls now reveals a significant difference for GSTT1 null rates, which are lower in patients vs. controls (OR=0.49, $\mathrm{Cl}$ 0.32-0.76).

Conclusions Inter-regional differences exist, which may have significant effect in the

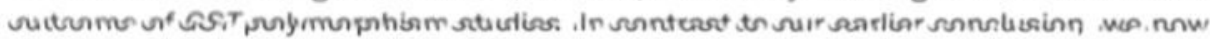
find that the GSTT1 null genotype appears to be involved in modulating the risk for HNSCC. The significance of the distribution patterns of GST polymorphisms in head and neck cancer patient populations can only be analyzed in comparison to a regional control group. 


\section{Introduction}

In 1998 we investigated genetic polymorphisms in glutathione S-transferase M1 (GSTM1) and GSTT1 in relation to head and neck squamous cell carcinoma (HNSCC) (1). In this study we reported that GSTM1 and GSTT1 null genotypes were not related to HNSCC susceptibility, but that the GSTT1 null genotype occurred significantly more often in a patient population with benign head and neck lesions (BHNL). We therefore concluded that the GSTT1 null genotype was not a risk factor for HNSCC, but may be a risk factor for development of benign head and neck disease.

In this collaborative study between the University Hospitals of Nijmegen and Maastricht, the GST polymorphisms in healthy blood donors from the Nijmegen region were compared to patients with HNSCC from the Maastricht region. Since these two cities are separated geographically by only $125 \mathrm{~km}$, we did not expect that significant differences in variant GST genotype rates could occur between two study groups originating from such close regions.

There have appeared many conflicting reports on the contribution of genetic polymorphisms in GSTs, in association with head and neck cancer or other malignancies, which may be partly due to mismatching of patient- and control populations. Therefore, we now compared the variant genotype frequencies of GSTM1, GSTP1 and GSTT1 in the control population of Nijmegen and a recently established control population of the Maastricht region. Also, we investigated whether these new data have any effect on our previously published results (1).

\section{Materials and Methods}

\section{Populations studied}

The first Dutch Caucasian control group (control group Nijmegen) consisted of 207 healthy blood donors ( 76 men; 131 women) and was recruited as described before (1) by advertising in a local paper at the University Medical Center Nijmegen (mean age 34 \pm 12 years; range 19 - 64). A second Dutch Caucasian control group (control group Maastricht) consisted of 285 healthy blood donors (199 men, 86 women; mean age $50 \pm 10$ years; range $19-91$ ) and was recruited from the same geographical area as the HNSCC and BHNL patients, at the Blood Bank of Maastricht. The geographical distance between the two cities Nijmegen and Maastricht is approximately $125 \mathrm{~km}$. An extra control population (control group BHNL) consisted of 78 patients (mean age $49 \pm$ 16 years; range $16-86$ ) with benign head and neck lesions (BHNL) such as polyps, cysts, and vocal cord nodules, as described before (1).

The 185 Dutch Caucasian patients with HNSCC participating in the initial study (1) were recruited preoperatively or postoperatively as described previously during their scheduled outpatient visit at the University Hospital Maastricht between 1994 and 1996 (mean age $60 \pm 12$ years; range $23-86$ ). This group consisted of 73 patients with laryngeal carcinoma (mean age $62 \pm 11$ years; range $36-86$ ), 76 patients with 
oral and oropharyngeal carcinoma (mean age $58 \pm 12$ years; range $23-82$ ) and a remaining group of 36 patients (mean age $60 \pm 13$ years; range $28-86$ ).

At the time when informed consent was obtained, medical and other anamnestic data were obtained by interview. The investigations were approved by both the Nijmegen and Maastricht local Medical Ethical Review Committees.

\section{Genotyping by PCR Analyses}

Blood was collected by venapuncture in EDTA vacutainer tubes, and blood was stored at $-20^{\circ} \mathrm{C}$ until use. Genomic DNA was isolated from whole blood using the Wizzard genomic DNA isolation kit, according to the instructions of the manufacturer (Promega, Madison Wisconsin, USA). Genetic polymorphism rates were determined by initial PCR, followed by analysis on agarose gel.

Fifty to hundred ng of DNA were amplified by PCR in a total volume of $25 \mu$ l containing $10 \mathrm{mM}$ Tris/ $\mathrm{HCl}$ pH 9.0, $50 \mathrm{mM} \mathrm{KCl}, 0.1 \%$ Triton X-100, $2 \mathrm{mM} \mathrm{MgCl}, 200 \mu \mathrm{M}$ of deoxynucleotide triphosphate, $1 \mu \mathrm{M}$ of each primer, and 0.2 units of Taq polymerase, overlaid with one drop of mineral oil. PCR was carried out in a programmable Thermojet thermocycler (Eurogentec, Seraing, Belgium). After 5 min of pretreatment at $95^{\circ} \mathrm{C}, 35$ cycles of $30 \mathrm{sec}$ denaturation at $95^{\circ} \mathrm{C}$ and $30 \mathrm{sec}$ annealing at $59^{\circ} \mathrm{C}$ were performed. All primers were selected based on studies by others (2-4). The primers were synthesized by Pharmacia Biotech (Roosendaal, The Netherlands). All chemicals needed for PCR were purchased from Promega (USA). For GSTM1 (primer set G2 and G3) and GSTT1 (primer set T1 and T2) one primer was situated in the deleted area. For evaluating GSTM1 and GSTT1 polymorphisms, reaction mixture products were analyzed by gel electrophoresis ( $2 \%$ agarose; $60 \mathrm{~V} ; 1 \mathrm{~h}$ ) for the presence of a 650 -base pair product, which was indicative of the GSTM1 gene or a 480-base pair product, indicative of the GSTT1 gene. When at first analysis no product was found, always a second and eventually a third analysis was done, in parallel with a control PCR from the same DNA samples, so that a false negative result (apparent null genotype) was excluded. For studying the genetic polymorphism in GSTP1 a primer set (105F and $105 R$ ) was designed so that the presence of the A to G substitution at codon 313 resulted in the appearance of an Alw261 restriction enzyme site (4).

\section{Statistical analysis}

Statistical analysis was performed by using the SPSS 8.0 statistical package. Odds Ratio analyses in $2 \times 2$ tables were used, as well as calculation of p-values.

\section{Results}

In Table 1 the frequencies of GSTM1 and GSTT1 genotypes of the two different normal control populations from Nijmegen and Maasticht are shown. The GSTM1 and GSTT1 genotypes of the group of patients with HNSCC and BHNL from the Maastricht region are included. For the GSTM1 genotype, both control groups compared to each other, and the HNSCC patient group compared to the frequencies of the control groups from Nijmegen and Maastricht show no statistical difference (see Table 2). 
The genotype frequencies for GSTT1 however, show a significant difference between the two control groups from Nijmegen and Maastricht $(p=0.003)$. The BHNL group shows a frequency that matches the control group Maastricht.

For GSTP1 there are no statistical differences between the two control groups from Nijmegen and Maastricht.

Table 2 shows risk estimates for the susceptibility of the various GSTM1 and GSTT1 genotypes on HNSCC when compared to different control groups. For the GSTP1 genotype only a risk estimate is shown when compared to the two control groups. For GSTM1 and GSTP1 genotypes no significant differences were found. For the GSTT1 genotype however, a significant difference was noted when the risk for HNSCC is estimated versus control group Maastricht, which matches with the patients with respect to recruiting area and race $(p=0.002)$.

Table 1. Frequencies of GSTM1 and GSTT1 genotypes in the different control populations and in patients with BHNL and HNSCC

\begin{tabular}{|c|c|c|c|c|}
\hline & Controls & Controls & BHNL & HNSCC \\
\hline & Nijmegen $(*)$ & Maastricht $\left(X_{0}\right)$ & Maastricht $\left(\Psi_{0}\right)$ & Maastricht (\%) \\
\hline GSTM1-(null) & $107(51.7)$ & $163(57.2)$ & $37(47.4)$ & $94(50.8)$ \\
\hline GSTM1+ & $100(48.3)$ & $122(42.8)$ & $41(52.6)$ & $91(49.2)$ \\
\hline GSTT1- (null) & $42(20.3)$ & $94(33.0)$ & 26 (33.3) & $36(19.5)$ \\
\hline GSTI1+ & $165(79.7)$ & $191(67.0)$ & $52(66.7)$ & $149(80.5)$ \\
\hline GSTP1 AB & $88(43.6)$ & $122(42.8)$ & $\#$ & $\#$ \\
\hline GSTP1 BB & $25(12.4)$ & $37(12.9)$ & $\#$ & 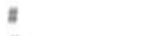 \\
\hline GSTP1 AA & $89(44.0)$ & $126(44.2)$. & $"$ & " \\
\hline Total & $207(202 *)$ & 285 & 78 & 185 \\
\hline
\end{tabular}

* - controls for GSTP1 (five DNA samples were not available any more), " = not evaluated

Table 2. Risk estimate of GSTM1. GST1 1 and GSTP1 genotype frequencies compared in two different control populations and HNSCC patients

Odds Ratio $(95 \% \mathrm{Cl})$

GSTM1 null

Control Maastricht vs. control Nijmegen HNSCC vs. Nijmegen

HNSCC vs. Maastricht

GSTT1 null

Control Maastricht vs. control Nijmegen

HNSCC vs. Nijmegen

HNSCC vs. Maastricht

$1.92(1.26-2.94$

$0.95(0.57-1.56)$

$0.49(0.32-0.76)$

$1.00(0.69-1.43)$

0.97

GSTP1 AB/BE

Control Maastricht vs. control Nijmegen

$1.25(0.86-1.78)$

$0.96(0.65-1.43$

$0.78(0.531 .12)$

0.26

0.94

0.21

* = Odds Ratio was calculated by combining GSTP1 AB and GSTP1 BB genotypes 


\section{Discussion}

In this study we found a highly significant difference in the rates of the GSTT1 null genotype between controls from the Nijmegen and Maastricht region. This has consequences for the interpretation of earlier results reported by us in 1998 (1), since now a significant lower risk for HNSCC of individuals with the GSTT1 null genotype is found. First of all, how can such inter-regional difference between controls be explained? Most probably the tendency to stay in the region of birth, may be a main reason, since it is well known that genetic inheritance contributes to the genetic profile of an individual.

Most studies that have been conducted on the role of polymorphisms in modulating the risk for HNSCC, do describe demographical data (see Table 3), with the exception of some papers (5-8) where no details on this are given. This does not mean however that demographic variation is present here. In several studies it is clearly mentioned that patients and controls were recruited from the same region, but not from the same hospital (9-12), thus similar to our earlier study (1). In other studies it was mentioned that patients and controls were recruited from different regions $(1,13,14)$. Since there are many national and international collaborations between the different research groups with exchange of samples between different labs, it may often occur that controls and patients have been recruited from different (parts of) countries, which may have similar consequences as described in this paper.

Recently in a large international collaborative study Garte et al. (15) reported significant differences between different racial populations for GSTM1 and GSTT1 genotypes. For the GSTM1 null genotype, frequencies found were $53.1 \%$ for Caucasians, $52.9 \%$ for Asians and $26.7 \%$ for Africans. The total number of African patients included however, was only $4 \%$ (479 individuals) on a total number of 12,504 patients evaluated. For the GSTT1 null genotype, the frequencies for Caucasians were $19.7 \%$ compared to $47.0 \%$ for Asians (15).

Garte et al. (15) reported considerable differences in GSTM1 and GSTT1 genotype frequencies in Caucasian populations of several European countries, Canada or the USA (47-58\% and $13-27 \%$ for null genotypes respectively). These findings suggest that these frequencies are rather variable in Caucasians all over the world. In addition, the data on GSTT1 null genotype frequency as found in our controls from the Maastricht region (33\%) seem to be higher as compared to earlier reported data from European countries (13-26\%) and are closer to those reported in the USA (27\%) or Japan (35\%) (15).

For the GSTT1 genotype we found an unexpected significant difference $(p=0.003)$ between the two Dutch control groups, collected at a distance of approximately $125 \mathrm{~km}$. In our earlier report we even suggested a possible role for GSTT1 genotype in the etiology of BHNL (1). 
Table 3. Demographics of control and HNSCC patient populations and GSTT 1 null genotype frequencies

\begin{tabular}{|c|c|c|c|c|c|c|c|}
\hline Author & Site & $\begin{array}{l}\text { GSTT1 null } \\
\text { Controls } \\
\% \text { (n=total) }\end{array}$ & $\begin{array}{l}\text { GSTT1 null } \\
\text { Cases } \\
\% \text { (n=total) }\end{array}$ & Race & Country & $\begin{array}{l}\text { Same demographics } \\
\text { patients-controls }\end{array}$ & Odds Ratio (95 \\
\hline \multicolumn{8}{|l|}{$\begin{array}{l}\text { No association GSTT1 null } \\
\text { genotype vs. HNSCC }\end{array}$} \\
\hline Buch et al. (17) & Oral & $12.3(450)$ & $18.3(297)$ & Indian & India & yes & $1.6(1.0-2.6)$ \\
\hline Cabelguenne et al. (18) & $\mathrm{HN}$ & $19.4(264)$ & $18.1(162)$ & n.s. & France & yes & $1.0(0.6-1.7)$ \\
\hline Deakin et al. (19) & Oral & $18.5(129)$ & $11.8(34)$ & Caucasian & UK & yes & n.s. \\
\hline Hanna et al. (7) & Larynx & $20.0(20)$ & $15.0(20)$ & n.s. & USA & n.s & n.s. \\
\hline Hong et al. (20) & Larynx & $36.5(63)$ & $57.3(82)$ & Korean & Korea & yes & $1.8(0.7-4.8)$ \\
\hline Hung et al. (21) & Oral & $52.9(123)$ & $58.5(41)$ & Chinese mixed & Taiwan & yes & $1.2(0.6-2.5)$ \\
\hline Jourenkova et al. (22) & Larynx & $15.7(172)$ & $19.4(129)$ & Caucasian & France & yes & $1.4(0.7 \cdot 2.9)$ \\
\hline Jourenkova et al. (23) & Pharynx & $15.7(172)$ & $18.0(50)$ & Caucasian & France & yes & $1.4(0.6-3.7)$ \\
\hline Katoh et al. (24) & Oral & $51.0(147)$ & $47.7(92)$ & Japanese & Japan & yes & $0.7(0.4-1.2)$ \\
\hline \multirow[t]{3}{*}{ Matthias et al. (25) } & Larynx & $22.2(203)$ & $19.4(263)$ & Caucasian & German & yes & $0.9(0.5-1.4)$ \\
\hline & Oropharynx & $22.2(203)$ & 27.7 (119) & Caucasian & German & yes & $1.5(0.9-2.5)$ \\
\hline & $\mathrm{HN}$ & $22.2(203)$ & $22.0(382)$ & Caucasian & German & yes & n.s. \\
\hline McWilliams et al. (26) & $\mathrm{HN}$ & $18.3(109)$ & $: 6.9(142)$ & Caucasian & USA & yes & $0.9(0.5-1.5)$ \\
\hline Otshan et at. (27) & $\mathrm{HN}$ & $13.0(168)$ & $17.0(109)$ & Caucasian & USA & yes & $1.4(0.7-2.7)$ \\
\hline \multirow{3}{*}{ Oude Ophuis et al. (1) } & $\mathrm{HN}$ & $20.3(207)$ & $19.5(185)$ & Caucasian & The Netherlands & no & $1.1(0.6-1.7)$ \\
\hline & Oral/oropharynx & $20.3(207)$ & $19.7(76)$ & Caucasian & The Netherlands & no & $1.0(0.5-2.0)$ \\
\hline & Larynx & $20.3(207)$ & $20.5(73)$ & Caucasian & The Netherlands & no & $1.0(0.5-1.9)$ \\
\hline Sreelekha et al. (8) & Oral & $8.3(60)$ & $18.4(98)$ & Indian & India & n.s. & $2.5(0.3-21.7)$ \\
\hline Trizna et al. (30) & $\mathrm{HN}$ & $36.0(42)$ & $45.0(186)$ & Mixed & USA & yes & $1.5(0.7-3.0)$ \\
\hline Worral et al. (28) & Oral & n.s. & n.s. & Caucasian & UK & yes & n.s. \\
\hline \multicolumn{8}{|l|}{$\begin{array}{l}\text { Association GSTT1 null } \\
\text { genotype vs HNSCC }\end{array}$} \\
\hline Cheng et al. (14) & $\mathrm{HN}$ & $17.5(315)$ & $32.7(162)$ & Moxed & USA & no & $2.3(1.4 .3 .6)$ \\
\hline Hamel et al. (29) & $\mathrm{HN}$ & $20.0(101)$ & $9.0(70)$ & Mixed & Canada & yes & $2.5(1.1 .5 .9)$ \\
\hline Jahnike et al. $(5.6)$ & Larynx & $12.4(145)$ & $21.3(169)$ & Caucasian & Germany & n.s. & n.s. \\
\hline \multirow[t]{2}{*}{ Jourenkova et al. (23) } & Oral & $15.7(172)$ & $22.4(67)$ & Caucasian & France & yes & $2.4(1.0-5.5)$ \\
\hline & $\mathrm{HN}$ & $15.7(172)$ & $21.5(121)$ & Caucasian & France & yes & $2.0(1.0-4.0)$ \\
\hline Oude Ophuis et al. (this article) & $\mathrm{HN}$ & $33.0(285)$ & $19.5(185)$ & Caucasian & The Netherlands & yes & $2.0(1.3-3.2)$ \\
\hline
\end{tabular}

n.s. not specified. $n=$ total number of patients or controls in group. $\mathrm{HN}=$ all sites of head and neck malignancies. $\mathrm{Cl}=$ confidence interval 
However, when the risk for HNSCC is estimated versus the new control group, we found a significant reverse association between GSTT1 null genotype and HNSCC $(\mathrm{OR}=0.49, \mathrm{Cl} 0.32-0.76, \mathrm{p}=0.002)$. We did not expect to find a difference in genotype frequency between such close regions, especially since the Netherlands is a very small country. Earlier, Roy et al. (16) found GSTT1 null genotype frequencies ranging from 3-39\% in different Indian ethnic populations. They, however, did not mention distance, which may be much larger since India is a large country. In our study the different results can not be explained by ethnicity, since in The Netherlands geographically confined ethnic variations do not exist. We also can not explain this by a misinterpretation of PCR results, since the lack of an amplification product was always tested three times.

The association of genetic polymorphisms in toxification / detoxification enzymes and HNSCC is still a matter of controverse (see Table 3). We now have shown that significant demographic variations in genotype frequencies may exist, even in a small country. Demographic variations may be the key solution in explaining the differences in outcome in genetic polymorphism studies. In contrast to our earlier conclusion (1), we now must conclude that the GSTT1 null genotype appears to be less common in patients with HNSCC. A similar finding was published recently by London et al. (31) who found lower GSTM1 and GSTT1 null genotype rates in patients with lung cancer, as compared to age and location matched controls. The authors could explain this finding as follows: consumption of cruciferous vegetables may protect against smoking induced cancers by their content of glucosinolates, precursors of isothiocyanates, the latter being potent inducers of glutathione S-transferases and other detoxification systems. However, since breakdown of isothiocyanates is also catalysed by GSTS, GSTT1 and/or GSTM1 null individuals may have a worse clearance of isothiocyanates and may be better protected when consuming glucosinolate containing diets.

In conclusion: in contrast to the hypothesis that GSTT1 null genotype occurs more in patients with HNSCC we found the opposite; a less frequent occurrence of GSTT1 null genotype in HNSCC patients.

\section{References}

1. Oude Ophuis MB, van Lieshout EMM, Roelofs HMJ, Peters WHM, Manni JJ. Glutathione S-transferase M1 and T1 and cytochrome P4501A1 polymorphisms in relation to the risk for benign and malignant head and neck lesions. Cancer 1998;82:936-943.

2. Brockmöller J, Kerb R, Drakoulis N, Nitz M, Roots I. Genotype and phenotype of glutathione S-transferase class mu isoenzymes mu and psi in lung cancer patients and controls. Cancer Res 1993;53:1004-1011.

3. Pemble S, Schroeder KR, Spencer SR, et al. Human glutathione S-transferase theta (GSTT1): cDNA cloning and the characterization of a genetic polymorphism. Biochem J 1994;300:271-276. 
4. Harries LW, Stubbins MJ, Forman D, Howard GC, Wolf CR. Identification of genetic polymorphisms at the glutathione S- transferase Pi locus and association with susceptibility to bladder, testicular and prostate cancer. Carcinogenesis 1997;18:641-644.

5. Jahnke V, Matthias C, Fryer A, Strange R. Glutathione S-transferase and cytochrome-P-450 polymorphism as risk factors for squamous cell carcinoma of the larynx. Am J Surg 1996;172:671-673.

6. Jahnke V, Strange R, Matthias C, Fryer A. Erste Ergebnisse über Glutathion-S-Transferase GSTM1 und GSTT1 Genotypen und die genetische Prădisposition beim Larynxkarzinom. Laryngorhinootologie 1995;74:691-694.

7. Hanna E, MacLeod S, Vural E, Lang N. Genetic deletions of glutathioneS-transferase as a risk factor in squamous cell carcinoma of the larynx: a preliminary report. Am J Otolaryngol 2001;22:121-123.

8. Sreelekha T, Ramadas K, Pandey M, Thomas G, Nalinakumari KR, Pillai MR. Genetic polymorphism of CYP1A1, GSTM1 and GSTT1 genes in Indian oral cancer. Oral Oncol 2001;37:593-598.

9. Kihara M, Kihara M, Kubota A, Furukawa M, Kimura H. GSTM1 gene polymorphism as a possible marker for susceptibility to head and neck cancers among Japanese smokers. Cancer Lett 1997;112:257-262.

10. Morita S, Yano M, Tsujinaka T, et al. Genetic polymorphisms of drug-metabolizing enzymes and susceptibility to head-and-neck squamous-cell carcinoma. Int J Cancer 1999;80:685-688.

11. Coutelle C, Ward PJ, Fleury B, et al. Laryngeal and oropharyngeal cancer, and alcohol dehydrogenase 3 and glutathione S-transferase M1 polymorphisms. Hum Genet 1997;99:319-325.

12. Sato M, Sato T, Izumo T, Amagasa T. Genetic polymorphism of drug-metabolizing enzymes and susceptibility to oral cancer. Carcinogenesis 1999;20:1927-1931.

13. Park JY, Muscat JE, Ren Q, et al. CYP1A1 and GSTM1 polymorphisms and oral cancer risk. Cancer Epidemiol Biomarkers Prev 1997;6:791-797.

14. Cheng L, Sturgis EM, Eicher SA, Char D, Spitz MR, Wei Q. Glutathione Stransferase polymorphisms and risk of squamous-cell carcinoma of the head and neck. Int J Cancer 1999;84:220-224.

15. Garte S, Gaspari L, Alexandrie AK, et al. Metabolic gene polymorphism frequencies in control populations. Cancer Epidemiol Biomarkers Prev 2001;10: 1239-1248.

16. Roy B, Majumder PP, Dey B, et al. Ethnic differences in distributions of GSTM1 and GSTT1 homozygous "null" genotypes in India. Hum Biol 2001;73:443-450.

17. Buch SC, Notani PN, Bhisey RA. Polymorphism at GSTM1, GSTM3 and GSTT1 gene loci and susceptibility to oral cancer in an Indian population. Carcinogenesis 2002:23:803-807.

18. Cabelguenne A, Loriot MA, Stucker I, et al. Glutathione-associated enzymes in head and neck squamous cell carcinoma and response to cisplatin-based neoadjuvant chemotherapy. Int J Cancer 2001;93:725-730.

19. Deakin M, Elder J, Hendrickse C, et al. Glutathione S-transferase GSTT1 genotypes and susceptibility to cancer: studies of interactions with GSTM1 in lung. oral, gastric and colorectal cancers. Carcinogenesis 1996;17:881-884. 
20. Hong YJ, Lee JK, Lee GH, Hong SI. Influence of glutathione S-transferase M1 and T1 genotypes on larynx cancer risk among Korean smokers. Clin Chem Lab Med 2000;38:917-919.

21. Hung HC, Chuang J, Chien YC, et al. Genetic polymorphisms of CYP2E1, GSTM1, and GSTT1; environmental factors and risk of oral cancer. Cancer Epidemiol Biomarkers Prev 1997;6:901-905.

22. Jourenkova N, Reinikainen M, Bouchardy C, Dayer P, Benhamou S, Hirvonen A. Larynx cancer risk in relation to glutathione S-transferase M1 and T1 genotypes and tobacco smoking. Cancer Epidemiol Biomarkers Prev 1998;7:19-23.

23. Jourenkova-Mironova N, Voho A, Bouchardy C, et al. Glutathione S-transferase GSTM1, GSTM3, GSTP1 and GSTT1 genotypes and the risk of smoking-related oral and pharyngeal cancers. Int J Cancer 1999;81:44-48.

24. Katoh T, Kaneko S, Kohshi K, et al. Genetic polymorphisms of tobacco- and alcohol-related metabolizing enzymes and oral cavity cancer. Int J Cancer 1999;83: 606-609.

25. Matthias C, Bockmuhl U, Jahnke V, et al. Polymorphism in cytochrome P450 CYP2D6, CYP1A1, CYP2E1 and glutathione S-transferase, GSTM1, GSTM3, GSTI1 and susceptibility to tobacco- related cancers: studies in upper aerodigestive tract cancers. Pharmacogenetics 1998;8:91-100.

26. McWilliams JE, Evans AJ, Beer TM, et al. Genetic polymorphisms in head and neck cancer risk. Head Neck 2000;22:609-617.

27. Olshan AF, Weissler MC, Watson MA, Bell DA. GSTM1, GSTT1, GSTP1, CYP1A1, and NAT1 polymorphisms, tobacco use, and the risk of head and neck cancer. Cancer Epidemiol Biomarkers Prev 2000;9:185-191.

28. Worrall SF, Corrigan M, High A, et al. Susceptibility and outcome in oral cancer: preliminary data showing an association with polymorphism in cytochrome P450 CYP2D6. Pharmacogenetics 1998;8:433-439.

29. Hamel N, Karimi S, Hebert-Blouin MN, et al. Increased risk of head and neck cancer in association with GSTT1 nullizygosity for individuals with low exposure to tobacco. Int J Cancer 2000;87:452-454.

30. Trizna Z, Clayman GL, Spitz MR, Briggs KL, Goepfert H. Glutathione S-transferase genotypes as risk factors for head and neck cancer. Am J Surg 1995;170:499501.

31. London SJ, Yuan JM, Chung FL, Gao YT, Coetzee GA, Ross RK, Yu MC. Isothiocyanates, glutathione S-transferase M1 and T1 polymorphisms, and lung cancer risk: a prospective study of men in Shanghai, China. Lancet 2000;356: 724-729. 


\section{CHAPTER}

\section{PLASMA GLUTATHIONE S-TRANSFERASE P1-1 LEVELS IN PATIENTS WITH HEAD AND NECK SQUAMOUS CELL CARCINOMA}

Michael B Oude Ophuis ${ }^{1}$, Theo PJ Mulder ${ }^{2}$, Wilbert H M Peters ${ }^{2}$, Johannes J Manni ${ }^{1}$

${ }^{1}$ Dept. of Otorhinolaryngology, Head and Neck Surgery, University Hospital Maastricht, The Netherlands

${ }^{2}$ Dept. of Gastroenterology, University Medical Center Nijmegen, The Netherlands

Published in Cancer 1998; 82: 2434-2438 


\section{Abstract}

Background Many tumors contain high amounts of the detoxification enzyme glutathione S-transferase P1-1 (GSTP1-1). Elevated levels of GSTP1-1 have also been detected in serum and plasma from patients with gastrointestinal, lung or head and neck tumors. We evaluated the role of GSTP1-1 as a plasma tumor marker in patients with larynx-hypopharynx-oropharynx sites of head and neck squamous cell carcinoma (HNSCC), and benign head and neck lesions (BHNL).

Methods GSTP1-1 levels were measured in EDTA plasma using a recently developed sensitive and specific sandwich ELISA. An upper normal reference level of $21.8 \mu \mathrm{g}$ GSTP1-1 per liter of plasma was calculated from results obtained from samples of 230 blood donors.

Results Median GSTP1-1 levels of 53 patients with oral/oropharyngeal SCC (10.6 $\mu \mathrm{g} / \mathrm{L}$; range $3.7-46.1 \mu \mathrm{g} / \mathrm{L}), 12$ patients with hypopharyngeal SCC $(11.9 \mu \mathrm{g} / \mathrm{L}$; range 5.2-146.6 $\mu \mathrm{g} / \mathrm{L})$ and 28 patients with laryngeal SCC (14.4 $\mu \mathrm{g} / \mathrm{L}$; range 6.4-141.5 $\mu \mathrm{g} / \mathrm{L}$ ) were significantly elevated when compared to plasma GSTP1-1 levels from 45 patients with BHNL $(8.1 \mu \mathrm{g} / \mathrm{L}$; range 3.3-32.3 $\mu \mathrm{g} / \mathrm{L}, \mathrm{P}<0.0001, \mathrm{P}<0.01$ and $\mathrm{P}<0.0001$ respectively). However, only $6 / 53$ patients $(11 \%)$ with oral/oropharyngeal SCC, 1/12 patients $(8 \%)$ with hypopharyngeal SCC, and $6 / 28$ patients $(21 \%)$ with laryngeal SCC had plasma GSTP1-1 levels above the upper normal reference level. Thus overall only $13 / 93$ patients $(14 \%)$ with HNSCC had elevated plasma GSTP1-1 levels. No significant relation between plasma GSTP1-1 levels and TNM classification of the tumors was detected.

Conclusions GSTP1-1 is not a suitable plasma tumor marker for HNSCC. 


\section{Introduction}

Glutathione S-transferases (GSTs) are enzymes that catalyze the addition of glutathione to electrophillic centers of a wide variety of compounds. This reaction is the first step in the formation of mercapturic acids, a pathway mostly resulting in the elimination of potentially toxic compounds. GSTs also serve as transport proteins for a broad range of lipophillic compounds, such as bilirubin, bile acids, steroid hormones, and various xenobiotics (1,2). Based on structural, physiochemical, enzymatic, and immunological properties the family of enzymes is divided into four classes: Alpha, Mu, Pi and Theta (1-4).

Malignancies from colon, stomach, urinary bladder, uterine cervix, lung and larynx often contain increased amounts of GSTP1-1 when compared to the adjacent normal tissue $(5,6)$. Three studies published in 1989 all indicated that a considerable number of patients with gastrointestinal malignancies had elevated serum GSTP1-1 levels (7-9).

Hirata et al. reported elevated plasma GSTP1-1 levels in 41/61 patients (76\%) with primary oral cancer (10). These authors also reported an impressive decline in plasma GSTP1-1 levels after surgical resection of the tumor: 16 of 25 patients (64\%) with good prognoses had elevated GSTP1-1 levels before surgery and all values normalized within eight weeks post-operatively. High GSTP1-1 levels were not only reported in plasma; immunohistochemical investigations also showed increased levels of GSTP1-1 in head and neck tumor tissue, which decreased after radiation therapy (11).

Because blood cells and platelets contain large amounts of GSTP1-1, the sampling procedures for serum or plasma are exceptionally critical (12-14). We recently reported that plasma samples had to be collected in special silicone coated ethylene diamine tetra-acetic acid (EDTA) blood collection tubes and should be processed under strict conditions to avoid spuriously high plasma GSTP1-1 levels (14).

In the current study, we investigated plasma GSTP1-1 levels in blood samples from patients with head and neck squamous cell carcinoma (HNSCC) and benign head and neck lesions (BHNL).

\section{Materials and methods}

\section{Patients}

All blood samples from patients were collected at the Department of Otorhinolaryngology, Head and Neck Surgery, University Hospital Maastricht, the Netherlands. 53 patients with oral/oropharyngeal SCC, 12 patients with hypopharyngeal SCC and 28 patients with laryngeal SCC were studied. All diagnoses were confirmed by histology. Tumors were staged according to the TNM regulation of the International Union Against Cancer (15). The median age of the 93 HNSCC patients was 59 years (range 23-82 years) and 70 patients (75\%) were males. Forty five patients with BHNL were studied ( 7 patients with parotic pleomorphic adenoma, 6 patients with submandibular disorders, 12 patients with rhinological disorders, 12 patients with vocal cord disorders, and 8 patients with neck disorders). The median age of this BHNL group was 47 
years (range $16-86$ years) and 26 patients $(58 \%)$ were males. Patients with hepatic disorders were excluded from the study. As a control group served 230 blood donors, median age 35 years (range $18-69$ years).

This study was approved by the local Medical Ethical Review Committee.

\section{Plasma samples}

Approximately $3 \mathrm{ml}$ of blood was collected by venapuncture in vacuumed, silicone coated, K3 EDTA containing tubes (Vacutainer, order no. 606601 Becton Dickinson, Grenoble, France). Immediately after collection of the sample, blood was gently mixed with the EDTA solution. Tubes were centrifuged for 10 minutes at $3000 \times g$ at room temperature within 2 hours. The upper two-third part of the plasma was collected and care was taken not to aspirate the platelets on top of the cell layer. Plasma samples were stored in portions at $-20^{\circ} \mathrm{C}$.

\section{Assays}

Plasma GSTP1-1 concentration was measured using a recently developed enzyme linked immuno assay (ELISA) (14). Briefly, microtiter plates were coated overnight with purified anti-GSTP1-1 monoclonal antibody. One hundred $\mu \mathrm{L}$ of standard (0.4-100 $\mu \mathrm{g} / \mathrm{L}$ GSTP1-1), or 1:1 diluted plasma samples were added to the wells and incubated overnight. The next day the plates were washed and incubated with rabbit anti-GSTP1-1 serum, washed again, incubated with horseradish peroxidase labeled swine anti-rabbit and after a final wash, plates were stained with o-phenylenediamine- $\mathrm{H}_{2} \mathrm{O}_{2}$. Standards and samples were measured in duplicate. A four parameter weighted logistic regression model was used to calculate standard curves and unknowns. The assay had no cross reactivity with GSTs of the Alpha or the Mu classes; the detection limit was $0.4 \mu \mathrm{g} / \mathrm{L}$ GSTP1-1 and the intra- and inter-assay coefficients of variation were $5.8 \%$ and $10.9 \%$, respectively.

\section{Calculations and statistics}

Plasma samples were categorized according to whether their GSTP1-1 content was below (normal) or above (elevated) the upper limit of the normal reference level. An upper normal reference limit of $21.8 \mu \mathrm{g} / \mathrm{L}$ GSTP1-1 was calculated from plasma samples of the 230 healthy blood donors (14).

The statistical significance of differences between groups of patients and healthy controls was evaluated using the two-tailed Wilcoxon's rank-sum test. To avoid spurious differences, data were initially subjected to a Kruskal-Wallis analysis. All statistical analyses were performed using SPSS/PC+ statistical computer software version 5.0.

GSTP1-1 levels are expressed as medians with ranges, unless stated otherwise. 


\section{Results}

The median GSTP1-1 levels for 53 patients with oral/oropharyngeal SCC (10.6 $\mu \mathrm{g} / \mathrm{L}$; 3.7-46.1 $\mu \mathrm{g} / \mathrm{L}), 12$ patients with hypopharyngeal SCC $(11.9 \mu \mathrm{g} / \mathrm{L} ; 5.2-146.6 \mu \mathrm{g} / \mathrm{L})$ and 28 patients with laryngeal SCC $(14.4 \mu \mathrm{g} / \mathrm{L} ; 6.4-141.5 \mu \mathrm{g} / \mathrm{L})$ were significantly elevated when compared to the median plasma GSTP1-1 levels for $45 \mathrm{BHNL}$ patients $(8.1 \mathrm{\mu g} / \mathrm{L}$; 3.3-32.3 $\mu \mathrm{g} / \mathrm{L} ; \mathrm{P}<0.0001, \mathrm{P}<0.01$ and $\mathrm{P}<0.0001$, respectively). The median plasma GSTP1-1 levels for these three groups of patients with SCC were also significantly elevated when compared with the median plasma GSTP1-1 levels for 230 healthy controls $(7.2 \mu \mathrm{g} / \mathrm{L} ; 2.2-71.6 \mu \mathrm{g} / \mathrm{L})(\mathrm{P}<0.0001, \mathrm{P}<0.007$ and $\mathrm{P}<0.001$, respectively).

However, plasma GSTP1-1 levels were above the upper limit of the normal reference level in only 6 of 53 patients (11\%) with oral/oropharyngeal SCC, 1 of 12 patients (8\%) with hypopharyngeal SCC and in 6 of 28 patients (21\%) with laryngeal SCC (Figure 1). Overall 13 of 93 patients (14\%) with HNSCC had elevated plasma GSTP1-1 levels, whereas only 1 of 45 patients (2.2\%) with BHNL had an elevated plasma GSTP1-1 level (Figure 1). Plasma GSTP1-1 levels were not related to TNM stage grouping of the tumors (Table 1). Patients with HNSCC were significantly older than patients with BHNL (median 59 years, range 23-82 years and median 47 years, range 16-86 years, respectively; $\mathrm{P}<0.002$ ).

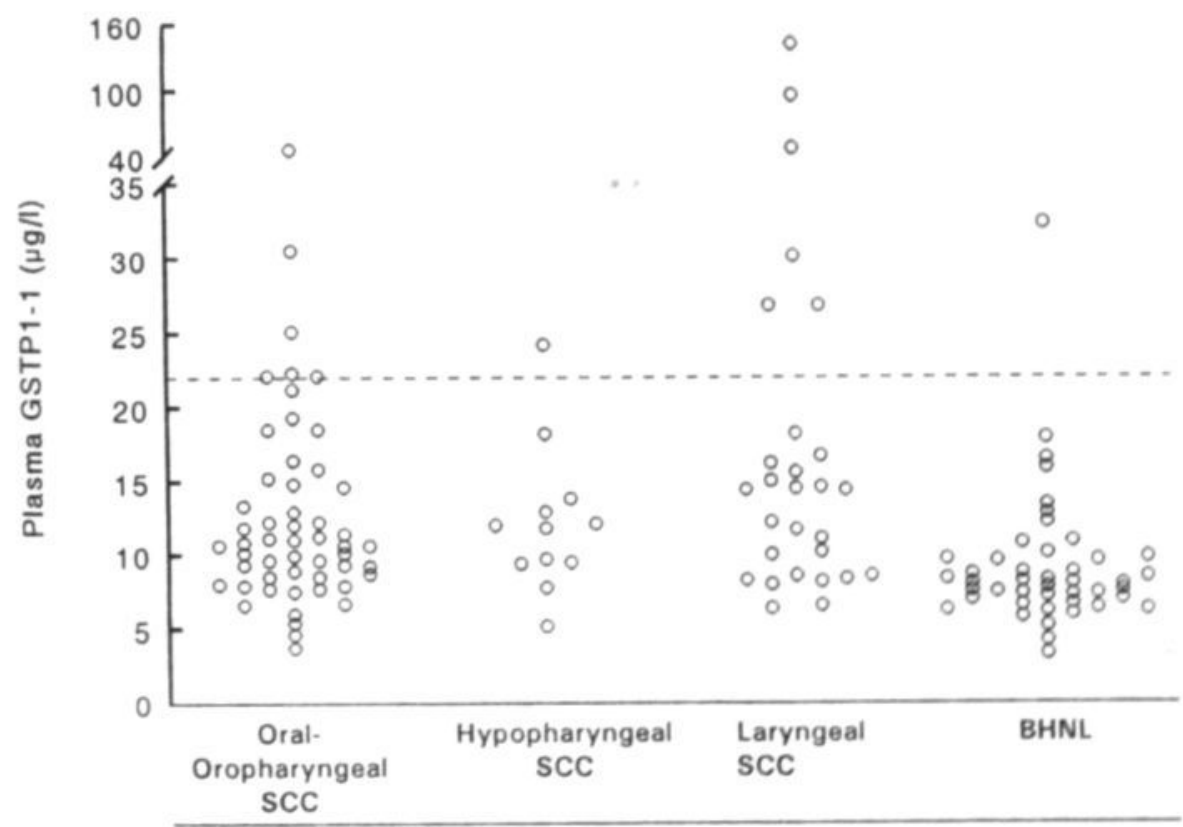

Figure 1. Plasma glutathione S-transferase P1-1 (GSTP1-1) levels in patients with head and neck squamous cell carcinoma and patients with benign head and neck disorders. The dashed line denotes the upper normal reference limit. 
Table 1. Plasma glutathione S-transferase P1-1 (GSTP1-1) levels in patients with head and neck squamous cell carcinoma according to stage of disease.

\begin{tabular}{|c|c|c|c|c|}
\hline $\begin{array}{l}\text { TNM } \\
\text { Stage }\end{array}$ & $\begin{array}{l}\text { Plasma GSTP1-1 ( } \mathrm{LE} / \mathrm{L} \text { ) } \mathrm{n} \\
\text { (number of patients) }\end{array}$ & an (range) & & \\
\hline & Oral/oropharyngeal SCC & Hypopharyngeal SCC & Laryngeal SCC & All sites HNSCC \\
\hline 1 & $\begin{array}{l}9.3(5.4-22.1) \\
(9)\end{array}$ & $\overline{(0)}$ & $\begin{array}{l}14.6(8.3-30.1) \\
(6)\end{array}$ & $\begin{array}{l}11.8(5.4-30.1) \\
(15)\end{array}$ \\
\hline "I & $\begin{array}{l}9.4(6.6-22.1) \\
(12)\end{array}$ & $\begin{array}{l}10.8(9.5-12.1) \\
(2)\end{array}$ & $\begin{array}{l}17.6(6.4-141.5) \\
(6)\end{array}$ & $\begin{array}{l}9.6(6.4-141.5) \\
(20)\end{array}$ \\
\hline III & $\begin{array}{l}10.8(4.6-46.1) \\
\text { (11) }\end{array}$ & $\begin{array}{l}12.9(12.0-13.8) \\
(2)\end{array}$ & $\begin{array}{l}14.0 \\
\text { (1) }\end{array}$ & $\begin{array}{l}11.2(4.6-46.1) \\
(14)\end{array}$ \\
\hline IV & $\begin{array}{l}10.9(3.7-30.5) \\
(20)\end{array}$ & $\begin{array}{l}10.7(5.2-24.2) \\
(8)\end{array}$ & $\begin{array}{l}11.7(6.6-94.9) \\
(13)\end{array}$ & $\begin{array}{l}11.1(3.7-94.9) \\
(41)\end{array}$ \\
\hline
\end{tabular}

Differences between TNM stage grouping were not significant. From one patient with an oral/oropharyngeal tumor and from two patients with laryngeal tumors the TNM classification and stage was not recorded.

\section{Discussion}

The ideal tumor marker is a tumor specific screening tool that assists in the workup and follow up of oncologic patients. It can also monitor the response to therapy, in which case it should be directly related to tumor bulk or tumor load. By these means, the marker should be able to detect tumor recurrence and/or regional or distant metastases before clinical presentation.

Hirata et al. reported elevated plasma GSTP1-1 levels in 41 of 61 patients (76\%) with primary oral cancer and normal GSTP1-1 levels in patients with benign oral disease (10) . These authors also reported an impressive decline in plasma GSTP1-1 levels after surgical resection of the tumor: 16 of 25 patients $(64 \%)$ with good prognoses had elevated GSTP1-1 levels before surgery and all values normalized within eight weeks postoperatively. They also detected elevated plasma GSTP1-1 levels in most patients with tumor recurrence after surgery, even before this recurrence was detected clinically.

Because blood cells and platelets contain large amounts of GSTP1-1, the sampling procedures for serum or plasma are exceptionally critical $(1,2,13,14,16)$. Recently we reported that even minor variations in the type of blood collection tubes or in the procedures used to handle and centrifuge the blood may substantially affect the resulting GSTP1-1 levels (14). This implies the need for identical sampling procedures for patients and controls. In our study the sampling, handling, storage, and assay procedures were identical for all patients and other donors.

Hirata et al. also reported that mean plasma GSTP1-1 levels were higher in patients with more advanced stages of SCC (10). More than $70 \%$ of patients with Stage III or IV oral cancer, in contrast to approximately $50 \%$ of those with Stage I and II disease, had elevated levels of GSTP1-1 in plasma. Niitsu et al. described elevated serum GSTP1-1 in more than $80 \%$ of patients with Stage III or IV gastric cancer, as opposed to only 
about $50 \%$ of patients with Stage I and II (9). We could not confirm this relation in a larger group of patients (Hirata et al. (10) $n=61$, Niitsu et al. (9) $n=52$; this study $n=93$ ). Median plasma GSTP1-1 levels were not significantly different among patients with Stage I, II, III or IV HNSCC. Furthermore, when median GSTP1-1 plasma levels were compared among tumor sites (oral-oropharynx, hypopharynx, larynx) and tumor stages, no significant differences were found (Table 1).

In most earlier studies, no differences in serum or plasma GSTP1-1 levels between males and females or among different age groups were observed $(8-10,17,18)$. Various serum GSTP1-1 cutoff levels have been reported by different authors. Upper normal reference limits of $3.7 \mu \mathrm{g} / \mathrm{L}, 15.4 \mu \mathrm{g} / \mathrm{L}, 34.0 \mu \mathrm{g} / \mathrm{L}, 34.8 \mu \mathrm{g} / \mathrm{L}$ GSTP1-1 in serum, $30.4 \mu \mathrm{g} / \mathrm{L}$ GSTP1-1 in heparin plasma and $5.4 \mu \mathrm{g} / \mathrm{L}$ and $13.99 \mu \mathrm{g} / \mathrm{L}$ in EDTA plasma were reported in literature, based on samples from between 30 and 117 healthy controls $(7-10,13,17,18)$. In agreement with the results reported by Takahashi et al., our control plasma GSTP1-1 levels also had to be log-transformed to obtain a nearly normal distribution (7). This transformation led to an upper normal reference level of 21.8 $\mu \mathrm{g} / \mathrm{L}$, as compared to a value of $21.9 \mu \mathrm{g} / \mathrm{L}$, when calculated by taking mean value plus 2 times the standard deviation.

Our results also indicated that males had significantly higher GSTP1-1 levels than females. Among both males and females, a significant increase of GSTP1-1 levels was noted with increasing age (14). Males ages 20-40 years, 40-60 years or older than 60 years had median plasma GSTP1-1 levels of $8.2 \mu \mathrm{g} / \mathrm{L}, 9.1 \mu \mathrm{g} / \mathrm{L}$ or $12.0 \mu \mathrm{g} / \mathrm{L}$, respectively. The values for females in the same age groups were $5.5 \mu \mathrm{g} / \mathrm{L}, 6.6 \mu \mathrm{g} / \mathrm{L}$ and 11.0 $\mu \mathrm{g} / \mathrm{L}$ respectively (14). The group of $93 \mathrm{HNSCC}$ patients comprised 70 males and 23 females. The HNSCC group was also significantly older than the group of patients with benign head and neck disorders. These demographical variations may explain in part the difference in plasma GSTP1-1 levels between HNSCC and BHNL or control groups.

Hirata et al. also reported that the reappearance of elevated levels of GSTP1-1 in plasma occurred earlier than the clinical detection of recurrent disease in 10 of 13 patients with head and neck cancer (76.9\%) (10). Several groups reported a decrease of GSTP1-1 to normal levels after radical surgical resection of the tumor $(9,10)$.

Because we found that a small minority of patients (14\%) had elevated GSTP1-1 levels in the diagnostic phase of our study, no collection of plasma for follow up studies was performed.

Earlier we studied 20 patients with gastrointestinal carcinomas before and after surgical resection of their tumors and found elevated plasma GSTP1-1 levels after resection of the tumor in some patients with normal preoperative levels (14). This indicates that, in patients with gastrointestinal tumors a postoperative GSTP1-1 elevation may well be caused by other mechanisms not related to tumorload. It is possible that this also occurs in patients with HNSCC; however, further studies are needed to ascertain this.

Perhaps manipulation of tumor and/or normal tissue may cause high intravascular GST levels. When tumor or adjacent normal tissue contains a very high level of 
GSTP1-1, damage to these tissues during surgery could cause intravascular leakage resulting in increased plasma levels postoperatively.

Elevated GSTP1-1 levels were found in patients with non-malignant hepatic disorders (cirrhosis, hepatitis) suggesting that elevation of plasma or serum GSTP1-1 is not specific for malignant disease $(8,9)$. In our study, patients were screened on hepatic disorders by liver enzyme counts. Patients with high entries have been excluded for this study. These criteria were not mentioned in most other reports.

In the current study, the clinical application of GSTP1-1 as a tumor marker for HNSCC was evaluated. The levels of GSTP1-1 in HNSCC were significantly higher than the levels in BHNL and control groups. However, only 13 of 93 patients with HNSCC demonstrated elevated GSTP1-1 plasma levels. In contrast to earlier reports by others, we conclude that GSTP1-1 can not be used as a tool for the diagnostic screening of patients with HNSCC.

\section{References}

1. Boyer T, Kenney W. Preparation, characterization and properties of glutathione S-transferases. In: Zakim D, Vessey D, eds. Biochemical Pharmacology and Toxicology, vol. 1. New York: Wiley, J. and Sons, 1985; 297-364.

2. Mannervik B. The isoenzymes of glutathione transferase. Adv Enzymol Relat Areas Mol Biol 1985; 57:357-417.

3. Hayes JD, Strange RC. Potential contribution of the glutathione S-transferase supergene family to resistance to oxidative stress. Free Radic Res 1995; 22: 193-207.

4. Beckett GJ, Hayes JD. Glutathione S-transferases: biomedical applications. Adv Clin Chem 1993; 30:281-380.

5. Tsuchida S, Sato K. Glutathione transferases and cancer. Crit Rev Biochem Mol Biol 1992; 27:337-84.

6. Mulder TPJ, Manni JJ, Roelofs HMJ, Peters WHM, Wiersma A. Glutathione S-transferases and glutathione in human head and neck cancer. Carcinogenesis 1995; 16:619-24.

7. Takahashi Y, Hirata Y, Saito T, et al. Enzyme immunoassay for human serum Glutathione S-transferase Pi using monoclonal and polyclonal antibodies. Cancer J 1989; 2:225-9.

8. Tsuchida S, Sekine Y, Shineha R, Nishihira T, Sato K. Elevation of the placental glutathione S-transferase form (GST-pi) in tumor tissues and the levels in sera of patients with cancer. Cancer Res 1989; 49:5225-9.

9. Niitsu Y, Takahashi Y, Saito T, et al. Serum glutathione S-transferase-pi as a tumor marker for gastrointestinal malignancies. Cancer 1989; 63:317-23.

10. Hirata S, Odajima T, Kohama G, Ishigaki S, Niitsu Y. Significance of glutathione S-transferase-pi as a tumor marker in patients with oral cancer. Cancer 1992; 70:2381-7.

11. Tanita J, Tsuchida S, Hozawa J, Sato K. Expression of glutathione S-transferasepi in human squamous cell carcinomas of the pharynx and larynx. Loss after radiation therapy. Cancer 1993; 72:569-76. 
12. Howie AF, Hayes JD, Beckett GJ. Purification of acidic glutathione S-transferases from human lung, placenta and erythrocyte and the development of a specific radioimmunoassay for their measurement. Clin Chim Acta 1988; 177:65-75.

13. Hao XY, Castro VM, Bergh J, Sundstrom B, Mannervik B. Isoenzyme-specific quantitative immunoassays for cytosolic glutathione transferases and measurement of the enzymes in blood plasma from cancer patients and in tumor cell lines. Biochim Biophys Acta 1994; 1225:223-30.

14. Mulder TPJ, Peters WHM, Wobbes T, Witteman BJM, Jansen JBMJ. Measurement of glutathione S-transferase P1-1 in plasma; pitfalls and significance of screening and follow-up of patients with gastrointestinal carcinoma. Cancer 1997; 80: 873-80.

15. Hermanek P, Sobin L. Head and Neck tumors TNM classification of malignant tumors (UICC). Berlin: Springer-Verlag, 1992; 15-37.

16. Howie AF. Measurement of glutathione S-transferase pi by radioimmunoassay: elevated plasma levels in lung cancer patients. Br J Biomed Sci 1993; 50: 187-99.

17. Hida T, Kuwabara M, Ariyoshi Y, et al. Serum glutathione S-transferase-pi level as a tumor marker for non-small cell lung cancer. Potential predictive value in chemotherapeutic response. Cancer 1994; 73:1377-82.

18. Fan KC, Huang YC, Li CH. Radioimmunoassay for plasma glutathione S-transferase-pi and its clinical application in gastrointestinal cancer. Cancer 1995; 76: 1363-7. 


\section{CHAPTER}

\section{POLYMORPHISMS OF THE GLUTATHIONE S-TRANSFERASE P1 GENE AND HEAD AND NECK CANCER SUSCEPTIBILITY}

Michael B Oude Ophuis ${ }^{1}$, Hennie MJ Roelofs ${ }^{2}$, Piet A van den Brandt ${ }^{3}$, Wilbert HM Peters ${ }^{2}$, Johannes J Manni ${ }^{1}$

${ }^{1}$ Dept. of Otorhinolaryngology, Head and Neck Surgery, University Hospital Maastricht, The Netherlands

${ }^{2}$ Dept. of Gastroenterology, University Medical Center Nijmegen, The Netherlands

${ }^{3}$ Dept. of Epidemiology, Maastricht University, The Netherlands

Published in Head and Neck $2003 ; 25: 37-43$ 


\begin{abstract}
Background Factors determining the individual susceptibility to head and neck squamous cell carcinoma (HNSCC) are still largely unknown. An imbalance between enzymes involved in the toxification and detoxification of (pre)-carcinogens closely related to HNSCC which may appear during smoking and alcohol consumption, may play a role. Genetic polymorphisms in glutathione S-transferases (GSTs) often result in altered detoxification, which may contribute to individual susceptibility to HNSCC.

Methods We studied the frequencies of polymorphic variants in the GSTP1 gene in 235 patients with HNSCC and 285 healthy controls. In addition, data on exposure to alcohol and tobacco were recorded. DNA was extracted from whole blood and polymerase chain reaction (PCR) based methods were used to detect genetic polymorphisms.

Results In patients with HNSCC and control groups the homozygous GSTP1 BB genotype was observed in $12.3 \%$ and $13.6 \%$ respectively. No statistical differences were found for the GSTP1 AA and GSTP1 AB / GSTP1 BB genotypes.
\end{abstract}

Conclusions Our study showed that genetic polymorphisms of GSTP1 are not associated with altered susceptibility to HNSCC. 


\section{Introduction}

An imbalance in phase I drug metabolism enzymes such as cytochromes P450 (CYPs) or phase II detoxification enzymes such as glutathione S-transferases (GSTs) may contribute to the individual susceptibility to head and neck squamous cell carcinoma (HNSCC). These enzymes, for instance, are involved in the toxification and detoxification of metabolites of polycyclic aromatic hydrocarbons (PAHs), one of the primary carcinogens of tobacco smoke (1). Most PAHs first require activation by phase I enzymes to become potential carcinogens that are subsequently detoxified by phase II enzymes.

As a result of conjugation with glutathione, the potential carcinogens are eliminated and DNA or other important biomolecules are protected against damage or adduct formation (2-5). In humans, the GST enzymes can be divided into 5 main classes: Alpha (GSTA), Mu (GSTM), Pi (GSTP), Theta (GSTT), and Zeta (GSTZ). Each class consists of one or more iso-enzymes with different, but sometimes overlapping, substrate specificity $(4,5)$. At present, genetic polymorphisms have been demonstrated for the GSTM1, GSTT1, and GSTP1 genes (5-9).

Polymorphisms in the GSTP1 gene consist of the variant genotypes GSTP1 AB and GSTP1 BB next to the wild type GSTP1 AA. The frequency of GSTP1 AA in healthy controls ranges from $42-69 \%(9-14)$. A transition of Adenine (A) to Guanine (G) at nucleotide 313 in exon 5 of the GSTP1 gene results in substitution of isoleucine (Ile) to valine (Val) at position 104 in the amino acid sequence of the protein $(7,15,16)$. The valine variants exhibit lower specific activity and affinity for the electrophillic substrates of the enzyme $(7,13,15)$. The valine containing homozygous variant, GSTP1 BB, occurs in approximately $10 \%$ of healthy controls, whereas the heterozygous Ile-Val variant, GSTP1 $A B$, occurs in approximately $35 \%$ of controls (9-14).

The GSTP1 gene encodes for the iso-enzyme GSTP1-1. The GSTP1-1 enzyme level has been extensively studied in relation to tobacco associated malignancies. The GSTP1-1 enzyme is overexpressed in many pre-neoplastic and neoplastic lesions. Elevated tissue levels of GSTP1-1 enzyme have been found in stomach, colorectal, bladder, oral, pharynx, larynx, lung, skin and breast tumors compared with normal tissues of matched controls (5,17-22). The GSTP1-1 enzyme may be involved in the resistance to chemotherapeutic agents and radiotherapy (5,23-25). Since GSTP1-1 is also involved in the metabolism and subsequent removal of anti-cancer drugs, high levels of GSTP1-1 in tumors may contribute to drug resistance in several different cancers (26-28). However, there are also contradictory reports.

Because the amino acid change as result of the polymorphism close to the area of hydrophobic binding site for electrophiles, the homozygous GSTP1 BB and heterozygous GSTP1 AB gene products result in a decreased specific activity and affinity of the GSTP1-1 enzyme for electrophillic compounds (7). Thus, the altered metabolic activity of these enzymes could influence susceptibility to head and neck cancer. Earlier we investigated the possible involvement in HNSCC and in benign head and neck lesions (BHNL) of genetic polymorphisms in CYP1A1, GSTM1 and GSTT1 but we found no enhanced rates of GST null genotypes in the cancer population (29). Earlier work from 
our group showed that the GSTP1-1 enzyme, in a quantitative sense, is by far the most important detoxification enzyme in human head and neck tissues (30). Therefore we now investigated genetic polymorphisms in the GSTP1 gene in a large series of patients with HNSCC and in matched healthy controls. We also evaluated exposure to alcohol and tobacco of these subjects and evaluated the potential effect modification between GSTP1 polymorphisms and these environmental exposures.

\section{Materials and Methods}

\section{Patients and controls}

This case-control study was conducted in the patient referral region of Maastricht University Hospital. A total of 235 Caucasian patients (185 males, 50 females) with primary HNSCC were recruited during their scheduled admission at the Department of Otolaryngology, Head and Neck Surgery of the University Hospital Maastricht between 1994 and 1998 (mean age 59 years; range 23-86 years). This group consists of 100 patients with larynx carcinoma (mean age 60 years; range 35-85 years), 114 patients with oral-cavity/oropharynx carcinoma (mean age 58 years; range 23-86 years), and a group of 21 patients (mean age 61 years; range $41-82$ years) with hypopharynx carcinoma.

From the same base population, a group of 285 healthy Caucasian blood donors (199 males, 86 females) were recruited at the Blood Transfusion Centre Limburg and served as a control group, frequency matched on age in 10 year age groups (mean age 50 years; range 19-91). The investigations were approved by the Medical Ethical Review Committee of the University Hospital of Maastricht and informed consent was obtained from all patients and controls according to the Helsinki Declaration II (1975, revised 1983).

\section{Exposure assessment, blood sampling and genotyping}

Information on tobacco use and alcohol consumption was collected for all patients and controls by interview. The amount of packyears (PY) was calculated as the number of years smoking $x$ the number of packs a day (assuming 20 cigarettes $=1$ pack). Individuals were defined as never smokers when they had smoked less than one pack year cumulatively.

Blood was collected by venapuncture in sterile siliconized EDTA K3 (15\%) $4 \mathrm{ml}$ vacutainer tubes (Becton Dickinson, San Jose, CA, USA). Immediately after collection whole blood was stored at $-20^{\circ} \mathrm{C}$ until use. Genomic DNA was isolated from whole blood using the Wizard ${ }^{\mathrm{TM}}$ genomic DNA purification kit, according to the instructions of the manufacturer (Promega, Madison Wisconsin, USA).

Genetic polymorphisms were detected by polymerase chain reaction-restriction fragment length polymorphism (PCR-RFLP). For studying the genetic polymorphism in GSTP1 a primer set ( $105 \mathrm{~F}$ and 105R) was designed so that the presence of the $A$ to $G$ substitution at codon 313 resulted in the appearance of an Alw261 restriction enzyme site (9). All primers were synthesized by Life Technologies (Breda, the Netherlands). All chemicals needed for PCR were purchased from Promega, Madison Wisconsin, USA. 


\section{Statistical analysis}

The statistical program SPSS 8.0 for Windows was used. Information on GSTP1 genotype, smoking or alcohol was missing in 0,0 , and 11 of the cases and 0,3 , and 1 of controls, respectively. For the purpose of the analysis, the PY of cigarette smoking were categorized as <1, 1-20, 21-40, 41-60, and 60+ PY or in increments of 10 PY. Alcohol consumption was categorized as 0-9, 10-50, 51+ gram/day. Because there were only 3 subjects who indicated never to have consumed alcohol, the first category consists of 0-9 grams per day. Analyses were conducted for the total group of patients with HNSCC, as well as for oral cavity/oropharyngeal and laryngeal carcinoma seperately. Because of small numbers of hypopharyngeal carcinoma, this group was not evaluated separately.

The association between GSTP1 polymorphisms, smoking, alcohol and HNSCC was modelled through multivariate logistic regression analysis, controlling for age and gender. First, analyses were conducted to examine the associations between GSTP1 genotype and HNSCC, controlling for age, gender, smoking and alcohol. Specifically, we evaluated whether subjects with GSTP1 AA are less susceptible to HNSCC than those with GSTP1 $A B / B B$. Likewise associations between smoking and HNSCC or alcohol consumption and HNSCC were examined, controlling for age, gender and alcohol or smoking, respectively. The strength of the associations were estimated as Odds Ratios combined with $95 \%$ Confidence Intervals. Subsequently, logistic regression analyses were performed in which the association between smoking or alcohol and HNSCC (and its subgroups) was evaluated within subgroups of the GSTP1 genotypes; the wildtype GSTP1 AA group and the combined heterozygote/homozygote GSTP1 AB/BB group. Likelyhood ratio tests were conducted to test statistical significance of regression model terms, as well as for test for trends and interactions. Two-sided p values are reported throughout.

Finally, the interaction between smoking and alcohol was evaluated, specifically within subgroups of the GSTP1 genotypes.

\section{Results}

Table 1 shows the frequency analyse for the A to G substitution at codon 313 in the GSTP1 gene, which was examined in 235 HNSCC patients and 285 controls. The GSTP1 BB frequency is low in the control group, as well as in the total HNSCC group or its subgroups. To maintain values for appropriate statistical analysis, we combined the frequencies for GSTP1 AB and GSTP1 BB (Tables 3-5). 
Table 1. Frequency distribution of GSTP1 genotypes in HNSCC cases and controls

\begin{tabular}{lllll} 
GSTP1 genotype & \multicolumn{1}{l}{$\begin{array}{l}\text { Controls } \\
\text { N }(\%)\end{array}$} & $\begin{array}{l}\text { All HNSCC cases } \\
\text { N }(\%)\end{array}$ & $\begin{array}{l}\text { Oral/oropharynx } \\
\text { N }(\%)\end{array}$ & $\begin{array}{l}\text { Larynx } \\
\text { N }(\%)\end{array}$ \\
\hline AA & $125(43.9)$ & $116(49.4)$ & $53(46.5)$ & $51(51.0)$ \\
AB & $121(42.5)$ & $90(38.3)$ & $48(42.1)$ & $36(36.0)$ \\
BB & $39(13.6)$ & $29(12.3)$ & $13(11.4)$ & $13(13.0)$ \\
Total & 285 & 235 & 114 & 100
\end{tabular}

In Table 2, the frequency distribution is given on the smoking habits and the alcohol consumption in HNSCC cases, subgroups of HNSCC and the control group. The HNSCC group in total, as well as the two subgroups, show a significant higher tobacco exposure compared to the control group. The control group shows a significantly lower alcohol consumption than the HNSCC cases (total or subgroups). In the oral/ oropharyngeal subgroup, the rate of daily alcohol consumption more than 51 gram/day is much higher compared to the laryngeal subgroup (54.1\% vs $30.4 \%$ respectively). Alcohol consumption more than $51 \mathrm{gram} /$ day hardly exists in the control group.

Table 2. Frequency distribution of smoking and alcohol consumption in HNSCC cases and controls

\begin{tabular}{|c|c|c|c|c|}
\hline \multirow{2}{*}{ Covariable } & Controls & All HNSCC cases & Oral/Oropharynx & Larynx \\
\hline & $N(*)$ & $N(7)$ & $N(\%)$ & $N(\%)$ \\
\hline \multicolumn{5}{|c|}{ Smoking Packyears } \\
\hline$<1$ & $86(30.2)$ & $13(5.5)$ & $7(6.1)$ & $3(3.0)$ \\
\hline 1.20 & $130(45.6)$ & $36(15.3)$ & $20(17.5)$ & $13(13.0)$ \\
\hline $21-40$ & $60(21.1)$ & $113(48.1)$ & $52(45.6)$ & $53(53.0)$ \\
\hline $41-60+$ & $9(3.2)$ & $73(31.1)$ & $35(30.7)$ & $31(31.0)$ \\
\hline Total & 285 & 235 & 114 & 100 \\
\hline \multicolumn{5}{|c|}{ Alcohol Gram/day } \\
\hline $0-9$ & $139(48.8)$ & $18(8.0)$ & $7(6.3)$ & $10(10.9)$ \\
\hline $10-50$ & $142(49.8)$ & $106(47.4)$ & $44(39.6)$ & $54(58.7)$ \\
\hline $51+$ & $3(1.1)$ & $100(44.6)$ & $60(54.1)$ & $28(30.4)$ \\
\hline Total & 284 & 224 & 111 & 92 \\
\hline
\end{tabular}

Table 3 shows that the Odds Ratios (OR) for alcohol or smoking are similar in the HNSCC group as a total and the two subgroups, except for alcohol consumption more than 51 gram/day, where there is a higher OR in the oral/oropharyngeal group. To provide appropriate statistical values, smoking is displayed with an increment of 10 PY. When no adjustment is made for smoking and alcohol (but only for age and gender), the OR for GSTP1 AA vS GSTP1 AB/BB will be 1.31 in the total HNSCC group.

The association between alcohol and smoking and the GSTP1 polymorphisms is shown in Table 4. For oral/oropharyngeal cases with the GSTP1 AA genotype, alcohol consumption more than doubles the OR compared to the GSTP1 AB/BB genotype. This is also shown for larynx carcinoma. In the oral/oropharyngeal cases, as well as the laryngeal cases with the GSTP1 AB/BB genotype, Odds Ratios are increased by smoking compared with the GSTP1 AA genotype. We tested for interaction of alcohol consumption between subgroups of GSTP1 in the total HNSCC group; LR (Likelyhood Ratio) $-\chi^{2}$ $=0.96, \mathrm{df}=2, \mathrm{p}>0.05$. Also the interaction of smoking between subgroups of GSTP 1 in the total HNSCC group is calculated; $L R-\chi^{2}=6.04, \mathrm{df}=1, \mathrm{p}<0.025$. 
Table 3. Association between alcohol, smoking and GSTP1 genotype and HNSCC (total group of cases and subgroups of oral/oropharyngeal and laryngeal cancer)

\begin{tabular}{|c|c|c|c|}
\hline \multirow[t]{2}{*}{ Risk factor } & Total HNSCC & Oral/oropharynx & Larynx \\
\hline & $\mathrm{N}=235$ & $\mathrm{~N}=114$ & $\mathrm{~N}=100$ \\
\hline & OR $(95 \% \mathrm{Cl})$ & OR $(95 \% \mathrm{Cl})$ & OR $(95 \%$ Cl) \\
\hline \multicolumn{4}{|l|}{ Alcohol Gram/day } \\
\hline $0-9$ & $1.0 *($ ref $)$ & $1.0 *($ ref $)$ & $1.0 *($ ref $)$ \\
\hline $10-50$ & $5.36(2.68-10.72)$ & $8.23(3.05-22.20)$ & $5.00(1.97-12.68)$ \\
\hline $51+$ & $194.16(49.21-766.31)$ & $420.03(87.47-2016.92)$ & $113.36(22.91-560.84)$ \\
\hline Test for trend, p-value & $<0.001$ & $<0.001$ & $<0.001$ \\
\hline \multicolumn{4}{|l|}{ Smoking Packyears } \\
\hline Increment $10 \mathrm{PY}$ & $1.80 \dagger(1.51-2.14)$ & $1.63 \dagger(1.34-1.97)$ & $1.85+(1.51-2.26)$ \\
\hline GSTP1 AB/BB & $1.0 \S($ ref) & $1.0 \S$ (ref) & $1.0 \mathrm{~g}$ (ref) \\
\hline GSTP1 AA & $0.99(0.58-1.71)$ & $0.78(0.38-1.60)$ & $0.90(0.46-1.79)$ \\
\hline
\end{tabular}

* Odds ratio, adjusted for age, gender, smoking, GSTP1 genotype

$\dagger$ Odds ratio, adjusted for age, gender, alcohol consumption, GSTP1 genotype

§ Odds ratio, adjusted for age, gender, alcohol consumption, smoking

ref $=$ reference value

$\mathrm{Cl}=$ confidence interval

Table 4. Association between alcohol consumption, smoking and HNSCC in subgroups of GSTP1 genotype

\begin{tabular}{llll} 
Risk factor & $\begin{array}{l}\text { Total HNSCC } \\
\text { OR }(95 \% \mathrm{Cl})\end{array}$ & $\begin{array}{l}\text { Oral/oropharynx } \\
\text { OR }(95 \% \mathrm{Cl})\end{array}$ & $\begin{array}{l}\text { Larynx } \\
\text { OR }(95 \%, \mathrm{Cl})\end{array}$ \\
\hline $\begin{array}{l}\text { Subgroup GSTP1 AA } \\
\text { (108 cases, 122 controls) }\end{array}$ & & & \\
Alcohol Gram/day & & & \\
$0-9$ & $1.0 *(\mathrm{ref})$ & $1.0 *($ ref $)$ & $1.0 *($ ref $)$ \\
$10-50$ & $7.89(2.75-22.68)$ & $15.88(2.66-94.66)$ & $6.95(1.76-27.50)$ \\
$51+$ & $232.24(38.22-1407.08)$ & $696.88(70.08-6930.15)$ & $140.16(16.22-1211.12)$ \\
Test for trend, p-value & $<0.001$ & $<0.001$ & $<0.001$ \\
& & & \\
Smoking Packyears & $1.51 \uparrow(1.21-1.80)$ & $1.34 \dagger(1.10-1.80)$ & $1.63 \uparrow(1.21-1.97)$ \\
Increment 10 PY & & &
\end{tabular}

\section{Subgroup GSTP1 AB/BB}

(116 cases, 159 controls)

Alcohol Gram/day

$0-9$

$10-50$

$1.0 *($ ref $)$

$4.21(1.65-10.70)$

$1.0 *$ (ref)

$51+$

$191.67(20.88-1759.33) \quad 307.88(26.42-3588.09)$

$10 *$ iref

Test for trend, p-value

$<0.001$

$<0.001$

$3.70(1.07-12.84)$

\section{Smoking Packyears}

Increment 10 PY

$2.28+(1.73-3.01)$

$2.41 \dagger(1.67-3.47)$

$2.46+(1.74-3.49)$

- adjusted for age, gender, smoking

$\dagger$ adjusted for age. gender, alcohol ref = reference value.

$\mathrm{Cl}=$ confidence interval 
In Table 5 we show a significant interaction between smoking and alcohol consumption in HNSCC susceptibility when not adjusted for GSTP1 genotype. The effect of smoking is stronger when more alcohol is consumed (OR increases from 1.27 to 3.53) However, because of small numbers (especially in high alcohol consumption category), interaction between alcohol and smoking and GSTP1 genotype can not be fully calculated.

Table 5. Interaction between alcohol and smoking regarding risk of HNSCC, in total group and in subgroups defined by GSTP1 genotype

Alcohol category

Smoking OR (95\% Cl)

per 10 Packyears

Total group GSTP1 AA/AB/BB

(224 cases, 281 controls)

Alcohol Gram/day

$0-9$

$1.27(1.03-1.57)$

$10-50$

$2.46(1.90-3.20)$

$51+$

$3.53(1.27-9.81)$

Test for interaction smoking/aicohol, $x^{2}$ (p-value) $18.2(p<0.01)$

Subgroup GSTP1 AA

(108 cases, 122 controls)

Alcohol Gram/day

$0-9$

$10-50$

$1.24(0.96-1.60)$

$51+$

Test for interaction smoking/aicohol, $\chi^{2}$ (p-value)

$2.08(1.44-3.01)$

n.p.

Subgroup GSTP1 AB/BB

(116 cases, 159 controls)

Alcohol Gram/day

$0-9$

$10-50$

$1.43(0.91-2.28)$

$2.85(1.96-4.16)$

$51+$

$0.57(0.06-5.48)$

Test for interaction smoking/alcohol, $\chi^{2}$ (p-value)

$3.5(p>0.05)$

n.p. = no estimation possible

$\mathrm{Cl}=$ confidence interval

\section{Discussion}

Glutathione S-transferases are involved in the detoxification of a wide variety of chemical carcinogens, including those derived from tobacco smoke (5).

The enzyme GSTP1-1 is known to catalyze the detoxification of PAH in vitro, and may be a major enzyme involved in the detoxification of tobacco related metabolic products in vivo (5). The expression in tissues may vary depending on site or localisation, and immunohistochemical studies have shown a constant and widespread GSTP1-1 expression throughout pharynx and larynx squamous cell epithelium in both normal and tumor tissue (10). Earlier we showed that GSTP1-1 is the most important GST enzyme in human head and neck tissues (30). Therefore, we studied the occurrence of polymorphisms of this gene (GSTP1) in patients with different head and neck tumors and controls. 
We previously reported that the GSTM1 and GSTT1 null genotypes are not associated with an increased susceptibility for HNSCC (29). In one of the largest studies performed so far, we found no significant association between risk of HNSCC and occurrence of genetic polymorphisms in the GSTP1 gene. This was also found for oral/oropharyngeal cancers and laryngeal cancers separately.

The GSTP1-1 enzyme is overexpressed in many neoplastic lesions, such as malignancies of stomach, colorectum, bladder, oral tissue, pharynx, larynx, lung, skin and breast, compared with corresponding normal tissues (5,17-22,30). However, when estimating GSTP1-1 serum levels in patients with head and neck cancer, we found significantly higher levels compared to controls, but no association with GSTP1 genotype was observed (31). This may indicate that the overexpression of GSTP1-1 in head and neck cancer is not dependent on genotype but most probably transcriptionally regulated.

We found a strong association between smoking and alcohol consumption and HNSCC susceptibility. Assessment of smoking or alcohol consumption is difficult, especially with respect to patient history for the total accumulative exposure. Exposure usually takes place over many years and is not always consistent. In addition, different cigarette brands may yield completely different nicotine and tar exposures. High consumption of alcohol often is not revealed by patients because of its social inacceptance. It therefore would help much to determine additional biomarkers such as serum gamma glutamyltransferase, which could be indicative of recent consumption of alcohol. Development of biomarkers which could indicate the exposure and the period of consumption would be more helpful.

In our control population, GSTP1 BB occurs in 13.6\%, and GSTP1 AB in $42.5 \%$. Our data for the healthy controls are in agreement with the genotype frequencies in the control populations reported by other researchers (9-14). Similar observations were found for the HNSCC group (12.3\% and $38.3 \%$ respectively).

Our data for HNSCC patients are also in agreement with several other studies performed. Lin et al. (14) found that polymorphisms in GSTP1 were not associated with increased risk for esophageal cancer. They even found a slightly lower occurrence of GSTP1 AB or BB genotypes in cancer and hyperplasia cases than in controls (14). Jourenkova et al. (32) and Matthias et al. (10) found no association between the GSTP1 AB or BB genotypes and risk of larynx cancer. Harries et al. (9) reported an association between occurrence of the GSTP1 polymorphism and susceptibility to bladder or testicular cancer, but found no association with breast or colon cancer. In other studies no association was found between the GSTP1 polymorphism and colorectal, lung or breast cancer $(33,34)$.

Several other studies, however, revealed a significant correlation between occurrence of GSTP1 polymorphisms and pre-neoplastic and neoplastic lesions. Lung cancer patients had a significantly higher frequency of GSTP1 BB genotype (15.9\%) and a lower frequency of GSTP1 AA genotype (38.4\%) than controls ( $9.1 \%$ and $51.5 \%$ respectively) (12). Homozygous GSTP1 BB was found significantly more often in patients with Barrett's esophagus and esophageal adenocarcinoma (35). Matthias et al. (10) have 
reported that the GSTP1 polymorphism influences susceptibility to pharyngeal but not to laryngeal squamous cell carcinoma. However, when comparing our patient groups in a similar way as Matthias et al. (10) (oral cavity/oropharyngeal SCC and hypopharyngeal SCC versus laryngeal SCC), we did not find a significant difference in the genotype distributions.

Ryberg et al. (12) reported that patients with the GSTP1 BB genotype had higher DNA adduct levels in lung tissue than the GSTP1 AA genotypes. They also found a linear trend between DNA adduct levels and occurrence rates of GSTP1 B genotypes.

The variant genotypes GSTP1 AB and GSTP1 BB showed a different specific activity and affinity for several electrophillic substrates but were identical in their affinity for glutathione $(7,15)$. The properties of the variant genotypes were conducted in "in vitro experiments" with recombinant proteins by Ali-Osman et al. (7), which however, does not necessarily provide adequate information on the enzymes and their reactions "in vivo." In agreement with the in vitro results, Watson et al. (13) and van Lieshout et al. (35) reported a significantly lower conjugating activity with 1-chloro-2,4-dinitrobenzene (CDNB) in lung and esophageal tissue samples, respectively, in patients with GSTP1 AB and GSTP1 BB compared to GSTP1 AA genotypes.

In summary, we found no evidence for a possible genetic predisposition to HNSCC due to a genetic polymorphism in the GSTP1 gene. This suggests that the carcinogens involved in the etiology of HNSCC may not be critically dependent on detoxification by the GSTP1-1 enzyme. Further studies on other combinations of polymorphic genotypes in detoxification enzymes and their relation to local and systemic enzyme concentration seem to be justified.

\section{References}

1. Pelkonen O, Nebert DW. Metabolism of polycyclic aromatic hydrocarbons: etiologic role in carcinogenesis. Pharmacol Rev 1982; 34: 189-222.

2. Mannervik B, Danielson UH. Glutathione transferases-structure and catalytic activity. CRC Crit Rev Biochem 1988; 23: 283-337.

3. Board P, Coggan M, Johnston P, Ross V, Suzuki T, Webb G. Genetic heterogeneity of the human glutathione transferases: a complex of gene families. Pharmacol Ther 1990; 48: 357-369.

4. Beckett GJ, Hayes JD. Glutathione S-transferases: biomedical applications. Adv Clin Chem 1993; 30: 281-380.

5. Hayes JD, Pulford DJ. The glutathione S-transferase supergene family: regulation of GST and the contribution of the isoenzymes to cancer chemoprotection and drug resistance. Crit Rev Biochem Mol Biol 1995; 30: 445-600.

6. Ahmad H, Wilson DE, Fritz RR, et al. Primary and secondary structural analyses of glutathione S-transferase pi from human placenta. Arch Biochem Biophys 1990; 278: $398-408$. 
7. Ali-Osman F, Akande O, Antoun G, Mao JX, Buolamwini J. Molecular cloning, characterization, and expression in Escherichia coli of full-length cDNAs of three human glutathione S-transferase $\mathrm{Pi}$ gene variants. Evidence for differential catalytic activity of the encoded proteins. J Biol Chem 1997; 272: 10004 . 10012.

8. Pemble S, Schroeder KR, Spencer SR, et al. Human glutathione S-transferase theta (GSTT1): cDNA cloning and the characterization of a genetic polymorphism. Biochem J 1994; 300: 271-276.

9. Harries LW, Stubbins MJ, Forman D, Howard GC, Wolf CR. Identification of genetic polymorphisms at the glutathione S- transferase $\mathrm{Pi}$ locus and association with susceptibility to bladder, testicular and prostate cancer. Carcinogenesis 1997; 18: 641-644.

10. Matthias C, Bockmuhl U, Jahnke V, et al. The glutathione S-transferase GSTP1 polymorphism: effects on susceptibility to oral/pharyngeal and laryngeal carcinomas. Pharmacogenetics 1998; 8: 1-6.

11. Morita S, Yano M, Tsujinaka T, et al. Genetic polymorphisms of drug-metabolizing enzymes and susceptibility to head-and-neck squamous-cell carcinoma. Int J Cancer 1999; 80: 685-688.

12. Ryberg D, Skaug V, Hewer A, et al. Genotypes of glutathione transferase M1 and P1 and their significance for lung DNA adduct levels and cancer risk. Carcinogenesis 1997; 18: 1285-1289.

13. Watson MA, Stewart RK, Smith GB, Massey TE, Bell DA. Human glutathione S-transferase P1 polymorphisms: relationship to lung tissue enzyme activity and population frequency distribution. Carcinogenesis 1998; 19: 275-280.

14. Lin DX, Tang YM, Peng Q, Lu SX, Ambrosone CB, Kadlubar FF. Susceptibility to esophageal cancer and genetic polymorphisms in glutathione S-transferases T1, P1, and M1 and cytochrome P450 2E1. Cancer Epidemiol Biomarkers Prev 1998; 7: 1013-1018.

15. Zimniak P, Nanduri B, Pikula S, et al. Naturally occurring human glutathione S-transferase GSTP1-1 isoforms with isoleucine and valine in position 104 differ in enzymic properties. Eur J Biochem 1994; 224: 893-899.

16. $\mathrm{Hu} X, \mathrm{O}^{\prime}$ Donnell R, Srivastava SK, et al. Active site architecture of polymorphic forms of human glutathione S- transferase P1-1 accounts for their enantioselectivity and disparate activity in the glutathione conjugation of 7 beta, 8alpha-dihydroxy-9alpha,10alpha-oxy-7,8,9,10-tetrahydrobenzo(a)pyrene. Biochem Biophys Res Commun 1997; 235: 424-428.

17. Peters WHM, Boon CEW, Roelofs HMJ, Wobbes T, Nagengast FM, Kremers PG. Expression of drug-metabolizing enzymes and P-170 glycoprotein in colorectal carcinoma and normal mucosa. Gastroenterology 192; 103: 448-455.

18. Katagiri A, Tomita Y, Nishiyama T, Kimura M, Sato S. Immunohistochemical detection of P-glycoprotein and GSTP1-1 in testis cancer. Br J Cancer 1993; 68: 125-129.

19. Tsuchida S, Sekine Y, Shineha R, Nishihira T, Sato K. Elevation of the placental glutathione S-transferase form (GST-pi) in tumor tissues and the levels in sera of patients with cancer. Cancer Res 1989; 49: 5225-5229.

20. Niitsu Y, Takahashi Y, Saito T, et al. Serum glutathione S-transferase-pi as a tumor marker for gastrointestinal malignancies. Cancer 1989; 63: 317-323. 
21. Hirata S, Odajima T, Kohama G, Ishigaki S, Niitsu Y. Significance of glutathione S-transferase-pi as a tumor marker in patients with oral cancer. Cancer 1992; 70: 2381-2387.

22. Tanita J, Tsuchida S, Hozawa J, Sato K. Expression of glutathione S-transferase-pi in human squamous cell carcinomas of the pharynx and larynx. Loss after radiation therapy. Cancer 1993; 72: 569-576.

23. Armstrong DK, Gordon GB, Hilton J, Streeper RT, Colvin OM, Davidson NE. Hepsulfam sensitivity in human breast cancer cell lines: the role of glutathione and glutathione S-transferase in resistance. Cancer Res 1992; 52: 1416-1421.

24. Awasthi S, Sharma R, Singhal SS, Herzog NK, Chaubey M, Awasthi YC. Modulation of cisplatin cytotoxicity by sulphasalazine. Br J Cancer 1994: 70: 190-194.

25. Cheng X, Kigawa J, Minagawa Y, et al. Glutathione S-transferase-pi expression and glutathione concentration in ovarian carcinoma before and after chemotherapy. Cancer 1997; 79: 521-527.

26. Gilbert L, Elwood $\sqcup$, Merino M, et al. A pilot study of pi-class glutathione S-transferase expression in breast cancer: correlation with estrogen receptor expression and prognosis in node-negative breast cancer. J Clin Oncol 1993; 11: 49-58.

27. Gaffey MJ, lezzoni JC. Meredith SD, et al. Cyclin D1 (PRAD1, CCND1) and glutathione S-transferase pi gene expression in head and neck squamous cell carcinoma. Hum Pathol 1995; 26: 1221-1226.

28. Russo D, Marie JP, Zhou DC, et al. Coexpression of anionic glutathione Stransferase (GST pi) and multidrug resistance (mdr1) genes in acute myeloid and lymphoid leukemias. Leukemia 1994; 8: 881-884.

29. Oude Ophuis MB, van Lieshout EMM, Roelofs HMJ, Peters WHM, Manni JJ. Glutathione S-transferase M1 and T1 and cytochrome P4501A1 polymorphisms in relation to the risk for benign and malignant head and neck lesions. Cancer 1998; 82: 936-943.

30. Mulder TPJ, Manni JJ, Roelofs HMJ, Peters WHM, Wiersma A. Glutathione S-transferases and glutathione in human head and neck cancer. Carcinogenesis 1995; 16: 619-624.

31 Kelders WPA, Oude Ophuis MB, Roelofs HMJ, Peters WHM, Manni JJ. The association between Glutathione S-transferase P1 genotype and plasma level in head and neck cancer. Laryngoscope 2002 ; 112: 462-467.

32. Jourenkova-Mironova N, Voho A, Bouchardy C, et al. Glutathione S-transferase GSTM3 and GSTP1 genotypes and larynx cancer risk. Cancer Epidemiol Biomarkers Prev 1999; 8: 185-188.

33. Harris MJ, Coggan M, Langton L, Wilson SR, Board PG. Polymorphism of the Pi class glutathione S-transferase in normal populations and cancer patients. Pharmacogenetics 1998; 8: 27-31.

34. Helzlsouer KJ, Selmin O, Huang HY, et al. Association between glutathione S-transferase M1, P1, and T1 genetic polymorphisms and development of breast cancer. J Natl Cancer Inst 1998; 90: 512-518.

35. van Lieshout EMM, Roelofs HMJ, Dekker S, et al. Polymorphic expression of the glutathione S-transferase P1 gene and its susceptibility to Barrett's esophagus and esophageal carcinoma. Cancer Res 1999; 59: 586-589. 


\section{CHAPTER}

THE ASSOCIATION BETWEEN GLUTATHIONE

S-TRANSFERASE P1 GENOTYPE AND PLASMA LEVEL IN PATIENTS WITH HEAD AND NECK CANCER

Willem PA Kelders ${ }^{1}$, Michael B Oude Ophuis ${ }^{1}$, Hennie MJ Roelofs ${ }^{2}$, Wilbert HM Peters ${ }^{2}$, Johannes J Manni ${ }^{1}$

${ }^{1}$ Dept. of Otorhinolaryngology, Head and Neck Surgery, University Hospital Maastricht, The Netherlands

${ }^{2}$ Dept. of Gastroenterology, University Medical Center Nijmegen, The Netherlands

Published in Laryngoscope 2001; 112: 462-465 


\section{Abstract}

Background Glutathione S-transferase P1 (GSTP1-1) is an important enzyme as it plays a major role in many detoxification reactions, including tobacco related metabolic products. GSTP1-1 is the most abundant of all GST enzymes in normal human head and neck epithelium, whereas it is overexpressed in head and neck malignancies. At least three different GSTP1 genotypes exist, $A A, A B$ and $B B$, the latter two which have been correlated with reduced enzyme activity. Many authors have studied the GSTP1 genotypes in relation to the risk for human head and neck squamous cell carcinoma (HNSCC). A correlation between GSTP1 genotype and GSTP1-1 enzyme plasma levels has not been made before.

Materials and Methods GSTP1 genotype and GSTP1-1 plasma levels were established in 87 HNSCC patients and 51 patients with benign head and neck lesions (BHNL) who served as controls.

Results For all GSTP1 genotypes ( $A A, A B$ and $B B$ ) in HNSCC patients the mean corresponding plasma GSTP1-1 values were significantly higher compared to the controls. There was no significant difference in the plasma GSTP1-1 levels between the different genotypes in HNSCC patients.

Conclusion There is no association between GSTP1 genotype and GSTP1-1 plasma levels in patients with head and neck cancer. 


\section{Introduction}

Squamous cell carcinoma of the head and neck region (HNSCC) is the 5th most common malignancy in the world. Most cases of HNSCC are associated with alcohol abuse or smoking of tobacco but only a small number of individuals do develop HNSCC. This suggests the influence of genetic components in the susceptibility to HNSCC. Some of the factors that could explain this difference in susceptibility may be the presence of polymorphisms in genes coding for enzymes involved in carcinogen metabolism, such as the glutathione S-transferase (GST) enzymes. GSTs remain a focal point for research because of their role as defense mechanism against xenobiotics such as polycyclic aromatic hydrocarbons (PAHs), which are an important class of carcinogens present in tobacco smoke (1). Most precarcinogens have to be activated by phase I enzymes such as cytochrome P450 1A1 (CYP1A1) to become a carcinogen in the form of reactive epoxide intermediates such as benzo[a]pyrene diol epoxide (BPDE) (1). These carcinogens subsequently may be detoxified by various phase II enzymes such as GST enzymes.

Human GSTs can be subdivided into five classes, Alpha (A), Mu (M), Pi (P), Theta (T) and Zeta (Z). Each class includes one or more isoenzymes. Glutathione S-transferase P1-1 (GSTP1-1) is a major enzyme in the detoxification of tobacco related metabolic products (2) and because it is quantitatively the most abundant GST enzyme in the human head and neck area (3), many researchers have tried to link its genotype to the risk for HNSCC (4-7).

Several genotypes of the GSTP1 gene have been described, one resulting in isoleucine versus valine amino acid substitution at position 104 in the corresponding enzyme (8). This 104 valine or GSTP1 B variant is homozygously present in $10 \%$ of the Caucasian population. Approximately $55 \%$ of the Caucasian population is homozygous for the 104 isoleucine or GSTP1 A allele, whereas approximately $35 \%$ is heterozygous, containing both alleles (Ile and Val).

Homozygosity for the wildtype GSTP1 A allele has been found in a lower incidence in patients with oral and pharyngeal carcinoma in a Caucasian population $(4,5)$, whereas a higher incidence of the GSTP1 A allele in pharyngeal and laryngeal cancer patients in a Japanese study has been described (6). Another study revealed no significant differences in GSTP1 genotypes in laryngeal cancer patients as compared to healthy control subjects (7). Our group found that genetic polymorphisms of GSTP1 are not associated with altered susceptibility to HNSCC (9).

GSTP1 genotypes and their possible influence on the risk of other forms of malignant and benign tumors have been evaluated in patients with lung cancer, where one study showed a significantly higher incidence of the GSTP1 BB genotype in the cancer group (1) whereas another study revealed no difference (10). In urogenital malignancies significantly higher incidence of the GSTP1 B genotype was found (11) whereas in gastrointestinal malignancies no higher incidence was found $(11,12)$. In the premalignant Barrett's esophagus, however, a higher incidence of the GSTP1 B genotype was demonstrated (14). In breast carcinoma a higher incidence of the GSTP1 B genotype was found as well (15). 
Since the GSTP1-1 enzyme was shown to be overexpressed in a wide variety of tumors (16), another field of interest is the relevance of plasma GSTP1-1 levels as tumor-marker in several categories of cancer patients (17-21). However, some arguments pleading against a role of GSTP1-1 as a plasma tumor marker in patients with HNSCC and gastrointestinal cancer were recently given by us $(22,23)$. We found significantly higher GSTP1-1 plasma levels in HNSCC patients as compared to a group of benign head and neck lesions (BHNL) as controls. However, only $14 \%$ of patients with HNSCC had plasma levels above the upper normal reference level of $21.8 \mu \mathrm{g} / \mathrm{L}$, which was estimated after analyzing samples of 230 healthy blood donors. In the past, several investigators have correlated GSTP1 genotype and GSTP1-1 tissue levels, e.g. in lung malignancies (24), in human placenta (25) and in Barrett's esophagus (14). They all found significant differences between the individual genotypes GSTP1 AA, AB and BB. An association between the GSTP1 genotype and GSTP1-1 plasma levels in patients with head and neck malignancies has however never been studied.

Since GSTP1-1 enzyme activity may be associated with GSTP1 genotype $(14,24,25)$, we now want to investigate whether patients with elevated GSTP1-1 plasma levels all belong to a certain GSTP1 genotype. Therefore we investigated whether one of the genotype subcategories differed significantly in mean GSTP1-1 plasma level. We also compared the mean plasma levels in 51 controls and 87 HNSCC patients in each of the three genotype subcategories (GSTP1 AA, $A B$ or $B B$ ).

\section{Materials and Methods}

A total of 138 patients were included preoperatively during their scheduled admission at the department of Otorhinolaryngology, Head and Neck Surgery of the University Hospital of Maastricht between 1995 and 1998. The group consisted of 51 patients with BHNL who served as controls [23 females (45\%) and 28 males (55\%)] and 87 patients with HNSCC [21 females $(24 \%)$ and 66 males $(76 \%)$ ], all with no previous history of cancer.

In the BHNL group the mean age was $49 \pm 18$ years, range $16-86$ years. In the HNSCC group the mean age was $58 \pm 12$ years, range $23-82$ years. All sites of tumor expression are given in Table 1.

Table 1. Site of tumor origin in HNSCC.

Site of tumor origin

Number of cases

\begin{tabular}{ll}
\hline Oral cavity & 25 \\
Oropharynx & 23 \\
Hypopharynx & 12 \\
Larynx & 27
\end{tabular}

Informed consent was obtained and medical and other anamnestic data were obtained by interview. The Medical Ethical Review Committee approved the investigations. 
Blood sampling

Approximately $3 \mathrm{ml}$ of blood was collected by venapuncture in vacuumed, siliconecoated, K3 EDTA-containing tubes (Vacutainer, Order No. 606601, Becton Dickinson, Grenoble, France). Immediately after collection, blood was gently mixed with the EDTA solution. Approximately $0.5 \mathrm{ml}$ of whole blood was stored at $-20^{\circ} \mathrm{C}$ for genotyping. The remaining was centrifuged for 10 minutes at $3000 \mathrm{Xg}$ at room temperature within 2 hours. The upper two-third of the plasma was collected, and care was taken not to aspirate the platelets on top of the cell layer. Plasma samples were stored at $-20^{\circ} \mathrm{C}$ until use.

\section{Assays}

GSTP1 genotyping

Genomic DNA was isolated from whole blood using the Wizard ${ }^{\text {TM }}$ genomic DNA purification kit, according to the instructions of the manufacturer (Promega, Madison Wisconsin, USA). Genetic polymorphisms in GSTP1 were detected by polymerase chain reaction-restriction fragment length polymorphism (PCR-RFLP) analysis, using a primer set (105F and 105R), designed so that the presence of the rare $B$ allele (valine) resulted in the appearance of an A/w261 restriction enzyme site according to Harries et al. (11). All primers were synthesized by Pharmacia Biotech (Roosendaal, the Netherlands). All chemicals needed for PCR were purchased from Promega.

\section{Plasma GSTP1-1 measurement}

Plasma GSTP1-1 levels were measured using a recently developed enzyme linked immunosorbent assay (ELISA) (23). Briefly, microtiter plates were coated overnight with purified anti-GSTP1-1 monoclonal antibody. One hundred $\mu \mathrm{L}$ of standard (0.4-100 $\mu \mathrm{g} / \mathrm{L}$ GSTP1-1), or 1:1 diluted, plasma samples were added to the wells and incubated overnight. The next day the plates were washed and incubated with rabbit anti-GSTP1-1 serum, washed again, and incubated with horseradish peroxidase-labeled swine anti-rabbit antibody; and after a final wash, plates were stained with O-phenylenediamine- $\mathrm{H}_{2} \mathrm{O}_{2}$. Standards and samples were measured in duplicate. A four-parameter weighted logistic regression model was used to calculate standard curves and unknowns. The assay had no cross-reactivity with GSTs of the Alpha or Mu

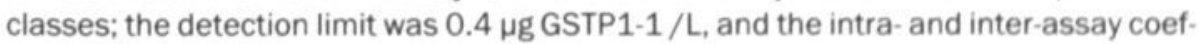
ficients of variation were $5.8 \%$ and $10.9 \%$, respectively.

\section{Statistical analysis}

For statistical analysis we used the statistical package SPSS for Windows 8.0. The statistical significance of differences between the individual means for the control and HNSCC groups for each genotype was tested with an independent t-test for equality of means. Possible unreliable variables were detected by the Cooks test.

The significance of the difference of means for the different genotypes in each category of disease (benign, malignant or total) was tested with a One-way Analysis of Variances, combined with a Levene's test for equality of variances and completed with Bonferroni and Tamhane post-hoc tests. 
The results of the assays and different comparative tests are shown in Tables 2-4.

The distribution of genotypes in the whole study group (HNSCC and BHNL controls) was 62 individuals (44.9\%) with the GSTP1 AA genotype, $56(40.6 \%)$ with the $A B$ genotype and $20(14.5 \%)$ with the $B B$ genotype. For the control group this was 26 individuals $(51.0 \%)$ with GSTP1 AA, $18(35.3 \%)$ with $A B$ and $7(13.7 \%)$ with the $B B$ genotype. For the HNSCC group the distribution was 36 individuals (41.4\%) with GSTP1 AA, 38 $(43.7 \%)$ with $A B$ and $13(14.9 \%)$ with the $B B$ genotype.

Table 2 shows the mean GSTP1-1 plasma levels according to GSTP1 genotype in the two study groups (HNSCC and controls). For all GSTP1 genotypes ( $A A, A B$ and $B B$ ) in HNSCC the mean and median values were higher as compared to corresponding controls. The highest mean values were observed in the heterozygotic GSTP1 AB groups in both study groups.

Table 2. Plasma GSTP1-1 levels.

\begin{tabular}{|c|c|c|c|c|c|c|c|}
\hline Group & $\begin{array}{l}\text { GSTP1 } \\
\text { Genotype }\end{array}$ & Mean* & $\mathrm{N}$ & $\mathrm{Sd}^{*}$ & Minimum* & Maximum * & Median* \\
\hline \multirow[t]{4}{*}{ Control } & $A A$ & 9.1 & 26 & 3.2 & 5.1 & 17.9 & 8.3 \\
\hline & $A B$ & 9.9 & 18 & 6.1 & 4.2 & 32.3 & 8.2 \\
\hline & $B B$ & 9.3 & 7 & 4.5 & 3.3 & 15.9 & 7.4 \\
\hline & Total & 9.4 & 51 & 4.5 & 3.3 & 32.3 & 8.2 \\
\hline \multirow[t]{4}{*}{ HNSCC } & $A A$ & 12.0 & 36 & 5.1 & 4.6 & 26.8 & 10.7 \\
\hline & $A B$ & 19.8 & 38 & 26.1 & 3.7 & 141.5 & 11.8 \\
\hline & $B B$ & 15.0 & 13 & 5.3 & 9.3 & 26.8 & 14.5 \\
\hline & Total & 15.9 & 87 & 17.9 & 3.7 & 141.5 & 11.2 \\
\hline \multirow[t]{4}{*}{ Total } & $A A$ & 10.8 & 62 & 4.6 & 4.6 & 26.8 & 9.5 \\
\hline & $A B$ & 16.6 & 56 & 22.1 & 3.7 & 141.5 & 10.0 \\
\hline & $B B$ & 13.0 & 20 & 5.6 & 3.3 & 26.8 & 12.8 \\
\hline & Total & 13.5 & 138 & 14.8 & 3.3 & 141.5 & 10.0 \\
\hline
\end{tabular}

* Values are given as $\mu \mathrm{g} / \mathrm{L}$.

$\mathrm{N}$ : number of subjects in each category.

Sd: standard deviation.

Table 3 shows the results of the independent samples t-tests in order to compare the mean GSTP1-1 plasma values in each genotype subgroup. When comparing the HNSCC to the control group for the GSTP1AA genotype, plasma GSTP1-1 values were significantly higher in the HNSCC-group (12.0 and $9.1 \mu \mathrm{g} / \mathrm{L}$ respectively, $\mathrm{p}=0.008$ ). A similar result was obtained for the $A B$ genotype, even when corrected for one abnormal high value $(141.5 \mu \mathrm{g} / \mathrm{L})$ which appeared unreliable according to Cook's test (19.8 vs. $9.9 \mu \mathrm{g} / \mathrm{L}, \mathrm{p}=0.031$ ). The GSTP1 BB genotype also showed a difference that was significant (15.0 vs. $9.3 \mu \mathrm{g} / \mathrm{L}, \mathrm{p}=0.028$ ). The difference in GSTP1-1 plasma values for the combined control and HNSCC groups was significant as well $(9.4 \mathrm{vs} .15 .9 \mu \mathrm{g} / \mathrm{L}$, $\mathrm{p}=0.002$ ). 


\begin{tabular}{ll} 
GSTP1 genotype & t-test \\
\hline$A A$ & 0.008 \\
$A B$ & 0.031 \\
$A B$, exclusion of highest value & 0.035 \\
$B B$ & 0.028 \\
Total & 0.002
\end{tabular}

(Difference in GSTP 1-1 plasma level between control and HNSCC for the different genotypes)

Table 4 shows the results of one-way analyses of variance to compare the mean GSTP1-1 plasma concentrations for the different genotypes in each study group. The difference between the mean plasma GSTP1-1 levels for each GSTP1 genotype in the control group was not significant $(9.1(A A) ; 9.9(A B)$ and $9.3 \mu \mathrm{g} / \mathrm{L}(B B)$ respectively, $\mathrm{p}=0.862)$. Neither was it for the HNSCC group (12.0; 19.9 and $15.0 \mu \mathrm{g} / \mathrm{L}, \mathrm{p}=0.170)$ and the total of both groups (both controls and HNSCC) $(10.8 ; 16.6$ and $13.0 \mu \mathrm{g} / \mathrm{L}$, $p=0.100$ ).

Table 4. Comparison of mean GSTP1-1 enzyme plasma levels for the different GSTP1 genotypes in the control and HNSCC population (One-way analysis of variances.)

\begin{tabular}{lr} 
Group & ANOVA \\
\hline Control & 0.862 \\
HNSCC & 0.170 \\
Total & 0.100
\end{tabular}

(Differences in mean GSTP1-1 plasma level between the genotypes in control. HNSCC and both)

\section{Discussion}

The purpose of this study was to evaluate the possible association between the genetic polymorphisms in the GSTP1 gene and the phenotypic expression (GSTP1-1 plasma levels) in patients with malignant head and neck tumors.

No previous studies have been performed on the correlation between GSTP1 genotype and GSTP1-1 plasma level. However, a correlation between enzyme function and GSTP1 genotype has been made before $(8,14,24,25)$. Ali-Osman et al. and Zimniak et al. have provided evidence of polymorphisms in the human GSTP1 gene locus, resulting in functionally different GSTP1-1 proteins $(8,25)$. Watson et al. and van Lieshout et al. found significant differences in GST enzyme conjugating activity between the GSTP1 $A A$ wildtype and the $A B$ and $B B$ genotypes in lung and esophageal tissues, respectively $(14,24)$.

We found no significant correlation between the different GSTP1 genotypes and the corresponding GSTP1-1 plasma levels. This was the case when the control- and HNSCC-groups were investigated separately and also when they were combined. This means that both in patients with HNSCC and controls, no direct relation was present 
between GSTP1 genotype and GSTP1-1 phenotype, as was found earlier in lung or esoephageal tissue of patients with corresponding lung or esophageal lesions $(14,24)$.

In a previous study on HNSCC we found that GSTP1-1 is not a plasma tumor marker for individual patients, despite the fact that median plasma levels in HNSCC were significantly higher as compared to controls, but only a small part of HNSCC patients had plasma levels elevated above the normal reference level of $21.8 \mu \mathrm{g} / \mathrm{L}$ (22).

When comparing HNSCC to controls, significantly different GSTP1-1 plasma levels were found for all GSTP1 genotype categories. These findings show that there is no difference in the influence of the genotypes on GSTP1-1 plasma levels between HNSCC and controls. The control group had a slightly higher percentage of GSTP1 AA genotypes than the HNSCC group (51.0\% vs. $41.4 \%)$ and a lower percentage of GSTP1 AB genotypes (35.3\% vs. $43.7 \%$ ). The clinical significance of this difference has to be investigated in a larger patient group.

Hirata et al. considered estimation of GSTP1-1 plasma levels a useful aid for early diagnosis, prediction of tumor extent and determining treatment efficacy and prognosis for oral cancer (17). We did not find arguments for such a role of GSTP1-1 for our HNSCC patients (22). The question is whether this difference can be explained by either methodological, racial or demographic factors or by the fact that Hirata et al. limited their investigation to oral cancers (17). Another explanation could be that the Japanese and Dutch patient groups investigated have a different distribution of GSTP1 genotypes. The GSTP1 frequency distribution in the Dutch population is $55 \%$ for GSTP1 AA, 35\% for GSTP1 AB and 10\% for the GSTP1 BB genotype. Hirata et al. (17) give no data on the genotype distribution, but another Japanese study by Morita et al. (6) indicates a frequency distribution of $69 \%$ for GSTP $1 A A, 29 \%$ for the $A B$ and $2 \%$ for the $B B$ genotype, which indeed differs considerably as compared to corresponding data in our Dutch population.

We conclude that there is no clear association between GSTP1 genotype and GSTP1-1 phenotypic expression in the form of plasma levels in patients with head and neck lesions as was found previously for GST enzyme activity in tissues of patients with lung cancer (24) or Barrett's esophagus (14). Perhaps further investigation of the corresponding GSTP1-1 tissue enzyme activity in head and neck patients will reveal such a correlation.

\section{References}

1. Ryberg D, Skaug V, Hewer A, et al. Genotypes of glutathione transferase M1 and P1 and their significance for lung DNA adduct levels and cancer risk. Carcinogenesis 1997;18:1285-9.

2. Hayes JD, Pulford DJ. The glutathione S-transferase supergene family: regulation of GST and the contribution of the isoenzymes to cancer chemoprotection and drug resistance. Crit Rev Biochem Mol Biol 1995;30:445-600. 
3. Mulder TPJ, Manni JJ, Roelofs HMJ, Peters WHM, Wiersma A. Glutathione Stransferases and glutathione in human head and neck cancer. Carcinogenesis 1995;16:619-24.

4. Matthias C, Bockmuhl U, Jahnke V, et al. The glutathione S-transferase GSTP1 polymorphism: effects on susceptibility to oral/pharyngeal and laryngeal carcinomas. Pharmacogenetics 1998;8:1-6.

5. Jahnke V, Matthias C, Bockmuhl U, Strange RC. Genetische Prädisposition für die Entstehung von Kopf- und Hals- karzinomen. Laryngo-Rhino-Otologie 1999; 78:24-7.

6. Morita S, Yano M, Tsujinaka T, et al. Genetic polymorphisms of drug-metabolizing enzymes and susceptibility to head and neck squamous cell carcinoma. Int J Cancer 1999;80:685-8.

7. Jourenkova-Mironova N, Voho A, Bouchardy C, et al. Glutathione S-transferase GSTM3 and GSTP1 genotypes and larynx cancer risk. Cancer Epidemiol Biomarkers Prev 1999;8:185-8.

8. Ali-Osman F, Akande O, Antoun G, Mao JX, Buolamwini J. Molecular cloning, characterization, and expression in Escherichia coli of full-length cDNAs of three human glutathione S-transferase $\mathrm{Pi}$ gene variants. Evidence for differential catalytic activity of the encoded proteins. J Biol Chem 1997;272:10004-12.

9. Oude Ophuis MB, Roelofs HMJ, van den Brandt PA, Peters WHM, Manni JJ. Polymorphisms of the glutathione S-transferase P1 gene and head and neck cancer susceptibility. Head and Neck 2003;25:37-43.

10. Saarikoski ST, Voho A, Reinikainen M, et al. Combined effect of polymorphic GST genes on individual susceptibility to lung cancer. Int J Cancer 1998;77:516-21.

11. Harries LW, Stubbins MJ, Forman D, Howard GC, Wolf CR. Identification of genetic polymorphisms at the glutathione S- transferase $\mathrm{Pi}$ locus and association with susceptibility to bladder, testicular and prostate cancer. Carcinogenesis 1997;18:641-4.

12. Morita S, Yano M, Shiozaki H, et al. CYP1A1, CYP2E1 and GSTM1 polymorphisms are not associated with susceptibility to squamous-cell carcinoma of the esophagus. Int J Cancer 1997;71:192-5.

13. Lin DX, Tang YM, Peng Q, Lu SX, Ambrosone CB, Kadlubar FF. Susceptibility to esophageal cancer and genetic polymorphisms in glutathione S-transferases T1, P1, and M1 and cytochrome P450 2E1. Cancer Epidemiol Biomarkers Prev 1998;7:1013-8.

14. van Lieshout EMM, Roelofs HMJ, Dekker S, et al. Polymorphic expression of the glutathione S-transferase P1 gene and its susceptibility to Barrett's esophagus and esophageal carcinoma. Cancer Res 1999;59:586-9.

15. Helzlsouer KJ, Selmin O, Huang HY, et al. Association between glutathione S-transferase M1, P1, and T1 genetic polymorphisms and development of breast cancer. J Natl Cancer Inst 1998;90:512-8.

16. Tsuchida S and Sato K. Glutahione transferases and cancer. Crit Revs Biochem Mol Biol 1992; 27:337-384.

17. Hirata S, Odajima T, Kohama G, Ishigaki S, Niitsu Y. Significance of glutathione S-transferase-pi as a tumor marker in patients with oral cancer. Cancer 1992; 70:2381-7.

18. Nitsu Y, Takahashi Y, Saito T, et al. Serum glutathione S-transferase-pi as a tumor marker for gastrointestinal malignancies. Cancer 1989;63:317-23. 
19. Hida T, Kuwabara M, Ariyoshi Y, et al. Serum glutathione S-transferase-pi level as a tumor marker for non-small cell lung cancer. Potential predictive value in chemotherapeutic response. Cancer 1994;73:1377-82.

20. Lee WH, Morton RA, Epstein Jl, et al. Cytidine methylation of regulatory sequences near the pi-class glutathione S-transferase gene accompanies human prostatic carcinogenesis. Proc Natl Acad Sci USA 1994;91:11733-7.

21. Veneroni S, Silvestrini R, Costa A, Salvatori P, Faranda A, Molinari R. Biological indicators of survival in patients treated by surgery for squamous cell carcinoma of the oral cavity and oropharynx. Oral Oncol 1997;33:408-13.

22. Oude Ophuis MB, Mulder TPJ, Peters WHM, Manni JJ. Plasma glutathione S-transferase P1-1 levels in patients with head and neck squamous cell carcinoma. Cancer 1998;82:2434-8.

23. Mulder TPJ, Peters WHM, Wobbes T, Witteman BJM, Jansen JBMJ. Measurement of glutathione S-transferase P1-1 in plasma: pitfalls and significance of screening and follow-up of patients with gastrointestinal carcinoma. Cancer 1997;80: 873-80.

24. Watson MA, Stewart RK, Smith GB, Massey TE, Bell DA. Human glutathione S-transferase $\mathrm{P} 1$ polymorphisms: relationship to lung tissue enzyme activity and population frequency distribution. Carcinogenesis 1998;19:275-80.

25. Zimniak P, Nanduri B, Pikula S, et al. Naturally occurring human glutathione S-transferase GSTP1-1 isoforms with isoleucine and valine in position 104 differ in enzymic properties. Eur J Biochem 1994;224:893-9. 


\section{CHAPTER}

\section{MULTIPLE GENETIC POLYMORPHISMS IN DETOXIFICATION ENZYMES AND HEAD AND NECK CANCER SUSCEPTIBILITY}

Michael B Oude Ophuis ${ }^{1}$, Johannes J Manni ${ }^{1}$, Wilbert HM Peters ${ }^{2}$

${ }^{1}$ Dept. of Otorhinolaryngology, Head and Neck Surgery, University Hospital Maastricht, The Netherlands

${ }^{2}$ Dept. of Gastroenterology, University Medical Center Nijmegen, The Netherlands 


\section{Abstract}

Background Genetic polymorphisms in single biotransformation enzymes may modulate the risk for head and neck squamous cell carcinoma (HNSCC). A pilot study evaluating the effect of combined polymorphisms in the glutathione S-transferase (GST) or the epoxide hydrolase $(E P H X)$ genes was performed in order to determine whether such a combination of polymorphisms influences the risk for HNSCC.

Materials and Methods Genotyping by PCR or PCR-RFLP of the GSTM1 and GSTT1 null polymorphisms, the GSTP1 B variant and the Tyr 113 His variant of exon-3 of EPHX was successfully performed from 225 patients with HNSCC and 266 healthy controls, recruited at the University Hospital Maastricht.

Results An analysis on the simultaneous occurrence of multiple polymorphisms in any of the genes described above, without adjusting for age, gender, smoking or alcohol consumption, revealed no statistical differences between patients with HNSCC and healthy controls.

Conclusion A combination of multiple polymorphisms in the GST and EPHX genes is not associated with a higher susceptibility for HNSCC. 
The risk of head and neck squamous cell carcinoma (HNSCC) is strongly associated with smoking of tobacco and consumption of alcohol (1), which may be responsible for a considerable load of (pre)carcinogens. Metabolism and detoxification of such exogenous harmful compounds often occurs by phase I and phase II enzymes such as epoxide hydrolase (EPHX) and glutathione S-transferase (GST).

Because genetic polymorphisms exist in glutathione S-transferase GSTM1, GSTT1, GSTP1 and EPHX, which may lead to complete absence of (GSTM1 and GSTT1) or partially deficient (GSTP1 and EPHX) corresponding enzyme activity, individuals bearing such genetic polymorphisms and therefore lack of a (partially) functional enzyme, may be at a higher risk of developing tobacco and alcohol related cancers (2-4). We have earlier investigated involvement of single polymorphisms in biotransformation enzymes in modulation of HNSCC risk (2-4) and found that the GSTT1 null genotype may modulate the risk of head and neck cancer (HNSCC) (Chapter 3). Reports in the literature are very conflicting on the significance of GST polymorphisms in HNSCC susceptibility (5-12). Possibly, this is due to: 1 . the relatively small patient and control study groups in most papers, 2. insufficient matching of patients and controls, and 3. the use of different methods for genotyping between the various research groups and sometimes even within the same study.

Since chemical modification of compounds to be detoxified is very complex and often requires several subsequent chemical reactions catalyzed by several different enzymes, we evaluated whether the simultaneous lack or dysfunction of one or more GST and EPHX enzymes as a result of a polymorphism in the corresponding gene, may influence the susceptibility for HNSCC.

\section{Materials and Methods}

Data and results of GST and EPHX genotyping obtained by polymerase chain reaction method (PCR) in material collected from HNSCC patients and healthy blood donors from earlier studies was used $(2-4,13)$. The PCR methods for genotyping of GSTM1, GSTT1, GSTP1 are described in detail in our earlier studies (Chapters 2, 3 and 5) $(2-4,13)$. The PCR method for EPHX is described in detail by Zusterzeel et al. (14) and will be briefly described below. The polymorphism Tyr 113 His in exon 3 was examined. DNA samples were amplified by PCR. The PCR mixture contained approximately $100 \mathrm{ng}$ of genomic DNA, $50 \mathrm{mM} \mathrm{KCl}, 10 \mathrm{mM}$ Tris $\mathrm{HCl}$ pH 8.0, 2 mM MgCl $2,1.5$ u Taq polymerase, and $1 \mu \mathrm{M}$ of amplification primers in a total volume of $50 \mu \mathrm{L}$. Denaturing of DNA during 5 min at $94^{\circ} \mathrm{C}$. Thirty amplification cycles. PCR product digestion with Tht111 and run on $3 \%$ agarose gel. Identification of 113 His by 2 DNA bands (209 and 22 base pairs), and detection of $113 \mathrm{Tyr}$ by an undigested DNA band of 231 base pairs.

Chi square and Odds Ratio (OR) analysis was made to compare polymorphisms of one or more of these genes in 225 patients with head and neck squamous cell carcinoma (HNSCC) and 266 healthy controls. Statistical analysis was performed by using SPSS 8.0 software. 


\section{Results}

In patients as well as in controls, an analysis on the number of genetic polymorphisms $(0-4)$ in GST or EPHX, co-occurring in the same individual was performed. The results are shown in Table 1. As the Odds Ratios clearly show, no significant difference is found between the group of HNSCC patients and the healthy controls with respect to the co-occurrence of $0-4$ different genetic polymorphisms in the detoxification enzymes studied here.

Table 1. Number of genetic polymorphisms in GSTM1, GSTT1, GSTP1 or EPHX in patients with HNSCC and healthy controls

$\begin{array}{llll}\text { Polymorphisms } & \text { HNSCC } & \text { Controls } & \text { Odds Ratio } \\ \mathrm{N}=225(\%) & \mathrm{N}=266(\%) & \\ \text { OR }(\mathrm{Cl} 95 \%)\end{array}$

\section{Discussion}

Tobacco smoke may contain a considerable number of carcinogens, and the metabolism of each carcinogen may be very complex, involving the interaction of several biotransformation enzymes, such as cytochrome P450, epoxide hydrolase, glutathione S-transferases and many others. In the studies we have performed so far, we have not found evidence that single genetic polymorphisms in CYP or GSTs are major modulators for the risk for head and neck cancer. Individually however, these metabolic polymorphisms may be very weak risk factors, explaining also the variable result in the literature. But in combination with other polymorphisms, which each confer a very small risk, the sum up of those small risk factors may become large enough to be visible. However, we found no evidence in our study for such a sum up effect of the four polymorphisms investigated here.

We conclude that co-occurrence of up to four different polymorphisms in the GST and EPHX genes are not associated with a higher susceptibility for HNSCC. The results of this pilot study remain in agreement with the results presented in the other chapters, since no effect at all or only a slightly protective effect of the GSTT1 null genotype was found. DNA mapping and evolving techniques may create new possibilities for the simultaneous investigation of many polymorphisms in biotransformation enzymes in the near future.

\section{References}

1. Blot WJ, McLaughlin JK, Winn DM, et al. Smoking and drinking in relation to oral and pharyngeal cancer. Cancer Res 1988;48:3282-3287. 
2. Oude Ophuis MB, van Lieshout EMM, Roelofs HMJ, Peters WHM, Manni JJ. Glutathione S-transferase M1 and T1 and cytochrome P4501A1 polymorphisms in relation to the risk for benign and malignant head and neck lesions. Cancer 1998;82:936-943.

3. Oude Ophuis MB, Roelofs HMJ, van den Brandt PA, Peters WHM, Manni JJ. Polymorphisms of the glutathione S-transferase P1 gene and Head and Neck cancer susceptibility. Head and Neck 2003;25:37-43.

4. Kelders WPA, Oude Ophuis MB, Roelofs HMJ, Peters WHM, Manni JJ. The association between glutathione S-transferase P1 genotype and plasma level in head and neck cancer. Laryngoscope 2002;112:462-466.

5. Jourenkova-Mironova N, Voho A, Bouchardy C, et al. Glutathione S-transferase GSTM1, GSTM3, GSTP1 and GSTT1 genotypes and the risk of smoking-related oral and pharyngeal cancers. Int J Cancer 1999;81:44-48.

6. Jourenkova N, Reinikainen M, Bouchardy C, Dayer P, Benhamou S, Hirvonen A. Larynx cancer risk in relation to glutathione S-transferase M1 and T1 genotypes and tobacco smoking. Cancer Epidemiol Biomarkers Prev 1998;7:19-23.

7. Jahnke V, Strange R, Matthias C, Fryer AA. Erste Ergebnisse über Glutathion-STransferase GSTM1 und GSTT1 Genotypen und die genetische Prådisposition beim Larynxkarzinom. Laryngorhinootologie 1995;74:691-694.

8. Matthias C, Bockmuhl U, Jahnke V, et al. Polymorphism in cytochrome P450 CYP2D6, CYP1A1, CYP2E1 and glutathione S-transferase, GSTM1, GSTM3, GSTT1 and susceptibility to tobacco- related cancers: studies in upper aerodigestive tract cancers. Pharmacogenetics 1998;8:91-100.

9. Kihara M, Kihara M, Kubota A, Furukawa M, Kimura H. GSTM1 gene polymorphism as a possible marker for susceptibility to head and neck cancers among Japanese smokers. Cancer Lett 1997;112:257-262.

10. Sato M, Sato T, Izumo T, Amagasa T. Genetic polymorphism of drug-metabolizing enzymes and susceptibility to oral cancer. Carcinogenesis 1999:20:1927-1931.

11. Sreelekha T, Ramadas K, Pandey M, Thomas G, Nalinakumari KR, Pillai MR. Genetic polymorphism of CYP1A1, GSTM1 and GSTT1 genes in Indian oral cancer. Oral Oncol 2001;37:593-598.

12. Trizna Z, Clayman GL, Spitz MR, Briggs KL, Goepfert H. Glutathione S-transferase genotypes as risk factors for head and neck cancer. Am J Surg 1995;170: 499-501.

13. Oude Ophuis MB, Mulder TP, Peters WHM, Manni JJ. Plasma glutathione S-transferase P1-1 levels in patients with head and neck squamous cell carcinoma. Cancer 1998;82:2434-2438.

14. Zusterzeel PLM, Peters WHM, Visser W, Hermsen KJM, Roelofs HMJ, Steegers EAP. A polymorphism in the gene of microsomal epoxide hydrolase is associated with preeclampsia. J Med Genet 2001; 38: 234-237. 


\section{CHAPTER}

\section{META- AND POOLED ANALYSES OF GSTM1, GSTT1, GSTP1, CYP1A1 POLYMORPHISMS AND RISK OF HEAD AND NECK CANCERS}

Mia Hashibe ${ }^{1}$, Paul Brennan ${ }^{1}$, Richard C Strange ${ }^{2}$, Rajani Bhisey ${ }^{3}$, Ingolf Cascorbi ${ }^{4}$, Philip Lazarus ${ }^{5}$, Michael B Oude Ophuis ${ }^{6}$, Simone Benhamou ${ }^{7}$, William D Foulkes ${ }^{8}$, Takahiko Katoh ${ }^{9}$, Christiane Coutelle $^{10}$, Marjorie Romkes ${ }^{11}$, Laura Gaspari ${ }^{12}$, Emanuela Taioli ${ }^{12}$, Paolo Boffetta ${ }^{1}$.

${ }^{1}$ International Agency for Research on Cancer, Lyon, France

${ }^{2}$ Keele University, Staffordshire, UK

${ }^{3}$ Cancer Research Institute, Mumbai, India

${ }^{4}$ University of Greifswald, Germany

${ }^{5}$ Temple University, Philadelphia, Pennsylvania, USA

${ }^{6}$ University of Maastricht, The Netherlands

${ }^{7}$ INSERM-Evry University, Evry, France

${ }^{8}$ McGill University, Montreal, Quebec, Canada

${ }^{9}$ Miyazaki Medical College, Miyazaki, Japan

${ }^{10}$ Université de Bordeaux, Bordeaux, France

${ }^{11}$ University of Pittsburgh, Pennsylvania, USA

${ }^{12}$ Ospedale Maggiore, Milan, Italy

Submitted for publication 
Background Variants in genes coding for phase I and II enzymes such as the cytochrome P450 (CYP) family and glutathione S-transferases (GST) may alter individual susceptibility to cancer. GSTM1, GSTT1, GSTP1 and CYP1A1 polymorphisms may be associated with head and neck cancers though evidence from previous studies has not been consistent.

Materials and Methods We conducted a meta-analysis of 30 published case-control studies on these polymorphisms including 4,286 head and neck cancer cases and 5,440 controls. Subsequently, in a pooled analysis of original data from 9 published and 2 unpublished case control studies ( 2,324 cases and 2,766 controls), we explored the same associations as well as potential gene-gene and gene-environment interactions.

Results The summary Odds Ratios from the meta-analysis were $1.24(95 \% \mathrm{Cl}=1.11$, 1.38) for the GSTM1 null genotype, $1.20(95 \% \mathrm{Cl}=1.00,1.44)$ for the GSTT1 null genotype, $1.10(95 \% \mathrm{Cl}=0.92,1.31)$ for the valine genotype of the GSTP1 polymorphism at codon 104 and $1.27(95 \% \mathrm{Cl}=0.99,1.63)$ for the valine genotype of the CYP1A1 polymorphism at exon 7. Sources of heterogeneity included sample size, geographic region, year of publication and matching status. The results of the pooled analysis also supported an association of the GSTM1 null genotype $(O R=1.32,95 \% \mathrm{Cl}=1.07,1.62)$ and GSTT1 null genotype $(\mathrm{OR}=1.35,95 \% \mathrm{Cl}=1.13,1.61)$ with head and neck cancers. An association was suggested for multiple GST genotypes and head and neck cancer risk.

Conclusion Our meta analysis results support the concept of a moderate association of GSTM1, GSTT1, CYP1A1 polymorphisms and the risk of head and neck cancers. 
The study of low penetrance genes in head and neck cancers is of importance since even low risk genes can be a substantial public health burden when the polymorphism is common (1). Variants in genes coding for phase I and phase II enzymes such as the cytochrome P450 (CYP) and glutathione S-transferases (GST) families may potentially alter individual susceptibility to cancer. Several studies have been conducted on potential genetic risk factors for head and neck cancer and a recent review on GSTM1 and GSTT1 polymorphisms summarized the results of case-control studies as inconclusive (2). Of the 21 studies reviewed for the GSTM1 null genotype, 13 studies reported ORs between 0.9 and 1.3, while 8 studies reported ORs between 1.4 and 3.9 (2). For the GSTT1 null genotype, 8 studies reported ORs from 0.5 to 1.2, while 6 reported ORs from 1.4 to 2.6 (2). Since these metabolic enzymes may be among numerous genes involved in the multistage pathway of cancer, they are expected to be low to moderate risk factors that may be difficult to detect. However, even a moderate effect on cancer risk would be of biological and medical importance because of the possibility of identifying high risk individuals for target prevention activities.

Tobacco smoke contains a range of different carcinogens including polycyclic aromatic hydrocarbons (PAH), aromatic amines and nitrosamines (3). The amount of carcinogenic exposure to the upper aerodigestive tract will depend on whether the carcinogen is activated by phase I enzymes and whether it is detoxified by phase II enzymes. Variants in genes coding for these enzymes may therefore alter the individual's exposure to tobacco carcinogens. The CYP1A1 gene codes for a phase I enzyme that activates tobacco procarcinogens such as benzo[a]pyrene and aromatic amines, into their carcinogenic forms (4). A point mutation in CYP1A1 exon 7, resulting in an amino acid replacement of isoleucine by valine in codon 462 , which is strongly linked to $3801 \mathrm{~T}>\mathrm{C}$ in the $3^{\prime}$-flanking region, was repcrted to be associated with increased enzyme activity $(5,6)$. The variant genotype is suggested to be harmful possibly by increasing carcinogen activation and generating reactive oxygen species (7). Moreover, smokers with the CYP1A1 variant polymorphism were shown to have elevated DNA adduct levels (8).

The GST family includes phase II enzymes that detoxify carcinogens and reactive oxygen species (9). Individuals who have homozygous deletions for the GSTM1 and T1 gene have no GSTM1-1 and T1-1 enzyme activity. Lack of these enzymes may potentially increase cancer susceptibility because of a decreased ability to detoxify carcinogens such as benzo[a]pyrene-7,8-diol epoxide, the activated form of benzo[a]pyrene. The GSTP1 polymorphism at codon 104 results in the replacement of isoleucine by valine due to an $A \rightarrow G$ transition. The valine variant of the GSTP1 polymorphism may be 2-3 times less stable (10) and may be associated with a higher level of DNA adducts (11).

The previous review on GSTM1, GSTT1 and head and neck cancer included papers written in English and published between $1993-2000$ (2). Since papers on 12 additional study populations not included in the review are available (12-23), we conducted an updated meta-analysis of head and neck cancer case-control studies on GSTM1, GSTT1, and additionally on GSTP1, CYP1A1 to assess whether the available evidence supports an association and to determine the sources of heterogeneity 
among the study results. In addition, we pooled the raw dataset from 11 case-control studies on these metabolic genes and head and neck cancer, to explore the main effect of the genes, as well as gene-gene and gene-environment interactions.

\section{Materials and Methods}

\section{Meta-Analysis}

A MedLine search was conducted for case-control studies reported up to March 2003 of GSTM1, GSTT1, GSTP1 and CYP1A1 on the risk of head and neck cancer, including oral, pharyngeal and laryngeal cancers. We focused on the null polymorphism of the GSTM1 and GSTT1 genes, the Ile104Val polymorphism of the GSTP1 gene, and the Ile462Val polymorphism of the CYP1A1 gene. The following keywords for genotypes were used in the MedLine search: "Glutathione," "GSTM1," "GSTT1," "GSTP1" and "CYP1A1." In addition, we reviewed the literature cited by each of the papers that we identified. A total of 36 publications were identified including 30 different populations (12-48).

We focused on studies that genotyped individuals for the polymorphisms by PCR (polymerase chain reaction) and excluded 23 studies that assessed gene expression via measurement of protein levels. Positive controls for the GSTM1 and GSTT1 genotyping were mentioned for the majority of studies. GSTP1 was genotyped in all studies by RFLP (Restriction Fragment Length Polymorphism)-PCR. For CYP1A1 genotyping, 3 studies used allele specific PCR $(14,33,46), 1$ study used PCR-SSCP (single-strand conformational polymorphism)(43) and the other studies used RFLP-PCR. When several papers were identified for the same population, we referred to the most updated information source. Studies that did not report Odds Ratios (ORs) and 95\% confidence intervals (Cls) and did not provide enough data to estimate crude ORs were excluded (49-51).

For each study we abstracted the date of publication, the country where the study was conducted, the organs within the head and neck cancer studied, the control source (hospital, hospital-healthy, population-based or mixed), the number of cases and controls, and whether controls were matched to cases (matching, frequency matching, no matching). Healthy subjects recruited from hospitals as controls were categorized as 'hospital-healthy.'

\section{Statistical Analysis}

We abstracted crude Odds Ratios (ORs) from the studies when available. We calculated for each study, crude ORs and $95 \%$ Cls when the study: 1) did not estimate the OR but presented enough data for estimation, 2) reported an OR adjusted for various factors, 3) reported only ORs stratified by factors such as race or site. For a study from France, we combined the data for cancers of the oral cavity, pharynx and larynx that had been presented in separate publications (30-32).

When both the data and crude ORs were presented, we checked the calculation for the crude ORs and $95 \% \mathrm{Cls}$. In the case of discrepancy (22), we retained the crude OR that we calculated, since the OR presented in the original publication may have been ad- 
justed for some factors. We did not perform a meta-analysis of the adjusted ORs because adjustment was not comparable among the studies. For the GSTP1 and the CYP1A1 polymorphisms, we combined the heterozygous and homozygous polymorphisms due to the limited number of subjects who were homozygous mutant.

Whenever possible we estimated or extracted study-specific ORs separately by organ within the head and neck (oral cavity, pharynx, larynx), and by smoking status (never, ever smokers). For 4 studies, we were unable to separate cancer cases of the nasopharynx, nasal cavity, sinus or salivary gland from other head and neck cancers $(28,36,39,42)$. The histology of head and neck cancer cases was squamous cell carcinoma (SCC) in most studies, but 2 studies $(22,29)$ did not specify the histology and one study (36) included 20 out of 156 cases with "other miscellaneous histologies."

Summary ORs were estimated with the statistical program STATA by inverse-variance weighting, using a random effects model that includes a term for heterogeneity between studies (52). Tests for heterogeneity between the studies were conducted for each analysis. Publication bias was assessed with Begg's funnel plots (53) and Egger's regression asymmetry test (54).

We conducted an influence analysis, where each study was excluded one at a time to determine the magnitude of influence on the summary estimate. We excluded several studies that appeared to be less consistent with the other studies in order to ensure that a few studies were not responsible for excessively influencing the summary estimate. We also excluded some studies that resulted in asymmetry in Begg's funnel plot, in an attempt to minimize publication bias. Both summary estimates including all studies identified and excluding several studies were presented.

Summary ORs were presented by specific organs within the head and neck and by smoking status. The meta-analysis was also stratified by geographic region (Asia, North America, Europe), period of publication (1995-1999, 2000-2002), number of subjects ( $<100$ cases or $<100$ controls, $\geq 100$ cases $\& \geq 100$ controls), matching of cases and controls (matched, frequency matched, not matched), and control source (hospital, hospital-healthy or population based). Summary ORs were estimated when there were at least 3 risk estimates available.

\section{Pooled Analysis}

The data on GSTM1, GSTT1, GSTP1, CYP1A1 and head and neck cancers for the pooled analysis was extracted from the International Collaborative Study on Genetic Susceptibility to Environmental Carcinogens (GSEC) database $(55,56)$, which contains individual level data from case-control studies on genes that metabolize environmental carcinogens. Investigators who had published their results from case-control studies on genetic polymorphisms and cancers were identified through a MedLine search and requested to provide published and unpublished original data from their studies. Our data included 11 case-control studies, of which 9 had been published and included in the meta-analysis $(12,25,26,28,30-32,34,35,37,38,42-45)$. Cases of cancer of the nasopharynx, maxillary sinus and salivary glands were excluded from the analysis. Of the 2,324 head and neck cancer cases included in the analysis, there were 840 oral cavity cancers, 501 pharyngeal cancers, 904 laryngeal cancers and 79 
cases with cancer at an unspecified organ within the head and neck. The control group included 2,766 subjects.

\section{Statistical Analysis}

In order to assess the association of the polymorphisms with head and neck cancer, the logistic regression model was used to estimate study-specific ORs and their $95 \%$ $\mathrm{Cls}$. We estimated a crude OR and an OR adjusted for age, sex and race for each study. In the case of GSTP1 and CYP1A1, we combined heterozygous and homozygous mutant genotypes for consistency with the meta-analysis approach. ORs estimated for individual studies and numbers of cases and controls may not precisely match those reported in the publications. Heterogeneity between studies was assessed with the test for heterogeneity while publication bias was assessed with the Begg's funnel plots (53) and Egger's regression asymmetry test (54). A summary OR was estimated by inverse-variance weighting, with the random effects model because of the heterogeneity detected among studies (52). Studies identified from the influence analysis and Begg's funnel plots were excluded in an attempt to minimize bias. Stratified analysis was conducted by cancer site and smoking status, as well as for Caucasians and cases with squamous cell carcinoma only. In the pooled analysis, we did not assess the effect of study characteristics due to the small number of studies available.

\section{Results}

Study-specific crude ORs and overall summary ORs from the meta-analysis of GSTM1, GSTT1, GSTP1, CYP1A1 polymorphisms are shown in table 1 . The distribution of the 4 polymorphisms among the head and neck cancer cases and controls from the 30 populations are presented in table 2. The frequency of the genotypes varied between geographic regions among controls: $24.7-57.8 \%$ for the GSTM1 null, $8.3-52.8 \%$ for GSTT1 null, 23.8 - $64.6 \%$ for the GSTP1 valine genotype and $5.8-39.5 \%$ for the CYP1A1 valine genotype. The percentage of Caucasians in the U.S. studies were: $88.9 \%$ in cases and $87.9 \%$ in controls (24), 95.6\% in cases and $93.3 \%$ in controls (39), $62 \%$ in cases and $86 \%$ in controls (41), $100 \%$ in cases and controls (43), $66.2 \%$ in cases and $67.3 \%$ in controls (44), $61.5 \%$ in cases and controls (45), or not specified $(15,48)$.

In the meta-analysis of the GSTM1 polymorphism, 29 studies were identified with a total of 4,096 cases and 5,146 controls (Table 1 , Figure 1). The overall summary OR was $1.36(95 \% \mathrm{Cl}=1.17,1.58)$ when adjusted for study center (Table 3$)$. Two studies were excluded as they were less consistent with the other studies $(12,17)$ and 4 studies were excluded to minimize the publication bias suggested by the funnel plot shown in Figure $2(15,18,20,25)$. These 4 studies were of a small sample size and had all identified a strong positive association. In the final model including 23 studies $(3,407$ cases $\& 4,373$ controls), the OR for the GSTM1 null genotype was $1.24(95 \% \mathrm{Cl}=1.11,1.38)$ and it was particularly high for oral cavity cancer and among ever smokers. The ORs for the GSTM1 null genotype was higher for studies with smaller sample sizes than for larger studies $(p=0.072)$. Differences between ORs in other strata were not identified. 


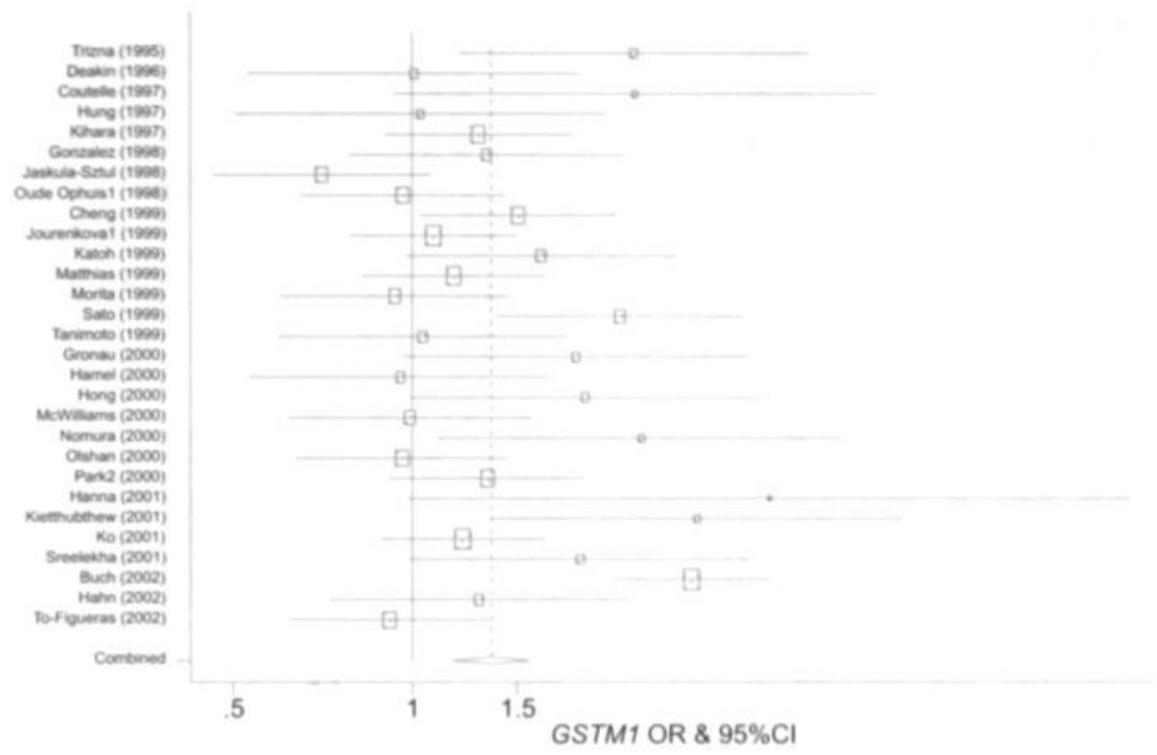

Figure 1. Study specific odds ratios and $95 \%$ confidence intervals from 29 case-control studies in the meta-analysis of head and neck cancers and GSTM1 null genotype, by year of publication

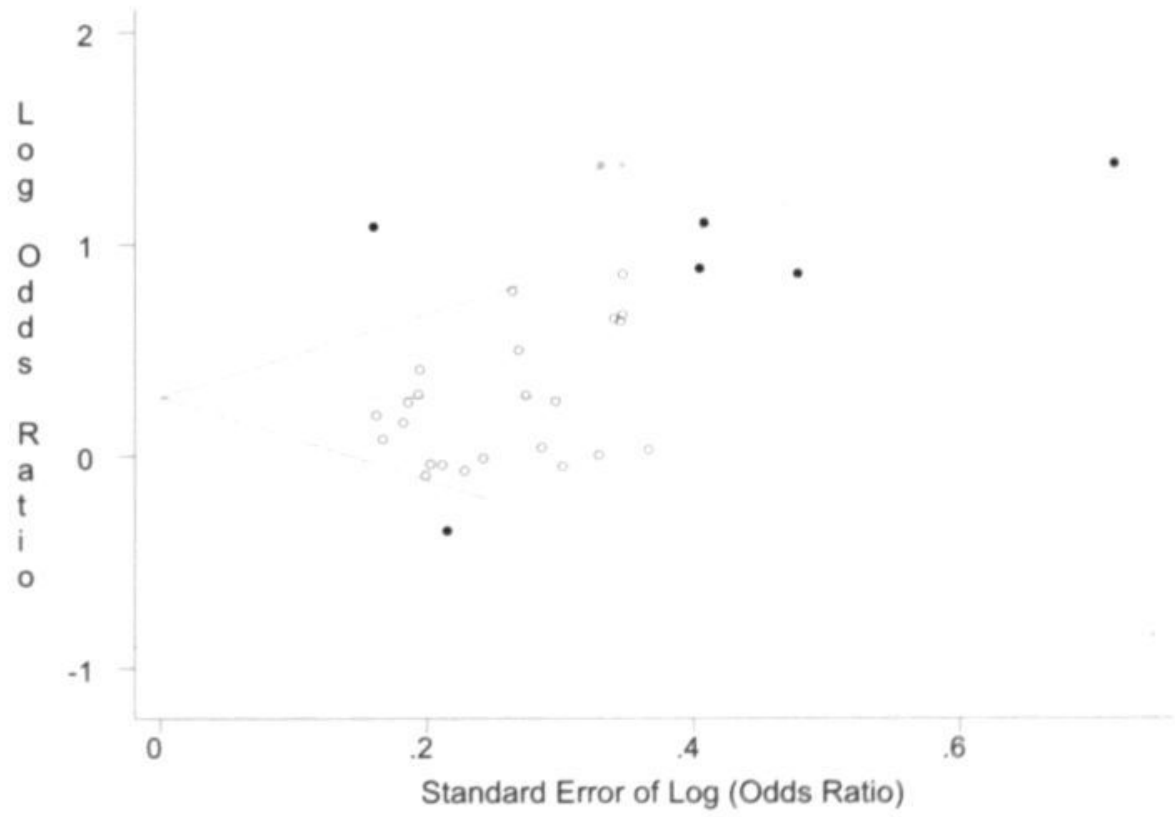

Figure 2. Begg's funnel plot of 29 studies in the meta-analysis of the GSTM1 null genotype and head and neck cancer (darkened circle $=$ study excluded from final model) 
Table 1. Summary of case-control studies included in meta-analysis of GSTM1. GSTT1. GSTP1 (ILE104VAL),. CYP1A1 (ILE462VAL) polymorphisms and head and neck cancers

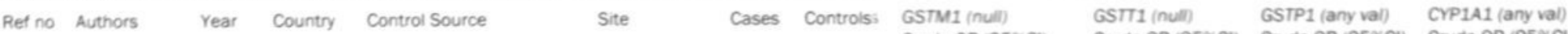
Crude OR $(95 \%$ Cl) Crude OR $(95 \%$ Cl) Crude OR $(95 \% \mathrm{Cl})$ Crude OR (95\%C)

\begin{tabular}{|c|c|c|c|c|c|c|c|c|c|c|c|c|c|}
\hline & & & & & Oral & Pharynx & Larynx & & & & & & \\
\hline (12) & Buch & 2002 & India & $\begin{array}{l}\text { Hospital, } \\
\text { Heaithy }\end{array}$ & $x$ & & & $297^{1.2}$ & $450^{2}$ & $2.95(2.16 .4 .04)^{* 6}$ & $1.60(1.06 .2 .41)^{*}$ & & \\
\hline (24) & Cheng & 1999 & USA & Hospital & Hea & Neck, Site N & NS & 162 & 315 & $1.51(1.03 .2 .21)$ & $2.30(1.48,3.56) 6$ & & \\
\hline (25) & Coutelle & 1997 & France & Alcoholic clinic & & $x$ & $x$ & $39^{2,3,4}$ & $37^{2.3 .4}$ & $2.38(0.93,6.06)^{* 6}$ & & & \\
\hline (26) & Deakin & 1996 & UK & Hospital & $x$ & & & 40 & 577 & $1.01(0.53,1.92)^{*}$ & $0.59(0.20,1.71)^{*}$ & & \\
\hline (27) & Gonzalez & 1998 & Spain & $\begin{array}{l}\text { Hospital, } \\
\text { heaithy }\end{array}$ & $x$ & $x$ & $x$ & $75^{4}$ & $200^{4}$ & $1.34(0.78 .2 .29)^{*}$ & & & \\
\hline (13) & Gronau & 2000 & Germany & $\begin{array}{l}\text { Hospital, } \\
\text { healthy }\end{array}$ & & $x$ & $x$ & 83 & 60 & $1.89(0.96,3.71)^{*}$ & & & \\
\hline (14) & Hahn & 2002 & Germany & $\begin{array}{l}\text { Hospital, } \\
\text { healthy }\end{array}$ & $x$ & & & 94 & 92 & $1.29(0.72,2.31)^{*}$ & & & $0.64(0.17,2.34)^{*}$ \\
\hline (28) & Hamel & 2000 & Canada & mixed & $x$ & $x$ & $x$ & $90^{1.5}$ & 90 & $0.96(0.53,1.73)$ & $2.57(1.12 .5 .90)$ & & \\
\hline (15) & Hanna & 2001 & USA & Hospital & & & $x$ & 20 & 20 & $4.00(0.98,16.27)^{.6}$ & $0.71(0.14 .3 .66)^{* 6}$ & & \\
\hline (16) & Hong & 2000 & Korea & Hospital & & & $x$ & $82^{2,4}$ & $63^{2.4}$ & $1.96(0.99,3.86)^{*}$ & $2.34(1.19 .4 .58)^{*}$ & & \\
\hline (29) & Hung & 1997 & Taiwan & $\begin{array}{l}\text { Population } \\
\text { based }\end{array}$ & $x$ & & & $41^{4}$ & $123^{4}$ & $1.03(0.50 .2 .12)^{*}$ & $1.26(0.61,2.58)^{*}$ & & \\
\hline (17) & Jaskula-Sztul & 1998 & Poland & NS, healthy & & & $x$ & 171 & 180 & $0.71(0.46 .1 .08)^{6}$ & $0.77(0.45,1.31)$ & & \\
\hline$(31,32)$ & Jourenkova 1 & 1999 & France & Hospital & $x$ & $x$ & $x$ & $250^{2}$ & $172^{2}$ & $1.09(0.74,1.60)^{*}$ & $1.38(0.82,2.30)^{*}$ & & \\
\hline$(30.31)$ & Jourenkova2 & 1999 & France & Hospital & $x$ & $x$ & $x$ & $250^{2}$ & $172^{2}$ & & & $1.23(0.86,1.82)^{*}$ & \\
\hline (33) & Kao & 2002 & Taiwan & Hospital & $x$ & & & 106 & 146 & & & & $5.42(2.83,10.38)^{* 6}$ \\
\hline (35) & Katoh1 & 1999 & Japan & $\begin{array}{l}\text { Hospital, } \\
\text { healthy }\end{array}$ & $x$ & & & 92 & 147 & $1.65(0.98,2.80)$ & $0.88(0.52 .1 .48)$ & & $1.29(0.76,2.18)$ \\
\hline (34) & Katoh2 & 1999 & Japan & $\begin{array}{l}\text { Hospital, } \\
\text { healthy }\end{array}$ & $x$ & & & 83 & 122 & & & $1.91(1.04,3.52)^{*}$ & \\
\hline (18) & Kietthubthew & 2001 & Thailand & $\begin{array}{l}\text { Population } \\
\text { based }\end{array}$ & $x$ & & & 53 & 53 & $3.02(1.36,6.71) 6$ & $0.58(0.26,1.26) 6$ & & \\
\hline (36) & Kinara & 1997 & Japan & $\begin{array}{l}\text { Hospital, } \\
\text { heaithy }\end{array}$ & $x$ & $x$ & $x$ & $156^{5}$ & 472 & $1.29(0.90,1.86)^{*}$ & & & \\
\hline (19) & Ko & 2001 & Germany & $\begin{array}{l}\text { Hospital, } \\
\text { healthy }\end{array}$ & $\mathrm{He}$ & Neck, Site I & & 312 & 300 & $1.22(0.88,1.67)^{*}$ & $1.01(0.68,1.50)^{*}$ & & \\
\hline (37) & Matthias 1 & 1998 & Germany & Hospital & $x$ & $x$ & $x$ & 380 & 193 & & & & $1.04(0.64,1.70)^{*}$ \\
\hline (38) & Matthias2 & 1999 & Germany & Hospital & $x$ & $x$ & $x$ & $398^{7}$ & $219^{7}$ & $1.18(0.82,1.68)^{*}$ & $0.99(0.66,1.49)^{*}$ & $1.39(0.98,1.96)^{*}$ & \\
\hline (39) & McWilliams & 2000 & USA & Hospital & $x$ & $x$ & $x$ & $160^{5.7}$ & $149^{7}$ & $0.99(0.62,1.59)$ & $0.91(0.47,1.74)$ & $1.26(0.78,2.04)^{*}$ & $0.42(0.18,0.99)^{6}$ \\
\hline (40) & Morita & 1999 & Japan & Hospital. & $x$ & $x$ & $x$ & 145 & 164 & $0.94(0.60,1.46)^{*}$ & & $0.73(0.44,1.21)^{*}$ & $0.88(0.55,1.41)^{*}$ \\
\hline
\end{tabular}




\begin{tabular}{|c|c|c|c|c|c|c|c|c|c|c|c|c|c|}
\hline (20) & Nomura & 2000 & Japan & Hospital & $\mathrm{x}$ & $\mathrm{x}$ & & $109^{5}$ & 33 & $2.43(1.10 .5 .38)^{* 6}$ & & & \\
\hline (41) & Oishan & 2000 & USA & Hospital & $x$ & $x$ & $\mathrm{x}$ & $182^{7}$ & $202^{7}$ & $0.96(0.64,1.46)^{*}$ & $1.47(0.84,2.58)^{*}$ & $1.25(0.81,1.92)^{*}$ & $1.33(0.58,3.06)^{*}$ \\
\hline (42) & Oude Ophuis1 & 1998 & $\begin{array}{l}\text { Nether- } \\
\text { lands }\end{array}$ & $\begin{array}{l}\text { Hospital, } \\
\text { healthy }\end{array}$ & $x$ & $x$ & $\mathrm{x}$ & $185^{1.5}$ & 207 & $0.97(0.65,1.44)^{*}$ & $0.95(0.58,1.56)^{*}$ & & $1.15(0.68,1.93)^{*}$ \\
\hline (21) & Oude Ophuis2 & 2003 & $\begin{array}{l}\text { Nether- } \\
\text { lands }\end{array}$ & $\begin{array}{l}\text { Hospital, } \\
\text { healthy }\end{array}$ & $x$ & $x$ & $x$ & 235 & 285 & & & $0.80(0.57,1.13)^{*}$ & \\
\hline (43) & Park1 & 1997 & USA & Hospital & $x$ & $x$ & $x$ & 131 & 131 & & & & $2.58(1.17,5.66)^{*}$ \\
\hline (44) & Park2 & 1999 & USA & Hospital & $x$ & $x$ & $x$ & 154 & 246 & & & $0.91(0.60,1.38)^{*}$ & \\
\hline (45) & Park3 & 2000 & USA & Hospital & $x$ & $x$ & $x$ & 164 & 344 & $1.34(0.92,1.95)^{*}$ & & & \\
\hline (46) & Sato & 2000 & Japan & $\begin{array}{l}\text { Hospital, } \\
\text { healthy }\end{array}$ & $\mathrm{x}$ & & & 142 & 142 & $2.24(1.40,3.61)$ & & & $1.88(1.17,3.03)^{*}$ \\
\hline (22) & Sreelekha & 2001 & India & $\begin{array}{l}\text { Hospital, } \\
\text { healthy }\end{array}$ & $x$ & & & 98 & 60 & $1.92(0.99,3.74)^{*}$ & $2.48(0.87,7.06)^{*}$ & & $5.21(2.37,11.43) * 6$ \\
\hline (47) & Tanimoto & 1999 & Japan & Hospital & $x$ & & & 100 & 100 & $1.04(0.59,1.83)^{*}$ & & & \\
\hline (23) & To-Figueras & 2002 & Spain & $\begin{array}{l}\text { Hospital. } \\
\text { healthy }\end{array}$ & & & $\mathrm{x}$ & $204^{7}$ & $203^{2,7}$ & $0.92(0.62,1.35)^{*}$ & $0.67(0.41,1.09)^{* 6}$ & $1.01(0.68,1.49)^{*}$ & \\
\hline \multirow[t]{6}{*}{ (48) } & Trizna & 1995 & USA & $\begin{array}{l}\text { Hospital, } \\
\text { heaithy }\end{array}$ & $x$ & $x$ & $x$ & $186^{7}$ & $42^{7}$ & $2.37(1.20 .4 .67)$ & $1.47(0.71,3.02)$ & & \\
\hline & \multirow{2}{*}{\multicolumn{9}{|c|}{$\begin{array}{r}\text { Number of studies (cases/controls) identified } \\
\text { Number of studies (cases/controls) included in meta-analysis }\end{array}$}} & $29(4,096 / 5,146)$ & $19(2,914 / 3,439)$ & $9(1,768 / 1,699)$ & $11(1,683 / 1,592)$ \\
\hline & & & & & & & & & & $23(3,407 / 4,373)$ & $15(2.679 / 3.104)$ & $9(1,768 / 1,699)$ & $8(1,340 / 1,265)$ \\
\hline & & & & \multicolumn{6}{|c|}{$\begin{array}{r}\text { Number of studies (cases/controls) included in meta-analysis } \\
\text { Summary OR ( } 95 \% \mathrm{Cl})\end{array}$} & $1.24(1.11,1.38)$ & $1.20(1.00,1.44)$ & $1.10(0.92,1.31)$ & $1.27(0.99,1.63)$ \\
\hline & & & & \multirow{2}{*}{\multicolumn{6}{|c|}{$\begin{array}{l}\text { Test for heterogeneity } \\
\text { Publication bias (Eeger's test) }\end{array}$}} & 0.22 & 0.11 & 0.13 & 0.19 \\
\hline & & & & & \multicolumn{2}{|c|}{ Publication bias (Egger's test) } & & & & 0.11 & 0.31 & 0.52 & 0.93 \\
\hline
\end{tabular}

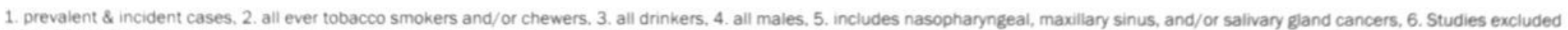
from final model, 7. Number of cases and controls genotyped varied for each polymorphism, thus overall numbers are presented, *Odds Ratio caiculated. NS $=$ not specified 
The summary OR for the 19 studies identified for the meta-analysis of GSTT1 and head and neck cancers was $1.18(95 \% \mathrm{Cl}=0.97,1.44)$ (Table 3$)$. Three studies $(15,18,24)$ were excluded since they appeared to be divergent from the other studies and another (18) was excluded to minimize the potential publication bias that was identified in Begg's funnel plot (Figure 3). Including 2,679 cases and 3,104 controls from 15 studies, the summary OR for the GSTT1 null genotype on the risk of head and neck cancers was $1.20(95 \% \mathrm{Cl}=1.00,1.44)$. The small number of available studies limited the analysis stratified by cancer site. The summary ORs were higher for studies from Asia $(p=0.061)$, studies published from 2000 to $2002(p=0.031)$ and matched studies $(p=0.011)$.

A small number of publications was identified on GSTP1 and CYP1A1 polymorphisms and the risk of head and neck cancers. For GSTP1, we identified 9 case-control studies with 1,768 head and neck cancer cases and 1,699 controls (Table 4). None of the studies was excluded since there were no strong indications of excessive influence or publication bias. There was some suggestion that the valine genotype of GSTP1 may elevate the risk of head and neck cancer (summary $O R=1.10,95 \% \mathrm{Cl}=0.92,1.31$ ), and specifically the risk of oral cancer. Summary ORs for some strata could not be estimated due to the small number of studies.

Eleven case-control studies were identified for the association between the CYP1A1 polymorphism and head and neck cancers, with a summary OR of $1.50(95 \% \mathrm{Cl}=1.00$, $2.26)$. Three studies $(22,33,39)$ were excluded as they appeared to be less consistent with the other studies. According to the meta-analysis of the remaining 8 studies with 1,340 cases and 1,265 controls, the risk of head and neck cancers may be increased moderately by the CYP1A1 valine polymorphism $(\mathrm{OR}=1.27,95 \% \mathrm{Cl}=0.99,1.63)$.

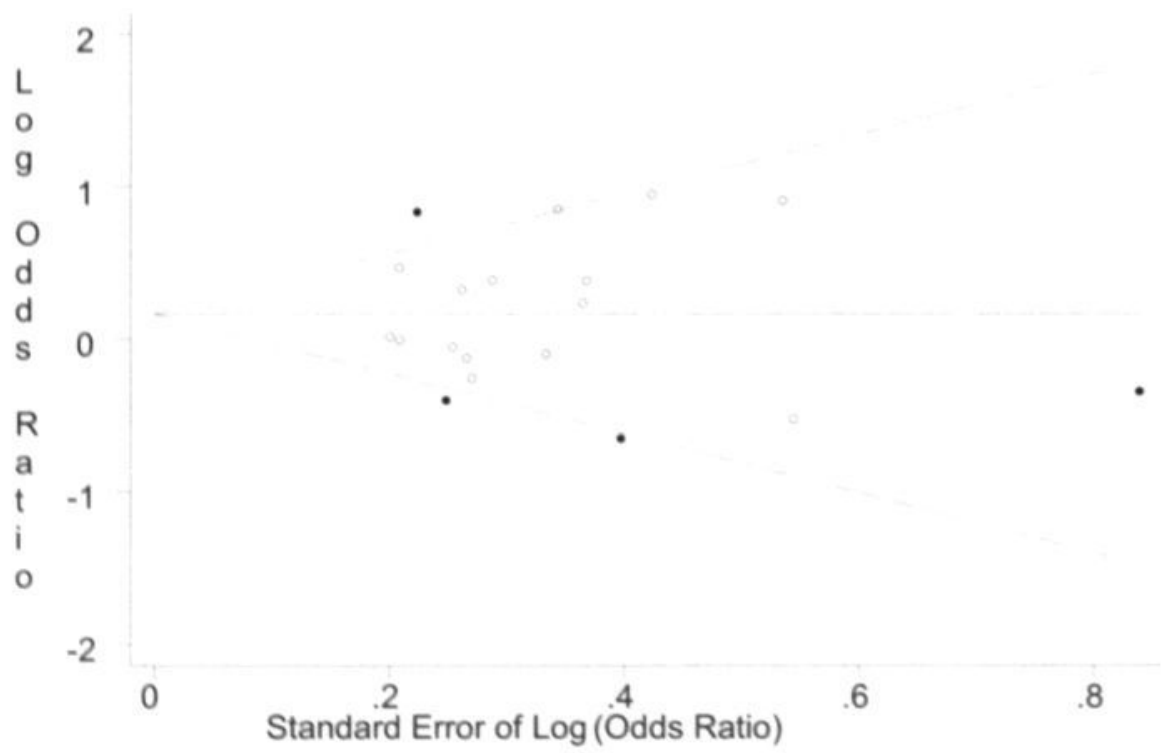

Figure 3. Begg's funnel plot of 19 studies in the meta-analysis of the GSTT1 null genotype and head and neck cancer (darkened circle $=$ study excluded from final model) 
Results of the pooled analysis of GSTM1, GSTT1, GSTP1, CYP1A1 and head and neck cancers are shown in Table 5. The race/ethnicity distribution for the Lazarus study was 64.3\% Caucasian and 35.7\% African-American among cases, and 61.8\% Caucasian and $38.2 \%$ African-American among controls. For the Romkes study, the cases were 97.4\% Caucasian and 2.6\% African-American, while the controls were $78.9 \%$ Caucasian, 15.5\% African-American, 4.2\% Latino and 1.4\% Asian. All 11 studies in the pooled analysis had data on GSTM1, but two studies were excluded since their study estimates were less consistent with respect to the other studies $(12,26)$. When including all studies, the OR was $1.32(95 \% \mathrm{Cl}=1.07,1.62)$ adjusting for study center. After excluding the 2 studies, the OR for the GSTM1 null genotype, adjusted for study center was $1.35(95 \% \mathrm{Cl}=1.13,1.61)$ and the OR adjusted for study center, age, sex and race was $1.32(95 \% \mathrm{Cl}=1.04,1.69)$. The GSTM1 null genotype was associated with an increased risk of head and neck cancers among smokers and Caucasians. The risk of head and neck cancer was also elevated by the GSTT1 null genotype (OR adjusted for study center $=1.35,95 \% \mathrm{Cl}=1.13,1.61$; OR adjusted for study center, age, sex and race $=1.41,95 \% \mathrm{Cl}=1.00,1.57$ ), but not by the GSTP1 and CYP1A1 polymorphisms, according to the pooled analysis. There appeared to be heterogeneity among the studies, especially in the case of the GSTP1 polymorphism.

Gene-gene interactions were assessed for all combinations of GSTM1, GSTT1, GSTP1 and CYP1A1 on the risk of head and neck cancers in the pooled analysis, but strong interactions were not identified. We also analyzed the data for possible gene-environment interactions between each polymorphism and smoking, but again interactions were not obvious. However, we did see an increasing risk of head and neck cancers with multiple GST polymorphisms in an analysis of a subset of studies that had data on all 3 polymorphisms (906 head and neck cancer cases and 543 controls) (26,30$32,37,38,42)$. The null genotypes GSTM1 and GSTT1, and the valine polymorphism of GSTP1 were considered high risk relative to subjects who had low risk genotypes for all 3 GSTs. Taking subjects with all low risk GST polymorphisms as the reference, the OR was $1.13(95 \% \mathrm{Cl}=0.83,1.53)$ for subjects who had 1 high risk GST polymorphism, $1.19(95 \% \mathrm{Cl}=0.87,1.63)$ for subjects who had 2 high risk GST polymorphisms and $1.69(95 \% \mathrm{Cl}=0.99,2.88)$ for subjects with all 3 high risk GST polymorphisms when adjusted for study center (test for trend, $p$-value $=0.08$ ). When further adjusted for age, sex, and race, the OR was $1.16(95 \% \mathrm{Cl}=0.83,1.63)$ for 1 high risk GST polymorphism, $1.23(95 \% \mathrm{Cl}=0.86,1.75)$ for 2 high risk GST polymorphisms, and $2.06(95 \% \mathrm{Cl}=1.11$, 3.81) for having 3 high risk GST polymorphisms (test for trend, p-value $=0.04$ ). When stratified by smoking, the results were not statistically significant. 
Table 2. Distribution of GSTM1, GSTT1, GSTP1 (ILEVAL), CYP1A1 (ILEVAL) genotypes among head and neck cancer cases and controls

\begin{tabular}{|c|c|c|c|c|c|c|c|c|c|}
\hline \multirow[t]{2}{*}{ Reference } & \multirow[t]{2}{*}{ Country } & \multicolumn{2}{|c|}{ \% GSTM1 Null } & \multicolumn{2}{|c|}{ * GSTr1 Null } & \multicolumn{2}{|c|}{ \$ GSTP1 any val } & \multicolumn{2}{|c|}{ \$ CYP1A1 any val } \\
\hline & & Cases & Controls & Cases & Controls & Cases & Controls & Cases & Controls \\
\hline \multicolumn{10}{|l|}{$\begin{array}{l}\text { Asia } \\
\text { (12) }\end{array}$} \\
\hline (12) & India & 49.2 & 24.7 & 18.2 & 12.2 & & & & \\
\hline (22) & India & 49.0 & 33.3 & 18.4 & 8.3 & & & 51.0 & 16.7 \\
\hline (35) & Japan & 58.7 & 46.3 & 47.8 & 51.0 & & & 45.7 & 39.5 \\
\hline (34) & Japan & & & & & 37.3 & 23.8 & & \\
\hline (36) & Japan & $\begin{array}{l}55.1 \\
49.0\end{array}$ & $\begin{array}{l}48.7 \\
50.6\end{array}$ & & & 24.8 & 31.1 & 33.8 & 36.6 \\
\hline $\begin{array}{l}(20) \\
(46)\end{array}$ & $\begin{array}{l}\text { Japan } \\
\text { Japan }\end{array}$ & $\begin{array}{l}67.0 \\
64.8\end{array}$ & 45.1 & & & & & 52.1 & 36.6 \\
\hline (47) & $\begin{array}{l}\text { Japan } \\
\text { Japan }\end{array}$ & 43.0 & 42.0 & & & & & & \\
\hline (16) & Korea & 68.3 & 52.4 & 57.3 & 36.5 & & & & \\
\hline (29) & Taiwan & 58.5 & 57.7 & 58.5 & 52.8 & & & & \\
\hline (33) & Taiwan & & & & & & & 86.8 & 54.8 \\
\hline \multirow[t]{2}{*}{ (18) } & Thailand & 56.6 & 30.2 & 34.0 & 47.2 & & & & \\
\hline & Overall in Asia & 55.0 & 41.7 & 30.9 & 27.7 & 29.3 & 28.0 & 52.7 & 39.5 \\
\hline \multicolumn{10}{|l|}{ Europe } \\
\hline $\begin{array}{l}(25) \\
(31,32)\end{array}$ & France & 69.2 & 48.6 & & & & & & \\
\hline $\begin{array}{l}(31,32) \\
(30,31)\end{array}$ & France & 54.4 & 52.3 & 20.4 & 15.7 & 55.2 & 50.0 & & \\
\hline $\begin{array}{l}(30,31) \\
(13)\end{array}$ & France & 63.9 & 48.3 & & & 55.2 & & & \\
\hline $\begin{array}{l}(13) \\
(14)\end{array}$ & Germany & $\begin{array}{l}63.9 \\
59.6\end{array}$ & 53.3 & & & & & 4.3 & 6.7 \\
\hline $\begin{array}{l}(14) \\
(19)\end{array}$ & $\begin{array}{l}\text { Germany } \\
\text { Germany }\end{array}$ & 53.2 & 48.3 & 20.5 & 20.3 & & & & \\
\hline (37) & Germany & & & & & & & 15.0 & 14.5 \\
\hline (38) & Germany & 57.4 & 53.4 & 22.0 & 22.2 & 55.0 & 46.9 & & \\
\hline (42) & Netherlands & 50.8 & 51.7 & 19.5 & 20.3 & & & 18.4 & 16.4 \\
\hline (21) & Netherlands & & & & & 50.6 & 56.1 & & \\
\hline (17) & Poland & 49.1 & 57.8 & 17.5 & 21.7 & & & & \\
\hline (27) & Spain & 58.7 & 51.5 & & & & & & \\
\hline (23) & Spain & 47.1 & 49.3 & 17.2 & 23.6 & 50.7 & 50.2 & & \\
\hline \multirow[t]{2}{*}{ (26) } & UK & 55.0 & 54.8 & 11.8 & 18.5 & & & & \\
\hline & Overall in Europe & 54.3 & 52.4 & 19.8 & 20.1 & 53.3 & 51.4 & 14.0 & 13.2 \\
\hline \multicolumn{10}{|c|}{ North America } \\
\hline (28) & Canada & 56.7 & 57.8 & 10.0 & 22.2 & & & & \\
\hline (24) & USA & 53.1 & 42.9 & 32.7 & 17.5 & & & & \\
\hline (15) & USA & 80.0 & 50.0 & 15.0 & 20.0 & & & & \\
\hline (39) & USA & 46.3 & 46.5 & 16.9 & 18.3 & 58.9 & 53.2 & 6.5 & 14.0 \\
\hline (41) & USA & 43.6 & 44.6 & 18.6 & 13.5 & 66.3 & 61.1 & 7.6 & 5.8 \\
\hline (43) & USA & & & & & & & 17.6 & 7.6 \\
\hline (44) & USA & & & & & 62.3 & 64.6 & & \\
\hline (45) & USA & 43.3 & 36.3 & & & & & & \\
\hline \multirow[t]{3}{*}{ (48) } & USA & 68.3 & 47.6 & 44.9 & 35.7 & & & & \\
\hline & Overall in North America & 52.5 & 43.1 & 25.0 & 18.2 & 62.7 & 60.9 & 9.4 & 7.8 \\
\hline & OVERALL & 54.1 & 46.6 & 23.6 & 21.6 & 52.7 & 50.6 & 26.6 & 23.0 \\
\hline
\end{tabular}


Table 3. Meta-Analysis of case-control studies for GSTM1, GSTT1 and head and neck cancer by cancer site, smoking status and study characteristics

GSTM1

GSTT1

\begin{tabular}{|c|c|c|c|c|c|c|c|c|}
\hline & & & & & \\
\hline & $\begin{array}{l}\text { No. of } \\
\text { studies }\end{array}$ & $\begin{array}{l}\text { OR }{ }^{a} \text { for null } \\
\text { genotype ( } 95 \% \mathrm{Cl})\end{array}$ & $\begin{array}{l}\text { Test for } \\
\text { Heterogeneity }\end{array}$ & $\begin{array}{l}\text { Egger s } \\
\text { Test }\end{array}$ & $\begin{array}{l}\begin{array}{l}\text { No. of } \\
\text { studies }\end{array} \\
\end{array}$ & $\begin{array}{l}\text { OR }{ }^{a} \text { for null } \\
\text { genotype }(95 \% \mathrm{Cl})\end{array}$ & $\begin{array}{l}\text { Test for } \\
\text { Heterogeneity }\end{array}$ & $\begin{array}{l}\text { Egger's } \\
\text { Test }\end{array}$ \\
\hline Overall & 29 & $1.36(1.17,1.58)$ & 0.00 & 0.20 & 19 & $1.18(0.97 .1 .44)$ & 0.00 & 0.98 \\
\hline Excluding several studies & $23^{1}$ & $1.24(1.11,1.38)$ & 0.22 & 0.11 & $15^{2}$ & $1.20(1.00,1.44)$ & 0.11 & 0.31 \\
\hline \multicolumn{9}{|l|}{ Cancer site } \\
\hline $\begin{array}{l}\text { Oral } \\
\text { Pharynx }\end{array}$ & $\begin{array}{l}9^{3} \\
3^{4}\end{array}$ & $1.31(1.02,2.69)$ & 0.13 & $\begin{array}{l}0.79 \\
0.17\end{array}$ & $6^{6}$ & $1.28(0.93,1.76)$ & 0.23 & 0.73 \\
\hline $\begin{array}{l}\text { Pharynx } \\
\text { Larynx }\end{array}$ & $\begin{array}{l}3^{4} \\
7^{5}\end{array}$ & $\begin{array}{l}1.14(0.77,1.67) \\
1.17(0.90,1.54)\end{array}$ & 0.58 & $\begin{array}{l}0.17 \\
0.10\end{array}$ & - & - & - & - \\
\hline \multirow{2}{*}{\multicolumn{7}{|c|}{$\begin{array}{l}\text { Smoking status } \\
\text { Never smokers }\end{array}$}} & 0.09 & 0.81 \\
\hline & $3^{8}$ & & 0.69 & 0.66 & & - & & \\
\hline $\begin{array}{l}\text { Never smokers } \\
\text { Ever smokers }\end{array}$ & $6^{9}$ & $1.27(0.98,1.64)$ & 0.07 & 0.49 & $-4_{10}$ & - & - & $=$ \\
\hline \multicolumn{6}{|c|}{$1.31(0.90,1.89)$} & $1.31(0.90,1.89)$ & 0.17 & 0.86 \\
\hline Asia & 8 & $1.42(1.19,1.79)$ & 0.14 & 0.62 & 5 & $1.48(1.03 .2 .13)$ & 0.15 & 0.58 \\
\hline North America & 6 & $1.24(0.98,1.57)$ & 0.17 & 0.76 & 4 & $1.43(0.97,2.09)$ & 0.28 & 0.47 \\
\hline Europe & 9 & $1.13(0.99 .1 .30)$ & 0.76 & 0.27 & 6 & $0.98(0.81,1.20)$ & 0.64 & 0.33 \\
\hline \multicolumn{9}{|l|}{$\begin{array}{l}\text { Year of Publication } \\
1995.1999\end{array}$} \\
\hline $1995 \cdot 1999$ & 13 & $1.27(1.09,1.47)$ & 0.17 & 0.44 & 8 & $1.01(0.83,1.23)$ & 0.65 & 0.93 \\
\hline $2000-2002$ & 10 & $1.20(1.02,1.40)$ & 0,34 & 0.12 & 7 & $1.49(1.11,2.00)$ & 0.12 & 0.18 \\
\hline \multicolumn{9}{|l|}{ Number of cases \& controls } \\
\hline$<100$ cases or $<100$ controls & 10 & $1.45(1.19,1.77)$ & 0.49 & 0.54 & 7 & $1.45(0.98,2.14)$ & 0.09 & 0.54 \\
\hline$\geq 100$ cases $\&$ zcontrols & 13 & $1.17(1.03,1.32)$ & 0.26 & 0.99 & 8 & $1.11(0.93,1.33)$ & 0.35 & 0.68 \\
\hline \multicolumn{7}{|l|}{$\begin{array}{l}\text { Control Source } \\
\text { Sosoital Heatthy Poution }\end{array}$} & & \\
\hline $\begin{array}{l}\text { Hospital Healthy or Population } \\
\text { Hospital }\end{array}$ & 10 & $1.17(1.02 .1 .34)$ & 0.66 & $\begin{array}{l}0.08 \\
0.96\end{array}$ & 8 & $1.13(0.90,1.40)$ & 0.24 & 0.44 \\
\hline \multirow{2}{*}{\multicolumn{8}{|c|}{$1.32(0.96,1.81)$}} & \\
\hline Matched & 5 & $1.32(1.04,1.67)$ & 0.47 & 0.70 & 3 & $1.82(1.29 .2 .57)$ & & \\
\hline Frequency matched & 4 & $1.12(0.91 .1 .37)$ & 0.70 & 0.78 & 3 & & 0.50 & $\begin{array}{l}0.18 \\
0.52\end{array}$ \\
\hline Not matched & 14 & $1.28(1.09,1.49)$ & 0.08 & 0.07 & 9 & $\begin{array}{l}1.38(0.99,1.93) \\
1.01(0.83,1.24)\end{array}$ & $\begin{array}{l}0.95 \\
0.31\end{array}$ & $\begin{array}{l}0.52 \\
0.77\end{array}$ \\
\hline
\end{tabular}

1. excluded Buch, Coutelle, Hanna, Jaskula Sztul, Kietthubthew. Nomura, 2. excluded Cheng, Hanna, Kietthubthew, To-Figueras, 3. included Deakin, Hahn, Hung, Katoh, Jourenkova, Morita. Nomura, Sreelekha, Tanimoto 4. included Gronau, Jourenkova, Morita, 5. included Gronau, H Jng Jaskula-Sztul, Jourenkova, Kihara, Matthias, Morita. To Figueras, 6. included Buch. Deakin, Hung, Jourenkova. Katoh, Sreelekha 7. included Hong, Jourenkova. Matthias, 8. incluo gd Kihara, Olshan, Park, 9. included Hong Jourenkova, Kihara, Ko, Olshan, Park, 10. included Hong , Jourenkova, Ko, Otshan

smoked at least 5 cigarettes/day for 5 years $(30-32)$, smoked at least 100 cigarettes in a lifetime $(4:-45)$ and not specifically defined (34.36). 
Table 4. Meta-analysis of case-control studies for GSTP1 (ILEVAL), CYP1A1 (ILEVAL) and head and neck Ccancer by cancer site, smoking status and study characteristics

GSTP1

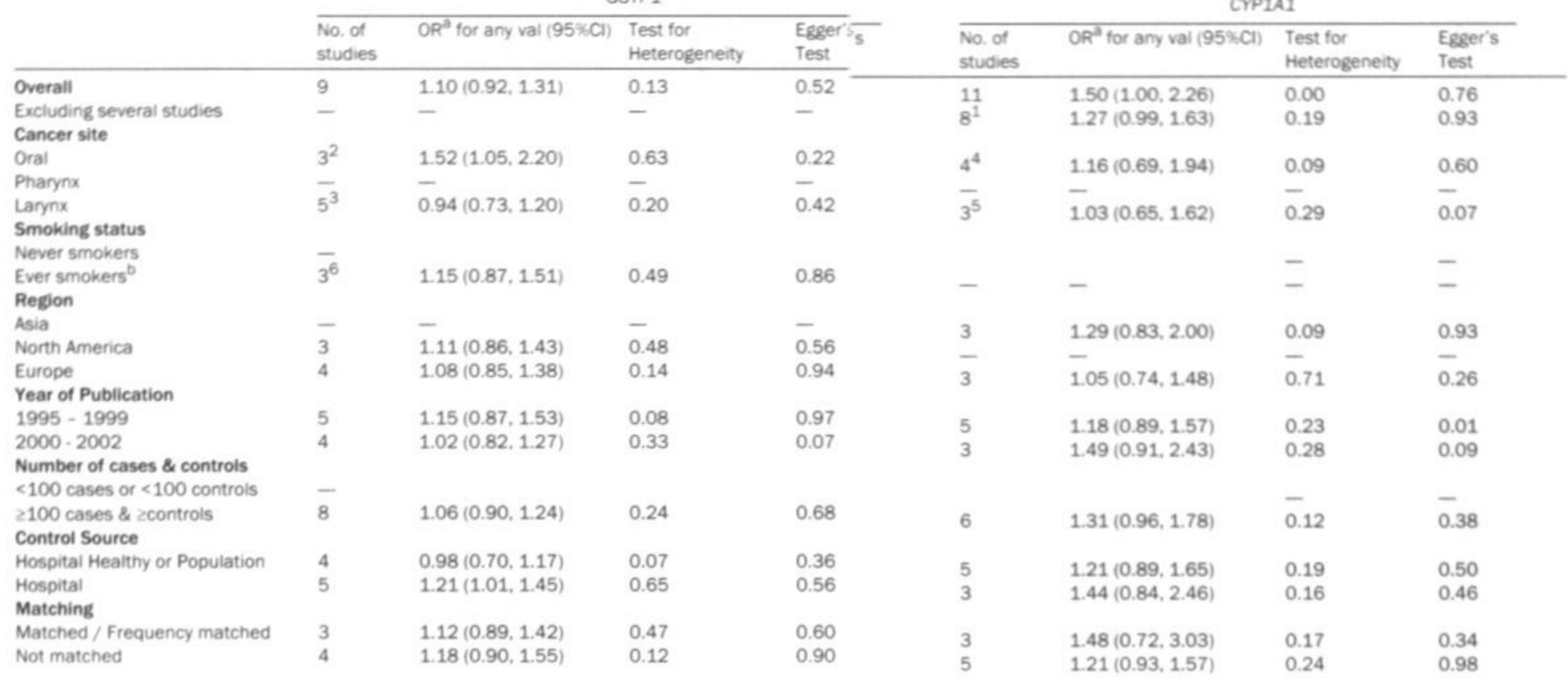

1. excluded Kao, McWilliams, Sreelekha, 2. included Jourenkova, Katoh, Morita, 3. included Jourenkov va, Matthias, Morita, Oude Ophuis, To-Figueras, 4. included Hahn, Katoh, Morita, Sato, 5. included Matthias, Morita, Park, 6. included Jourenkova, Katoh, Oishan

a. OR adjusted for study center b. ever smoking was categorized by different criteria in the studies: ( 30,31 ), smoked at least 100 cigarettes in a lifetime (41) and not specifically defined ( 34 ), 
Table 5. Pooled analysis of case-control studies on the GSTM1, GST1, GSTP1, CYP1A1 polymorphisms and head and neck cancer

Site

Country

Control Source

Oral Pha- La-

Cases Controls GSTM1 OR $(95 \% \mathrm{Cl})$ GSTT1 OR $(95 \% \mathrm{Cl})$ GSTP1 Any Val OR $(95 \% \mathrm{Cl})$

CYP1A1 Any Val rynx rynx

Benhamou Jourenkova (30-32) France

Bhisey Buch (12)

India

Hospital

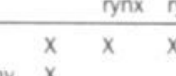

250

172

$1.09(0.74 .1 .60)$

\begin{tabular}{ll} 
& OR $(95 \% \mathrm{Cl})$ \\
\hline $1.38(0.82,2.30)$ & $1.23(0.83,1.82)$
\end{tabular}

$-$

Cascorbi unpublished Germany Hospital, Healthy

Coutelle Coutelle (25)

Hamel Hamel (28)

France

Alcoholic Clinic

Katoh $(34.35)$

Canada

Mixed

Katoh

Japan

Healthy

Lazarus

Park (43-45) USA

Hospital

Romkes

Oude Ophuis $(21,42)$ Netherlands

Strange

unpublished

USA Healthy

Hospital, Healthy

Strange

Deakin (26)

Hospital

$\begin{array}{ll}x & x \\ x & x \\ x & x\end{array}$

$\begin{array}{llll}300^{1.2 .4} & 678^{2.4} & 1.73(1.49 .1 .99)^{5} & 1.61(1.11 .2 .33)\end{array}$

$1.06(0.76 .1 .48)$

$1.06(0.76,1.48)$
$1.02(0.51,2.04)$

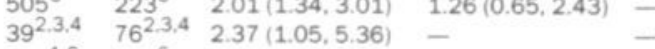

$-$

$\begin{array}{llll}196^{1.6} & 199^{6} & 1.09(0.74,1.62) & 1.15 \\ 45 & 91 & 1.59(0.78,3.27) & -\end{array}$

$\begin{array}{lll}45 & 91 & 1.59(0.78 .3 .27) \\ 185^{6} & 367^{6} & 1.40(0.96 .2 .03)\end{array}$

$1.40(0.96,2.03)$

$15(0.67 .1 .98)$

$\begin{array}{ll}x & x \\ X & x\end{array}$

Head \& Neck

$245^{1.6} \quad 159^{6}$

$1.33(0.77,2.29)$

$-$

$\overline{0.87}$

$-$

$\begin{array}{lllll}40^{6} & 70^{6} & 0.79(0.36 .1 .73) & 0.84(0.25 .2 .84)\end{array}$

$\begin{array}{lllllll}40^{6} & 70^{6} & 0.79(0.36 .1 .73) & 0.84(0.25 .2 .84) & - & & - \\ 107^{6} & 493^{6} & 0.69(0.45 .1 .05)^{5} & 1.38(0.84 .2 .27) & 1.53(0.94 .2 .48) & 2.11 \\ 422^{6} & 238^{6} & 1.31(0.94 .1 .83) & 1.54(0.91 .2 .63) & 1.56(1.11 .2 .19) & 0.87\end{array}$

$x$

$1.31(0.94,1.83)$

No of studies (cases/controls) in data Summary $\mathrm{OR}^{\mathrm{a}}$

$0.87(0.55,1.38)$

Test for heterogeneity

$9(1,820 / 1,352)$

$8(1,929 / 1,830) \quad 5(1.164 / 982)$

$5(1,558 / 1,467)$

Publication bias

0.27

0.27
0.78

$1.25(1.00,1.57)$

0.22

1.15
0.04

$0.98(0.75,1.29)$

Oral $\quad 1.24(0.97 .1 .57) \quad 1.34(0.99,1.82) \quad 1.37(0.88 .2 .14) \quad 0.97(0.56,1.69)$

$\begin{array}{lllll}\text { Pharynx } & 1.25(0.98,1.61) & 1.11(0.66 .1 .87) & 1.10(0.58,2.05) & 0.77(0.47,1.25)\end{array}$

Larynx $1.53(1.17 .2 .00) \quad 1.10(0.81 .1 .49) \quad 1.08(0.81,1.44) \quad 0.93(0.64 .1 .34)$

$\begin{array}{lllll}\text { Never smokers } & 1.37(0.84,2.23) & 1.29(0.83,1.99) & 1.38(0.46,4.12) & 0.95(0.62 .1 .45)\end{array}$

Ever smokers $1.30(1.07 .1 .59) \quad 1.23(0.77 .1 .94) \quad 1.01(0.76,1.33) \quad 0.87(0.50 .1 .51)$

$\begin{array}{ccccc}\text { Caucasians } & 1.29(1.04 .1 .59) & 1.17(0.91 .1 .50) & 1.15(0.86,1.54) & 0.95(0.64 .1 .43)\end{array}$

SCC $1.25(1.05,1.47) \quad 1.17(0.88,1.55) \quad 1.13(0.83,1.54) \quad-$

1. prevalent \& incident cases, 2. all ever tobacco smokers and/or chewers. 3. all drinkers, 4. all males, 5. studies excluded from final model, 6. number of cases and controls genotyped varied for each polymorphism, thus overall numbers are presented, 7. excluded Buch, Deakin

a. OR adjusted for study center 


\section{Discussion}

The results from the meta-analysis supported the hypothesis that GSTM1, GSTT1 and CYP1A1 polymorphisms increase the risk of head and neck cancers. Sources of heterogeneity included sample size among the GSTM1 studies, and geographic region, period of publication, and matching among the GSTT1 studies. The pooled analysis confirmed the association of head and neck cancers with GSTM1 and GSTT1 but the associations with GSTP1 or CYP1A1 polymorphisms were not clear. The pooled analysis was based on a subset of published studies from the meta-analysis that tended to report no associations or weak associations. Gene-gene and gene-environment interactions were not identified but a relationship was suggested between an increasing number of high risk GST genotypes and the risk of head and neck cancer.

Case-control studies with small sample size (less than 100 cases or 100 controls) may be reporting inflated ORs for the GSTM1 null genotype. These results may suggest caution in the interpretation of small case-control studies. Our summary estimates on the effect of the GSTT1 polymorphism may differ for the 3 general regions where the studies were conducted. A higher summary estimate was seen from studies in Asia for the GSTT1 genotype. The distribution of GSTT1 null in controls was low in the studies from India $(12,22)$ and when we excluded the 2 Indian studies, the summary estimate for Asia was no longer elevated $(\mathrm{OR}=1.34,95 \% \mathrm{Cl}=0.75,2.39)$. A detailed assessment of the role of this polymorphism in India goes beyond the scope of this study.

Studies on GSTT1 and head and neck cancers that were published since the year 2000 report an elevated summary risk, whereas studies published before 2000 did not. Though publication bias may be suspected for the more recent studies, it was not suggested by Egger's test $(p=0.18)$. A change in genotyping methods could be a possible explanation, but all studies had used PCR to amplify the GSTT1 gene and most studies mentioned using positive controls. Furthermore, since we were unable to control for matching factors in the meta-analysis, we may have bias in our study-specific effect estimates. However, matched studies did not seem to have ORs that were biased toward GSTT1 null as might be expected, when compared to unmatched studies. The heterogeneity observed between studies due to year of publication and matching status may reflect other study characteristics.

Carcinogen metabolism is complex, involving the interaction of numerous carcinogens and enzymes. The GSTs have a variety of substrates including environmental carcinogens, pesticides, drugs and endogenous molecules of lipid peroxidation as well as inducing agents, some of which double as substrates including polycyclic aromatic hydrocarbons, phenolic antioxidants, isothiocyanates, and reactive oxygen species (57). The metabolic action of GST enzymes may differ by tissue type, as the GSTP1 enzyme has been observed to be at the highest concentration in oral and pharyngeal tissues and the GSTM1 enzyme at the highest concentration in laryngeal tissue, relative to the other GSTs (2). GST enzyme expression levels may also differ by general controls of gene expression, such as the rates of transcription, translation and degradation as well as possible posttranslational modifications. 
Individually these metabolic polymorphisms may be weak to moderate risk factors, explaining the inconsistent results seen in epidemiologic studies. The meta-analysis supported the hypothesis that GSTM1, GSTT1, and CYP1A1 polymorphisms are moderate risk factors for head and neck cancer. On the other hand, combinations of genotypes that each confers a small relative risk may sum to a large enough relative risk that can be observed in epidemiologic studies. Our pooled analysis supported the idea that multiple GST polymorphisms combined may confer a greater risk of head and neck cancers. Future epidemiologic studies focusing on combinations of polymorphisms within the same gene family or other related gene families may be helpful in identifying individuals at high risk for head and neck cancers and in elucidating gene-gene interactions.

\section{Acknowledgements}

Mia Hashibe worked on this study under the tenure of a Special Training Award from the International Agency for Research on Cancer. WDF thanks Nancy Hamel for her help in compiling data for this publication.

\section{References}

1. Caporaso N, Goldstein A. Issues involving biomarkers in the study of the genetics of human cancer. IARC Sci Publ, 237-250, 1997.

2. Geisler SA, OIshan AF. GSTM1, GSTT1, and the risk of squamous cell carcinoma of the head and neck: a mini-HuGE review. Am J Epidemiol, 154: 95-105, 2001.

3. Hecht SS. Cigarette smoking and lung cancer: chemical mechanisms and approaches to prevention. Lancet Oncol, 3: 461-469, 2002.

4. Kawajiri K. CYP1A1. IARC Sci Publ, 159-172, 1999.

5. Cosma G, Crofts F, Taioli E, Toniolo P, Garte S. Relationship between genotype and function of the human CYP1A1 gene. J Toxicol Environ Health, 40: 309-316, 1993.

6. Crofts F, Taioli E, Trachman J, Cosma GN, Currie D, Toniolo P, Garte SJ. Functional significance of different human CYP1A1 genotypes. Carcinogenesis, 15: 2961-2963, 1994.

7. Barouki R, Morel Y. Repression of cytochrome P450 1A1 gene expression by oxidative stress: mechanisms and biological implications. Biochem Pharmacol, 61: 511-516, 2001.

8. Mooney LA, Bell DA, Santella RM, et al. Contribution of genetic and nutritional factors to DNA damage in heavy smokers. Carcinogenesis, 18: 503-509, 1997.

9. Rebbeck TR. Molecular epidemiology of the human glutathione S-transferase genotypes GSTM1 and GSTT1 in cancer susceptibility. Cancer Epidemiol Biomarkers Prev, 6: 733-743, 1997.

10. Johansson AS, Stenberg G, Widersten M, Mannervik B. Structure-activity relationships and thermal stability of human glutathione transferase P1-1 governed by the $\mathrm{H}$-site residue 105. J Mol Biol, 278: 687-698, 1998.

11. Ryberg D, Skaug V, Hewer A, et al. Genotypes of glutathione transferase M1 and P1 and their significance for lung DNA adduct levels and cancer risk. Carcinogenesis, 18: 1285-1289, 1997. 
12. Buch SC, Notani PN, Bhisey RA. Polymorphism at GSTM1, GSTM3 and GSTT1 gene loci and susceptibility to oral cancer in an Indian population. Carcinogenesis, 23: 803-807, 2002.

13. Gronau S, Konig-Greger D, Rettinger G, Riechelmann H. GSTM1 gene polymorphism in patients with head and neck tumors. Laryngorhinootologie, 79: 341-344, 2000.

14. Hahn M, Hagedorn G, Kuhlisch E, Schackert HK, Eckelt U. Genetic polymorphisms of drug-metabolizing enzymes and susceptibility to oral cavity cancer. Oral Oncol, 38: 486-490, 2002.

15. Hanna E, MacLeod S, Vural E, Lang N. Genetic deletions of glutathione Stransferase as a risk factor in squamous cell carcinoma of the larynx: a preliminary report. Am J Otolaryngol, 22: 121-123, 2001.

16. Hong YJ, Lee JK, Lee GH, Hong SI. Influence of glutathione S-transferase M1 and T1 genotypes on larynx cancer risk among Korean smokers. Clin Chem Lab Med, 38: 917-919, 2000.

17. Jaskula-Sztul R, Reinikainen M, Husgafvel-Pursiainen K, Szmeja Z, Szyfter W, Szyfter KT, Hirvonen A. Glutathione S-tranferase M1 and T1 genotypes and susceptibility to smoking related larynx cancer. Biomarkers, 3: 149-155, 1998.

18. Kietthubthew S, Sriplung H, Au WW. Genetic and environmental interactions on oral cancer in Southern Thailand. Environ Mol Mutagen, 37: 111-116, 2001.

19. Ko Y, Abel J, Harth V, et al. Association of CYP1B1 codon 432 mutant allele in head and neck squamous cell cancer is reflected by somatic mutations of p53 in tumor tissue. Cancer Res, 61: 4398-4404, 2001.

20. Nomura T, Noma H, Shibahara T, Yokoyama A, Muramatusu T, Ohmori T. Aldehyde dehydrogenase 2 and glutathione S-transferase M 1 polymorphisms in relation to the risk for oral cancer in Japanese drinkers. Oral Oncol, 36: 42-46, 2000.

21. Oude Ophuis MB, Roelofs HMJ, van den Brandt PA, Peters WHM, Manni JJ. Polymorphisms of the glutathione S-transferase P1 gene and head and neck cancer susceptibility. Head Neck, 25: 37-43, 2003.

22. Sreelekha TT, Ramadas K, Pandey M, Thomas G, Nalinakumari KR, Pillai MR. Genetic polymorphism of CYP1A1, GSTM1 and GSTT1 genes in Indian oral cancer. Oral Oncol, 37: 593-598, 2001.

23. To-Figueras J, Gene M, Gomez-Catalan J, et al. Microsomal epoxide hydrolase and glutathione S-transferase polymorphisms in relation to laryngeal carcinoma risk. Cancer Lett, 187: 95-101, 2002.

24. Cheng L, Sturgis EM, Eicher SA, Char D, Spitz MR, Wei Q. Glutathione Stransferase polymorphisms and risk of squamous-cell carcinoma of the head and neck. Int J Cancer, 84: 220-224, 1999.

25. Coutelle C, Ward PJ, Fleury B, et al. Laryngeal and oropharyngeal cancer, and alcohol dehydrogenase 3 and glutathione S-transferase M1 polymorphisms. Hum Genet, 99: 319-325, 1997.

26. Deakin M, Elder J, Hendrickse C, et al. Glutathione S-transferase GSTT1 genotypes and susceptibility to cancer: studies of interactions with GSTM1 in lung, oral, gastric and colorectal cancers. Carcinogenesis, 17: 881-884, 1996. 
27. Gonzalez MV, Alvarez V, Pello MF, Menendez MJ, Suarez C, Coto E. Genetic polymorphism of $\mathrm{N}$-acetyltransferase-2, glutathione S-transferase-M1, and cytochromes P450IIE1 and P450IID6 in the susceptibility to head and neck cancer. J Clin Pathol, 51: 294-298, 1998.

28. Hamel N, Karimi S, Hebert-Blouin MN, et al. Increased risk of head and neck cancer in association with GSTT1 nullizygosity for individuals with low exposure to tobacco. Int J Cancer, 87: 452-454, 2000.

29. Hung HC, Chuang J, Chien YC, et al. Genetic polymorphisms of CYP2E1, GSTM1, and GSTT1; environmental factors and risk of oral cancer. Cancer Epidemiol Biomarkers Prev, 6: 901-905, 1997.

30. Jourenkova-Mironova N, Voho A, Bouchardy C, et al. Glutathione S-transferase GSTM3 and GSTP1 genotypes and larynx cancer risk. Cancer Epidemiol Biomarkers Prev, 8: 185-188, 1999.

31. Jourenkova-Mironova N, Voho A, Bouchardy C, et al. Glutathione S-transferase GSTM1, GSTM3, GSTP1 and GSTT1 genotypes and the risk of smoking-related oral and pharyngeal cancers. Int J Cancer, 81: 44-48, 1999.

32. Jourenkova N, Reinikainen M, Bouchardy C, Dayer P, Benhamou S, Hirvonen A. Larynx cancer risk in relation to glutathione S-transferase M1 and T1 genotypes and tobacco smoking. Cancer Epidemiol Biomarkers Prev, 7: 19-23, 1998.

33. Kao SY, Wu CH, Lin SC, et al. Genetic polymorphism of cytochrome P4501A1 and susceptibility to oral squamous cell carcinoma and oral precancer lesions associated with smoking/betel use. J Oral Pathol Med, 31: 505-511, 2002.

34. Katoh T, Kaneko S, Takasawa S, et al. Human glutathione S-transferase P1 polymorphism and susceptibility to smoking related epithelial cancer; oral, lung, gastric, colorectal and urothelial cancer. Pharmacogenetics, 9: 165-169, 1999.

35. Katoh T, Kaneko S, Kohshi K, et al. Genetic polymorphisms of tobacco- and alcohol-related metabolizing enzymes and oral cavity cancer. Int J Cancer, 83: 606-609, 1999.

36. Kihara M, Kihara M, Kubota A, Furukawa M, Kimura H. GSTM1 gene polymorphism as a possible marker for susceptibility to head and neck cancers among Japanese smokers. Cancer Lett, 112: 257-262, 1997.

37. Matthias C, Bockmuhl U, Jahnke V, et al. Polymorphism in cytochrome P450 CYP2D6, CYP1A1, CYP2E1 and glutathione S-transferase, GSTM1, GSTM3, GSTT1 and susceptibility to tobacco-related cancers: studies in upper aerodigestive tract cancers. Pharmacogenetics, 8: 91-100, 1998.

38. Matthias C, Jahnke V, Hand P, Fryer AA, Strange RC. Immunohistologic and molecular genetic studies of the effect of glutathione S-transferases on the development of squamous epithelial carcinomas in the area of the head-neck. Laryngorhinootologie, 78: 182-188, 1999.

39. McWilliams JE, Evans AJ, Beer TM, Andersen PE, Cohen JI, Everts EC, Henner WD. Genetic polymorphisms in head and neck cancer risk. Head Neck, 22: 609-617. 2000.

40. Morita S, Yano M, Tsujinaka T, et al. Genetic polymorphisms of drug-metabolizing enzymes and susceptibility to head-and-neck squamous-cell carcinoma. Int J Cancer, 80: 685-688, 1999.

41. Olshan AF, Weissler MC, Watson MA, Bell DA. GSTM1, GSTT1, GSTP1, CYP1A1, and NAT1 polymorphisms, tobacco use, and the risk of head and neck cancer. Cancer Epidemiol Biomarkers Prev, 9: 185-191, 2000. 
42. Oude Ophuis MB, van Lieshout EMM, Roelofs HMJ, Peters WHM, Manni JJ. Glutathione S-transferase M1 and T1 and cytochrome P4501A1 polymorphisms in relation to the risk for benign and malignant head and neck lesions. Cancer, 82: 936-943, 1998.

43. Park JY, Muscat JE, Ren Q, et al. CYP1A1 and GSTM1 polymorphisms and oral cancer risk. Cancer Epidemiol Biomarkers Prev, 6: 791-797, 1997.

44. Park JY, Schantz SP, Stern JC, Kaur T, Lazarus P. Association between glutathione S-transferase pi genetic polymorphisms and oral cancer risk. Pharmacogenetics, 9: 497-504, 1999.

45. Park LY, Muscat JE, Kaur T, Schantz SP, Stern JC, Richie JP, Lazarus P. Comparison of GSTM polymorphisms and risk for oral cancer between African-Americans and Caucasians. Pharmacogenetics, 10: 123-131, 2000.

46. Sato M, Sato T, Izumo T, Amagasa T. Genetically high susceptibility to oral squamous cell carcinoma in terms of combined genotyping of CYP1A1 and GSTM1 genes. Oral Oncol, 36: 267-271, 2000.

47. Tanimoto K, Hayashi S, Yoshiga K, Ichikawa T. Polymorphisms of the CYP1A1 and GSTM1 gene involved in oral squamous cell carcinoma in association with a cigarette dose. Oral Oncol, 35: 191-196, 1999.

48. Trizna Z, Clayman GL, Spitz MR, Briggs KL, Goepfert H. Glutathione S-transferase genotypes as risk factors for head and neck cancer. Am J Surg, 170: 499-501, 1995.

49. Lucas D, Menez C, Floch F, et al. Cytochromes P4502E1 and P4501A1 genotypes and susceptibility to cirrhosis or upper aerodigestive tract cancer in alcoholic caucasians. Alcohol Clin Exp Res, 20: 1033-1037, 1996.

50. Amador AG, Righi PD, Radpour S, et al. Polymorphisms of xenobiotic metabolizing genes in oropharyngeal carcinoma. Oral Surg Oral Med Oral Pathol Oral Radiol Endod, 93: 440-445, 2002.

51. Worrall SF, Corrigan M, High A, et al. Susceptibility and outcome in oral cancer: preliminary data showing an association with polymorphism in cytochrome P450 CYP2D6. Pharmacogenetics, 8: 433-439, 1998.

52. Greenland S. Invited commentary: a critical look at some popular meta-analytic methods. Am J Epidemiol, 140: 290-296, 1994.

53. Begg CB Mazumdar M. Operating characteristics of a rank correlation test for publication bias. Biometrics, 50: 1088-1101, 1994.

54. Egger M, Davey SG, Schneider M, Minder C. Bias in meta-analysis detected by a simple, graphical test. BMJ, 315: 629-634, 1997.

55. Taioli E. International collaborative study on genetic susceptibility to environmental carcinogens. Cancer Epidemiol Biomarkers Prev, 8: 727-728, 1999.

56. Gaspari L, Marinelli D, Taioli E. International collaborative study on genetic susceptibility to environmental carcinogens (GSEC): an update. Int J Hyg Environ Health, 204: 39-42, 2001.

57. Eaton DL Bammler TK. Concise review of the glutathione S-transferases and their significance to toxicology. Toxicol Sci, 49: 156-164, 1999. 


\section{SUMMARY, CONCLUSIONS, DISCUSSION AND FUTURE PERSPECTIVES}

The incidence of head and neck squamous cell carcinoma (HNSCC) is strongly related to the consumption of alcohol and tobacco. However, the majority of the individuals consuming alcohol and tobacco ultimately do not develop HNSCC and therefore seem to be not susceptible to these hazardous substances. The explanation may be that considerable inter-individual differences exist in the detoxification capacity for alcohol and carcinogens of tobacco smoke. Several complex families of phase I and phase II detoxification enzymes exist, the levels of which may vary from one individual to another, as a result of induction or inhibition by dietary or lifestyle factors. In addition, genetic differences between individuals may also contribute to the actual differences in detoxification enzyme levels. The latter differences may be largely caused by genetic polymorphisms in detoxification enzymes, the knowledge on which is rapidly evolving during the last decade.

The overall aim of this thesis was to provide more information on the occurrence of genetic polymorphisms in cytochrome P4501 A1 (CYP1A1) and glutathione S-transferase (GST) detoxification enzymes in both patients with HNSCC as well as healthy controls, in order to be able to get insight in the eventual modulating effect of such polymorphisms on the susceptibility for HNSCC. The summary recapitulates the contents of the individual chapters.

In chapter 1 the mechanism of glutathione conjugation to a potential carcinogen compound is briefly described. Subsequently, an overview is presented on the literature published to this date concerning the GST polymorphisms in GSTM1, GSTT1 and GSTP1 and HNSCC susceptibility. The studies so far published have reported contradicting results, and possible explanations for these varying results are given.

In chapter 2 the genetic variability in the corresponding cytochrome P4501A1 (CYP1A1), GSTT1 and GSTM1 isoenzymes, which may contribute to individual differences in HNSCC susceptibility, is discussed. By Polymerase Chain Reaction / Restricted Fragment Length Polymorphism (PCR/RFLP) techniques, the different CYP and GST genotypes could be detected in DNA isolated from whole blood, in 185 patients with HNSCC, 207 healthy blood donors and an additional control group of 78 patients with benign head and neck lesions (BHNL). The GSTM1 null genotype was demonstrated equally frequent in patients with HNSCC, BHNL and blood donors, 
whereas the GSTT1 null genotype occurred significantly more often in patients with BHNL as compared to blood donors. This could mean that the GSTT1 null genotype may be a risk factor for BHNL.

In chapter 3 we had to revise our findings on the GSTT1 null genotype, as published before in chapter 2, due to demographic variations in the controls. By comparing the GST M1, T1 and P1 genotype frequencies of two healthy blood donor groups from the Nijmegen and Maastricht regions, we found inter-regional differences. The GSTM1, GSTT1 and GSTP1 genotype frequencies in two control populations ( $n=285$ and $n=207$ ) from different but neighboring (Maastricht/Nijmegen) geographical regions, were determined by PCR/RFLP methods. For the GSTT1 null polymorphism we found a significant difference $(p=0.003)$ between the two control groups. When the risk for HNSCC (all patients are from the Maastricht area) is estimated versus the Maastricht control group, we now found significantly less HNSCC patients with the GSTT1 null genotype as compared to the controls. In contrast to our earlier conclusion, we now have to conclude that GSTT1 null genotype appears to be involved in the modulation of the risk for HNSCC and not for BHNL.

In chapter 4 we evaluated the role of the GSTP1-1 enzyme plasma levels as a tumor marker in patients with different sites of HNSCC. GSTP1-1 enzyme levels were measured in plasma of patients and controls, using a sensitive and specific sandwich Enzyme Linked Immuno Sorbent Assay (ELISA). Median GSTP1-1 plasma levels of patients with oral/oropharyngeal, hypopharyngeal and laryngeal sites of HNSCC were significantly elevated when compared to GSTP1-1 levels from patients with BHNL, who served as controls. Overall however, only 13 out of 93 patients with HNSCC had elevated plasma GSTP1-1 levels, which makes GSTP1-1 not suitable as plasma tumor marker for HNSCC.

In chapter 5 we studied the frequencies of polymorphic variants in the GSTP1 gene, in patients with HNSCC and healthy controls. In patients with HNSCC and controls, the homozygous GSTP1 BB genotype was observed in $12.3 \%$ and $13.6 \%$ respectively. Also no statistical differences were found for the distribution of the GSTP1 AA and GSTP1 $A B$ genotypes between patients and controls. This study showed that genetic polymorphisms in GSTP1 are not associated with an altered susceptibility to HNSCC.

Many authors have studied the GSTP1 genotypes in relation to the risk for HNSCC. In chapter 6, the correlation between GSTP1 genotype and GSTP1-1 enzyme plasma levels was evaluated. GSTP1 genotype and GSTP1-1 plasma levels were measured in HNSCC patients and patients with BHNL who served as controls. For all GSTP1 genotypes $(A A, A B$ and $B B$ ) in HNSCC patients, the mean plasma GSTP1-1 values were significantly higher compared to the corresponding control groups. However, there was no significant difference in the plasma GSTP1-1 levels between the different groups of GSTP1 genotypes in HNSCC patients.

Since chemical modification of compounds to be detoxified is very complex and often requires several subsequent chemical reactions, with corresponding enzymes, we evaluated in chapter 7, whether the concurrent lack or dysfunction of one or more GST and Epoxide Hydrolase (EPHX) genes, influences the susceptibility for HNSCC. No sig- 
nificant difference was found between the group of HNSCC patients and the healthy controls with respect to the co-occurrence of zero to four $(0-4)$ different genetic polymorphisms. We conclude that multiple polymorphisms in the GST and EPHX genes are not associated with a higher susceptibility for HNSCC.

In chapter 8 a meta-analysis on the association between HNSCC and genetic polymorphisms in CYP1A1, GSTM1, GSTT1 and GSTP1 is presented in the form of an international collaborative study, including the results of 30 published case-control studies, including 4,286 head and neck cancer cases and 5,440 controls. Subsequently, in a pooled analysis of original data from 9 published and 2 unpublished case control studies ( 2,324 cases and 2,766 controls), the same associations as well as potential gene-gene and gene-environment interactions were explored. The summary Odds Ratios (OR) from the meta-analysis and the pooled analysis suggest a weak association for the GSTM1, GSTT1 and CYP1A1 genotypes and head and neck cancer risk.

\section{Conclusions}

1. Distribution of GSTT1 genotypes in The Netherlands is variable.

2. Research on the associations between genetic polymorphisms and the modulation of risk for HNSCC therefore should be conducted under strict conditions with respect to including both cases and controls.

3. Plasma GSTP1-1 can not be used as a tumor marker for the detection or follow-up of HNSCC patients.

4. The GSTP1 genotypes and the levels of plasma GSTP1-1 enzyme are not associated in patients with HNSCC.

5. Meta-analysis and pooled analysis in an international collaborative study show a weak association of GSTM1, GSTT1 and CYP1A1 genotypes and head and neck cancer, which becomes weaker when adjusted for study center, age, gender and race. For polymorphisms in GSTP1, when adjusted for study center, age, gender and race no such correlation is seen.

\section{Discussion}

Our hypothesis that polymorphisms in biotransformation enzymes could increase the risk of HNSCC is not supported by our case-control studies. In one of the first studies (chapter 2), we found no association between polymorphisms of the GSTM1, GSTT1 and CYP1A1 genes and a higher risk for head and neck cancer. In the same study, contradictory to the hypothesis, we initially found a significantly higher number of GSTT1 null genotypes in patients with BHNL, which suggested that the GSTT1 null genotype may be a risk factor for BHNL. This conclusion, however, was based on a case population recruited from a different geographical area (Maastricht) than the control population (Nijmegen). The BHNL group, also patients recruited from the Maastricht area, served as an additional control group. Later on (chapter 3 ) we recruited a second control group, this time from the same region (Maastricht) as our HNSCC and BHNL patients, since we missed data on alcohol consumption and smoking in the Nijmegen controls, and we did not expect to find significant differences in the GSTT1 genotype 
distribution between controls collected approximately 125 kilometers apart. The frequencies for the GSTT1 null genotype in this Maastricht control group, were comparable to the BHNL patient group, but not to the HNSCC patient group which meant that the BHNL group in fact served as a representative control group. More important however, was that these data were in contradiction with already published results (chapter 2). The GSTT1 null genotype frequencies were now significantly lower in HNSCC patients as compared to controls, suggesting involvement of GSTT1 null in the modulation of risk for HNSCC.

Chapter 4 evaluates the use of GSTP1-1 enzyme levels in the diagnostic stage of head and neck disease. Several studies have shown elevated GSTP1-1 enzyme levels in plasma of head and neck cancer patients in the first stage of disease, which declined after surgical resection of the tumor. In our patient-control groups we found no relation between HNSCC in any stage and GSTP1-1 plasma levels. We however found, that the methods for treatment of blood and preparing the plasma are very critical, since GSTP1-1 is present in large amounts in many blood cells, which may be released into the plasma when not properly processed. Thus, the procedures carried out in this study are very critical and the question remains, even if there would have been a positive correlation, whether such a critical procedure would be of clinical value.

Even though we found that measurement of GSTP1-1 enzyme plasma levels has no value as a tumor marker, there have been several reports on the GSTP1-1 enzyme to be present in high concentrations in several types of tumor tissue (head and neck tumors included).

We also evaluated whether a polymorphism of the GSTP1 gene may be involved in head and neck cancer (chapter 5), but found no correlation. The strong associations between smoking and laryngeal cancer, and between alcohol intake and oral/ oropharyngeal cancer, was expected because of the different ways carcinogen exposure may take place. Tobacco smoke is passing the larynx as most narrow site of the airway during in- and exhalation, whereas alcohol containing liquids remain temporarily in the oral cavity even after swallowing.

Having determined plasma GSTP1-1 enzyme levels and GSTP1 genotype in HNSCC patients and controls, in chapter 6 a combination of the results of the previous two chapters was made. We hypothesized that the elevated GSTP1-1 plasma levels in HNSCC patients may be caused by one of the GSTP1 genotypes. The fact that no association between GSTP1 genotype and phenotype was found, supports our view that the GSTP1 polymorphism alone appears to have minimal effect on GSTP1-1 enzyme activity in head and neck tissues and HNSCC susceptibility.

A study combining several polymorphisms of the GST and EPHX genes, also shows no evidence for an effect of these polymorphisms on the risk for HNSCC (chapter 7). In this study, we only studied the number of polymorphisms of any of these genes in patients and controls, without adjusting for age, gender, smoking or alcohol consumption.

In chapter 8 , an international multicenter meta- and pooled analysis was conducted. Only weak associations with HNSCC and GSTM1, GSTT1 and CYP1A1 genotypes were 
found. The conclusions of this meta analysis support the view of this thesis, that genetic polymorphisms in carcinogen metabolizing enzyme systems like glutathione S-transferases appear to be of minor importance in the development of HNSCC.

\section{Future perspectives}

The process of carcinogenesis is very complex. Even when main sources of the carcinogens are known, which are alcohol and tobacco smoke in many of the HNSCC cases, then the exact ways of the "route of carcinogenesis" are difficult to reconstruct. The metabolism of alcohol is relatively straightforward, but tobacco smoke contains many toxic and potentially carcinogenic compounds, the metabolism of each of those may involve many different enzymes, and a lot of research remains to be done before eventually important modulating enzymes may be characterized.

Alcohol dehydrogenase, acetaldehyde dehydrogenase, several other members of the cytochrome P450 and glutathione S-transferase families, UDP-glucuronosyltransferases which have recently been associated with $\mathrm{HNSCC}, \mathrm{N}$-acetyltransferases and many other enzymes or polymorphisms in the corresponding genes, may be investigated on their involvement in the modulation of the HNSCC risk.

To be able to perform this research properly, it is very important to have a large blood, tissue and databank from patients with HNSCC and the proper controls, which has already been set up. Tissue research may also provide valuable information on local enzyme activities.

In all our studies the statistical analyses were limited due to the large contrast in smoking and alcohol consumption behavior between patient and control groups. The number of non-smoking HNSCC patients is scarse, whereas in the healthy control groups there are almost no heavy smokers and/or alcoholics. Especially these extreme groups (heavy smoking and heavy drinking healthy elderly controls, and non-smoking. non-drinking elderly HNSCC patients) may be of particular interest for head and neck cancer research, since these individuals may have an extreme good, or an extreme bad functioning detoxification system.

In this thesis we have shown that head and neck cancer, which is strongly related to high tobacco and alcohol consumption, does not appear to be modulated by polymorphisms in some enzymes that detoxify tobacco carcinogens or alcohol, but many enzymes need to be investigated before definitive conclusions can be drawn. 


\section{SAMENVATTING, CONCLUSIE, DISCUSSIE EN TOEKOMSTIGE MOGELIJKHEDEN}

De mate van voorkomen van plaveisel cel carcinoom van het hoofd hals gebied (head and neck squamous cell carcinoma, HNSCC) is sterk gerelateerd aan de consumptie van alcohol en tabak. Echter, bij het merendeel van de personen die alcohol gebruiken of roken ontstaat uiteindelijk geen hoofd hals tumor. Deze personen lijken niet vatbaar voor de kwalijke gevolgen van deze stoffen. Het lijkt erop dat er behoorlijke verschillen bestaan tussen personen onderling in de ontgiftings-capaciteit van alcohol en de kankerverwekkende (carcinogene) stoffen uit tabaksproducten. Er bestaan enkele complexe families binnen de fase I en fase II detoxificatie enzymen. Bij deze enzymen kan de functie tussen personen onderling variëren door verschil in diëet of levensgewoonten. Ook genetische verschillen tussen personen kunnen bijdragen aan verschillen in functie van detoxificatie enzymen. Deze laatste verschillen kunnen vooral worden veroorzaakt door genetische polymorphismen in detoxificatie enzymen. De afgelopen tien jaar is hier veel over bekend geworden.

Dit proefschrift heeft tot doel meer informatie te verschaffen over de verschillende genetische polymorphismen van cytochroom P450 1A1 (CYP1A1) en glutathion S-transferase (GST) detoxificatie enzymen in relatie tot de vatbaarheid voor HNSCC. Deze samenvatting beschrijft de inhoud van de individuele hoofdstukken.

In hoofdstuk 1 wordt het mechanisme van koppeling (conjugatie) van glutathion aan een potentiëel kankerverwekkende stof kort beschreven. Tevens wordt een overzicht gegeven van de literatuur die tot nu toe is gepubliceerd betreffende de GST polymorphismen in GSTM1, GSTT1 en GSTP1 en de vatbaarheid voor HNSCC. Tot op dit moment zijn veel tegenstrijdige resultaten gerapporteerd en hiervoor wordt een aantal mogelijke verklaringen gegeven.

In hoofdstuk 2 wordt een studie beschreven waarin gekeken is naar de genetische variatie van de corresponderende cytochroom P450 1A1 (CYP1A1), GSTT1 en GSTM1 isoenzymen die een mogelijke bijdrage leveren aan de individuele verschillen in vatbaarheid voor HNSCC. Via polymerase ketting reactie methoden (polymerase chain reaction, PCR) werden de verschillende CYP en GST genotypen aangetoond in DNA, verkregen uit bloed monsters van 185 patiënten met HNSCC, 207 gezonde bloed-donoren en een extra controlegroep van 78 patiënten met goedaardige hoofd hals aandoeningen (benign head and neck lesions, BHNL). Het GSTM1 null genotype kwam even vaak voor bij patiënten met HNSCC, BHNL en de bloed-donoren. Het 
GSTT1 null genotype kwam significant vaker voor bij patiënten met BHNL dan bij bloed-donoren. Als gevolg hiervan zou het GSTT1 null genotype een risico-factor kunnen zijn voor het ontstaan van BHNL.

In hoofdstuk 3 komen wij terug op onze bevindingen ten aanzien van het GSTT1 null genotype, zoals reeds gepubliceerd in hoofdstuk 2, vanwege demografische verschillen in controlegroepen. Bij vergelijking van GST M1, T1 en P1 genotype frequenties van twee groepen gezonde bloed-donoren uit de regio's Nijmegen en Maastricht, bestonden aanwijzingen voor mogelijke regionale verschillen. De frequenties van de GSTM1, GSTT1 en GSTP1 genotypen in twee controle populaties ( $n=285$ en $n=207$ ) uit verschillende, maar aangrenzende geografische regio's (Maastricht/Nijmegen) werden bepaald door middel van de PCR methode. Bij vergelijking van deze controlegroepen werd een significant verschil $(p=0,003)$ gevonden voor het GSTT1 null genotype. Als de groep patiënten met HNSCC uit de regio Maastricht wordt vergeleken met de nieuwe controlegroep, die eveneens uit Maastricht komt, worden nu significant minder HNSCC patiënten met het GSTT1 null genotype gevonden. In tegenstelling tot onze eerdere opvatting, moeten wij nu concluderen dat het GSTT1 null genotype betrokken lijkt bij de beïnvloeding van het risico op HNSCC en niet op BHNL.

In hoofdstuk 4 werd gekeken naar de bruikbaarheid van GSTP1-1 enzym plasma waarden als tumor marker in patiënten met verschillende typen hoofd hals tumoren. GSTP1-1 plasma spiegels werden bepaald in plasma van patiënten en een controlegroep door middel van een gevoelige en specifieke sandwich Enzyme Linked Immuno Sorbent Assay (ELISA). De mediane GSTP1-1 plasma spiegels bij patiënten met HNSCC van de mond/mondbodem/oropharynx, hypopharynx en larynx waren significant verhoogd ten opzichte van een controlegroep patiënten met BHNL. Slechts 13 van 93 patiënten met HNSCC had een verhoogde plasma spiegel van GSTP1-1. GSTP1-1 is derhalve niet geschikt als plasma tumor marker voor hoofd hals tumoren.

In hoofdstuk 5 werden de polymorphismen van het GSTP1 gen bij patiënten met HNSCC vergeleken met een gezonde controlegroep. Het homozygote GSTP1 BB genotype kwam in deze groepen respectievelijk $12,3 \%$ en $13,6 \%$ voor. Ook voor GSTP1 AA en GSTP1 AB werden geen significante verschillen gevonden tussen patiënten en de controlegroep. Dit onderzoek heeft aangetoond dat genetische polymorphismen in het GSTP1 gen niet lijken bij te dragen aan veranderde vatbaarheid voor het ontstaan van HNSCC.

$\mathrm{Er}$ is door veel onderzoeksgroepen onderzoek gedaan naar een relatie tussen het GSTP1 genotype en het risico voor HNSCC. In hoofdstuk 6 is gekeken naar een relatie tussen het GSTP1 genotype en de GSTP1-1 enzym plasma spiegels bij patiënten met HNSCC en patiënten met BHNL. Voor alle GSTP1 genotypen ( $A A, A B$ en $B B$ ) in patienten met HNSCC waren de gemiddelde GSTP1-1 plasma spiegels significant hoger ten opzichte van de corresponderende BHNL groepen. Er werd echter geen significant verschil gezien van de GSTP1-1 plasma spiegels tussen de verschillende GSTP1 genotypen in patiënten met HNSCC.

Chemische verandering van stoffen die ontgift moeten worden is erg complex. Het vereist dikwijls een aantal opeenvolgende chemische reacties die vaak onder invloed van 
enzymen plaatsvinden. In hoofdstuk 7 hebben wij gekeken naar de relatie tussen gelijktijdige afwezigheid danwel functieverlies van één of meer GST en Epoxide Hydrolase $(E P H X)$ genen en de vatbaarheid voor HNSCC. Ten aanzien van het voorkomen van nul tot vier verschillende genetische polymorphismen werd geen significant verschil gevonden tussen de groep patiënten met HNSCC en de gezonde controlegroep. Wij concluderen dat meervoudige polymorphismen van de GST en EPHX genen de vatbaarheid voor HNSCC niet lijkt te beïnvloeden.

In hoofdstuk 8 wordt een meta-analyse gepresenteerd tussen HNSCC en genetische polymorphismen van CYP1A1, GSTM1, GSTT1 en GSTP1. Dit is een internationaal samenwerkingsverband, waarin de resultaten van 30 gepubliceerde studies zijn opgenomen (4286 patiënten met HNSCC, 5440 controlepersonen). Hierna zijn de resultaten van 9 gepubliceerde en 2 ongepubliceerde studies (2324 HNSCC patiënten, 2766 controles) onderworpen aan een pooled analyse. Hierbij zijn ook mogelijke gen-gen en gen-omgevings interacties bekeken. De samenvattende Odds Ratios (OR) van meta-analyse en pooled analyse suggereren een zwakke relatie tussen GSTM1, GSTT1 en CYP1A1 genotypen en risico voor hoofd hals kanker.

\section{Conclusies}

1. De spreiding van GSTT1 genotypen is in Nederland variabel.

2. Onderzoek naar het verband tussen genetisch polymorphismen en het risico voor HNSCC dient derhalve onder gestandaardiseerde condities plaats te vinden voor zowel patiënten als controlegroepen.

3. Plasma GSTP1-1 kan niet als tumor marker worden gebruikt voor diagnostiek of follow-up van patiënten met HNSCC.

4. De genotypen van GSTP1 en de GSTP1-1 enzym plasma spiegels staan niet in relatie tot elkaar bij patiënten met HNSCC.

5. Meta-analyse en pooled-analyse in een internationaal samenwerkingsverband laten een zwakke relatie zien tussen GSTM1, GSTT1 en CYP1A1 genotypen en hoofd hals kanker. Deze relatie wordt nog zwakker na correctie voor studie centrum, leeftijd, geslacht en ras. Voor de polymorphismen van het GSTP1 gen werd een dergelijke relatie niet gezien.

\section{Discussie}

Onze hypothese dat polymorphismen in biotransformatie enzymen het risico van HNSCC verhogen wordt niet ondersteund door onze patiënt-controle studies. In één van onze eerste onderzoeken (hoofdstuk 2), kon geen verband worden aangetoond tussen polymorphismen van de GSTM1, GSTT1 en CYP1A1 genen en een verhoogd risico op hoofd hals kanker. In dezelfde studie werd, in tegenstelling tot onze hypothese, aanvankelijk een significant verhoogd GSTT1 null genotype in patiënten met BHNL gevonden, hetgeen suggereerde dat het GSTT1 null genotype wellicht een risico factor kon zijn voor BHNL. Echter, deze bevinding was gebaseerd op een patiënten populatie uit Maastricht en een controle populatie uit Nijmegen. De BHNL groep bestond eveneens uit Maastrichtse patiënten en diende als een extra controle groep. 
Op een later moment (hoofdstuk 3 ) werd een tweede controle groep uit Maastricht samengesteld vanwege het feit dat data betreffende alcohol consumptie en rookgedrag ontbraken bij de Nijmeegse controle groep. Wij verwachtten geen significante verschillen in GSTT1 genotype aan te treffen tussen twee controle groepen uit regio's die geografisch circa 125 kilometer van elkaar zijn gescheiden. De frequenties voor het GSTT1 null genotype in de Maastrichtse controle groep waren vergelijkbaar met die van de BHNL groep, echter niet met die van de HNSCC patiënten groep. Dit betekende dat de $\mathrm{BHNL}$ groep in feite een representatieve controle groep was. Belangrijker echter, was dat deze resultaten tegenstrijdig waren met reeds gepubliceerde resultaten (hoofdstuk 2). Nu waren de GSTT1 null frequenties significant lager in patiënten met HNSCC ten opzichte van de controle groep, waaruit blijkt dat GSTT1 null genotype wel betrokken zou kunnen zijn bij het risico op HNSCC.

Hoofdstuk 4 beoordeelt de bruikbaarheid van GSTP1-1 enzym plasma spiegels in de diagnostische fase van hoofd hals kanker. Enkele onderzoeken hebben aangetoond dat bij patiënten waarbij zojuist HNSCC was aangetoond, een aanvankelijk verhoogde GSTP1-1 spiegel in het plasma zou dalen na chirurgische verwijdering van de tumor. In onze patiënt-controle groepen kon geen verband tussen HNSCC (in welk stadium dan ook) en GSTP1-1 plasma spiegels worden aangetoond. Wel vonden wij de methoden voor de behandeling van het bloed en de bereiding van het plasma kritiek omdat GSTP1-1 in hoge mate aanwezig is in veel bloedcellen en in het plasma wordt uitgescheiden indien de bereiding niet correct plaatsvindt. Deze procedures zijn dus erg complex waarbij de vraag blijft bestaan of, zelfs bij een duidelijke correlatie, een dergelijke procedure van klinische betekenis zou kunnen zijn.

Ook al hebben wij aangetoond dat GSTP1-1 enzym plasma spiegels geen nut hebben als tumor marker, zijn er toch studies die hoge concentraties GSTP1-1 enzym beschrijven in verschillende typen tumor weefsel (inclusief hoofd hals tumoren).

Wij hebben geen verband aangetroffen tussen het polymorphisme van het GSTP1 gen en hoofd hals kanker (hoofdstuk 5). Wel verwachtten wij conform de resultaten een duidelijke relatie tussen roken en larynx kanker en tussen alcoholgebruik en mond/mondbodemkanker vanwege de verschillende manier waarop blootstelling van de schadelijke stoffen plaatsvindt. Tabaksrook passeert tijdens in- en uitademing de larynx, zijnde het meest nauwe deel van de bovenste luchtwegen; alcoholhoudende dranken verblijven tijdelijk in de mondholte, zelfs na het doorslikken hiervan.

Nadat de GSTP1-1 enzym plasma spiegels en het GSTP1 genotype waren bepaald in dezelfde patiënt- en controlegroepen, werden de resultaten in hoofdstuk 6 met elkaar in verband gebracht. De werkhypothese was dat de verhoogde GSTP1-1 plasma spiegels bij patiënten met HNSCC wellicht werden veroorzaakt door één van de GSTP1 genotypen. Een verband tussen GSTP1 genotype en fenotype kon niet worden vastgesteld, hetgeen past bij onze visie dat alleen het GSTP1 polymorphisme een slechts minimaal effect lijken te hebben op de GSTP1-1 enzym activiteit in hoofd hals weefsel en op de vatbaarheid voor HNSCC.

Een onderzoek waarbij verschillende polymorphismen van de GST en EPHX genen worden gecombineerd levert ook geen bewijs op dat deze polymorphismen invloed uitoe- 
fenen op het risico op HNSCC (hoofdstuk 7). In dit onderzoek werd het aantal polymorphismen van elk van deze genen bepaald bij zowel patiënten met HNSCC als in de controle groep. Hierbij werd niet gecorrigeerd voor leeftijd, geslacht, rookgedrag of alcohol consumptie.

In hoofdstuk 8 werd door middel van een internationaal multicenter meta- en pooled analyse een zwak verband gevonden tussen HNSCC en GSTM1, GSTT1 en CYP1A1. De bevindingen van deze meta analyse ondersteunen de visie van dit proefschrift; genetische polymorphismen in carcinogeen metaboliserende enzym systemen zoals glutathion S-transferasen lijken van ondergeschikt belang in het ontstaan van hoofd hals kanker.

\section{Toekomstige mogelijkheden}

Het proces van carcinogenese is ingewikkeld. Zelfs al zijn de belangrijke bronnen van carcinogenen bekend, zoals alcohol en tabaksrook in veel gevallen van HNSCC, dan nog is reconstructie van wat zich exact afspeelt tijdens carcinogenese moeilijk. De metabole omzetting van alcohol is relatief eenvoudig, maar tabaksrook bevat veel toxische en mogelijk carcinogene stoffen, waarbij het metabolisme van elk van deze stoffen door veel verschillende enzymen beïnvloed wordt. Voordat mogelijk belangrijke enzymen volledig in kaart zijn gebracht is meer onderzoek noodzakelijk.

Alcohol dehydrogenase, acetaldehyde dehydrogenase, enkele anderen van de cytochrome P450 en glutathion S-transferase families, UDP-glucuronosyltransferasen welke recentelijk in relatie zijn gebracht met HNSCC, $\mathrm{N}$-acetyltransferasen en veel andere enzymen of polymorphismen in de corresponderende genen, kunnen nog worden onderzocht op hun invloed op het ontstaan van hoofd hals kanker.

Om in staat te zijn een gedegen onderzoek te verrichten is het heel belangrijk om een grote bloed-, weefsel- en databank te hebben van patiënten met HNSCC en van de juiste controles. Dit project is reeds gestart. Weefsel onderzoek kan nog belangrijke informatie verschaffen over lokale enzym activiteiten.

De statistische analyse in alle onderzoeken van dit proefschrift was beperkt vanwege het grote verschil in rook- en alcoholconsumptie gedrag tussen patiënt- en controlegroepen. Het aantal niet-rokende patiënten met HNSCC was klein, terwijl in de gezonde controle groepen vrijwel geen zware rokers en/of drinkers waren. Met name deze extreme groepen (zwaar rokende en zwaar drinkende gezonde oudere controle personen en niet rokende, niet drinkende oudere patiẻnten met HNSCC) zijn van bijzonder belang voor hoofd hals kanker onderzoek, omdat deze personen wellicht een extreem goed of extreem slecht functionerend detoxificatie systeem hebben.

In dit proefschrift hebben wij laten zien dat hoofd hals kanker, dat duidelijk een relatie heeft met overmatig roken en alcoholgebruik, niet beïnvloed lijkt te worden door polymorphismen in een aantal enzymen die tabak en alcohol detoxificeren. Nog veel meer enzymen zullen moeten worden onderzocht voordat hierover een definitieve uitspraak gedaan kan worden. 


\section{DANKWOORD}

De laatste loodjes wegen het zwaarst. Dit zullen velen hebben ervaren rondom de afronding van een proefschrift. Dan eindelijk is het moment aangebroken om na te denken over het dankwoord. Dit blijkt dan ook nog eens één van de drukste momenten te zijn, waarbij het gevaar bestaat dat bepaalde mensen worden vergeten. Daarom wil ik iedereen bedanken die bij heeft gedragen op welke manier dan ook aan de totstandkoming van dit proefschrift. Een aantal mensen wil ik in het bijzonder bedanken voor hun belangrijke bijdrage.

Prof. dr. J.J. Manni, beste Hans, ik ben je zeer dankbaar dat ik door jou in de gelegenheid ben gesteld om niet alleen KNO-arts te mogen zijn, maar daarnaast het vak ook vanuit de basaal wetenschappelijke kant te mogen ervaren. Als de dag van gisteren herinner ik me mijn sollicitatiegesprek waarin mijn oncologische interesse ter sprake kwam; hierin ben je mij volledig tegemoed gekomen. Ik vond het een voorrecht om met je te mogen samenwerken, waarbij ik vaak het gevoel kreeg met een "Superman" te maken te hebben.

Dr. W.H.M. Peters, beste Wilbert, zonder jou was ik waarschijnlijk nog steeds met hoofdstuk 1 bezig. Bijzondere dank voor al je constructieve commentaren en aanvullingen. De overdracht van je encyclopediale kennis op het gebied van ontgiftingsenzymen was altijd even verrassend als nuttig. Je stond altijd klaar om in te springen waar noodzakelijk. Bij afronding van dit project is gelukkig een vervolg in zicht waardoor onze samenwerking niet zomaar eindigt.

Zonder oncologische patiënten was dit onderzoek nooit tot stand gekomen. Dit is grotendeels te danken aan Dr. Johan van de Beek, die in mijn assistententijd "het gezicht" was van het Hoofd Hals team in Maastricht. Johan, jij bracht mijn database van patiënten voor dit onderzoek tot leven, zowel door onze gezamenlijke Hoofd Hals spreekuren als de vele chirurgische ingrepen die ik onder jouw toezicht heb mogen doen.

Het lab gastroenterologie van het UMCN en in het bijzonder Hennie Roelofs en Theo Mulder wil ik bedanken voor hun kundige PCR analyses van het DNA materiaal dat steeds maar weer vanuit Maastricht overkwam. 
De analisten van het lab speciële hematologie van het AZM wil ik bedanken voor hun enorme inspanningen die zij steeds maar weer verrichtten voor de ficol-scheiding van plasma en later het opslaan van volbloed. De buisjes bleven en blijven maar komen!

Willem Kelders, als co-assistent raakte je meteen enthousiast voor mijn onderzoek, waarbij je bijdrage ook terecht is bekroond met een publicatie. Onze brainstorming over enzymen en DNA was altijd plezierig. Je bent ook een goede "back-up" gebleken toen mijn aktentas met "harde" data uit de auto was ontvreemd. Je zal het nog ver gaan schoppen.

De leden van de beoordelingscommissie te weten Prof. dr. ir. P.A. van den Brandt (voorzitter), Dr. B.J.M. Braakhuis, Prof. dr. G.J. Hordijk, Prof. dr. Ph. Lambin, Prof. dr. F.C.S. Ramaekers wil ik bedanken voor hun tijd en interesse die zij hebben besteed aan het beoordelen van het manuscript.

Mijn ex-collega assistenten uit Maastricht: Anja, Ingrid, Jaap, Liesbeth, Jan, Lysandra, Janny, Rico, Harriet, Susan, Martijn. Jullie konden de gebeurtenissen rondom de opleiding èn het "GST" onderzoek relativeren naar een "GTST" verhaal (Goede Tijden Slechte Tijden). Ook dank voor jullie medewerking aan het verzamelen van patiënten. Ik hoop dat wij nog steeds jaarlijks één en ander kunnen blijven evalueren op het $\mathrm{H}_{2} \mathrm{O}$. Mijn goede vriend en collega Jaap van Twisk, tevens paranimf, brother in arms, vele, vaak nocturnale, verhelderende sessies aangaande het ST gedeelte van GTST hebben mij en ook jou op de been gehouden. Met plezier kijk ik hier op terug.

Ook wil ik niet voorbijgaan aan de steun die ik altijd heb gekregen van de verpleegkundigen van afdeling A-2, de dames èn heer van de polikliniek, alsmede het medisch-en staf-secretariaat van het AZM.

De maatschap Keel-, Neus- en Oorheelkunde van VieCuri Medisch Centrum voor Noord-Limburg, te weten Patrick Dammeijer, Welty Elprana en Eric Theunissen, heeft steeds interesse getoond in de voortgang van dit proefschrift, hetgeen ook mede heeft geleid tot daadwerkelijke afronding ervan.

Mijn broer, collega èn paranimf Dr. Ton Oude Ophuis heeft mij voortdurend aangespoord tot afronden van mijn onderzoek. Jij hebt mij laten zien bij je eigen promotie hoe de klus geklaard dient te worden.

Mijn ouders, de Ouwe en de Moe, wil ik bedanken voor de steun die ze mij steeds weer hebben geboden waar nodig. Voor sommige adviezen kun je alleen maar bij je ouders terecht. Ook jullie hebben mij altijd tijdens dit onderzoek gestimuleerd.

Last, but surely not least, mijn eigen gezin. Eindelijk komt er nu een tijd waarin ik onvoorwaardelijk kan genieten van de levens-stappen van mijn oogappeltjes Martijn (Oekjes) en Janneke (Moekjes). Het lijkt mij heerlijk om jullie nu de volledige aandacht te geven die jullie verdienen. Papa zal zich in zijn vrije tijd met jullie zeker niet vervelen. 
Lieve Marianne (Beest), alleen jij weet echt hoeveel tijd dit onderzoek ons heeft gekost. De afgelopen 3 jaar hebben wij in sneltreinvaart een serie "life-events" meegemaakt, waarbij deze één van de hekkensluiters zal zijn. Behind every able man is an able woman. Dit adagium is door jou ontstaan! lk heb veel respect voor de manier waarop jij de zaken in ons uitbreidende gezin steeds weet te regelen, temeer daar ik nogal eens "bezig was" voor het onderzoek. Jouw trouwe steun, geduld en liefde zullen nu ook eindelijk worden beloond. Beest bedankt! 


\section{CURRICULUM VITAE}

Michèl Oude Ophuis werd op 4 mei 1967 geboren te Hillegersberg in Rotterdam. Van 1979 tot 1985 was hij woonachtig in McLean, Virginia, USA. Aldaar heeft hij op Langley High School gezeten tot 1983. Met het oog op een studie in Nederland werd vanaf 1983 de opleiding voortgezet aan de Washington International School te Washington DC, waar hij met succes het International Baccalaureate Diploma heeft behaald in 1985. Vervolgens werd gestart met de studie Geneeskunde aan de Katholieke Universiteit Nijmegen. Het propaedeutisch examen werd in 1986 en het doctoraal examen in 1989 behaald. Tot aan zijn co-assistentschappen in 1990 werden extra-curriculaire stages Heelkunde / Plastische Chirurgie gevolgd aan het Mubarak al Kabeer Hospital in Kuwait, alsmede een onderzoekstage binnen de afdeling Plastic and Reconstructive Surgery (Prof. dr. D.A. McGrouther) van University College London. In 1993 werd het artsexamen behaald. Na werkzaam te zijn geweest als arts-assistent cardiochirurgie niet in opleiding in het Universitair Medisch Centrum Nijmegen (Prof. dr. L.K. Lacquet), startte hij op 1 januari 1995 met de opleiding tot Keel-, Neus- en Oorarts in het Academisch Ziekenhuis Maastricht onder leiding van Prof. dr. J.J. Manni. De B-opleiding vond plaats in het Atrium Medisch Centrum te Heerlen bij Dr. T.D. Zijlker. Tijdens zijn opleiding werd onder leiding van Prof. dr. J.J. Manni en Dr. W.H.M. Peters gestart met het wetenschappelijk onderzoek dat uiteindelijk heeft geleid tot dit proefschrift. Sinds 1 januari 2000 is hij werkzaam als Keel-, Neus- en Oorarts in VieCuri Medisch Centrum voor Noord-Limburg. Hij is getrouwd met Marianne Steenmetz. Zij hebben twee kinderen, Martijn en Janneke. 


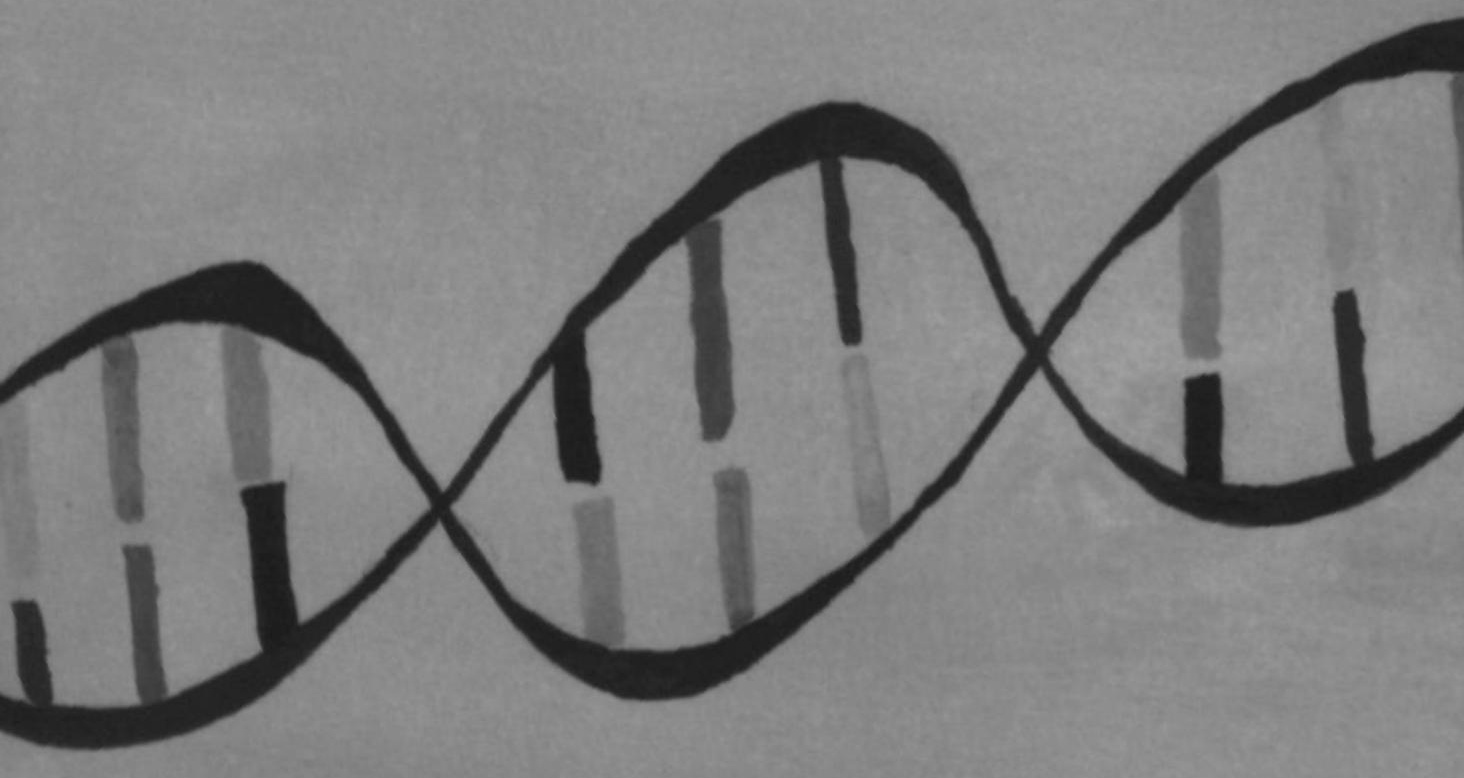

